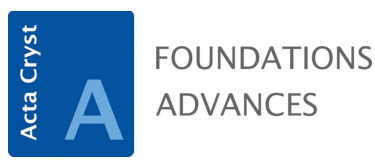

ISSN 2053-2733

Keywords: Executive Committee.

Supporting information: this article has supporting information at journals.iucr.org/a

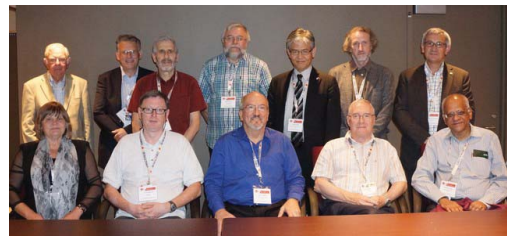

C 2016 International Union of Crystallography

\title{
Report of the Executive Committee for 2014
}

\section{Twenty-Third General Assembly and International Congress of Crystallography}

The Twenty-Third General Assembly and International Congress of Crystallography were held at the Palais des Congrès de Montreal, Montreal, Canada, 5-12 August 2014, by invitation of the National Research Council of Canada. A report, including a detailed report of the General Assembly, has been published. The General Assembly and Congress were attended by 2425 participants from 67 countries. The Tenth Ewald Medal and Prize were accepted by Professor A. Janner and Professor T. W. J. M. Janssen at the Opening Ceremony. The third Gjønnes Medal in Electron Crystallography was awarded to Professor J. Steeds and to Professor M. Tanaka. There were 4 Plenary Lectures, 36 Keynote Lectures, 112 Microsymposia and Open Commission Meetings. An easy-to-use mobile app and attendee web site were available to serve as the platform for the real-time Scientific Programme. A commercial exhibition comprising 63 companies and booksellers was organized. The General Assembly met on the evenings of Wednesday 6 August, Thursday 7 August and Monday 11 August. Applications for membership from Costa Rica, Pakistan, Turkey, Uruguay, Venezuela, Morocco, Cameroon and Algeria (all category I) were accepted. The changes in Names for the Adhering Bodies of (1) the Regional Committee of Crystallographers from Bangladesh, Malaysia, Singapore, Thailand and Vietnam and (2) the Regional Committee of Crystallographers from Algeria, Latvia, Morocco, Tunisia, Turkey and Ukraine were accepted. The Minutes of the Twenty-Second General Assembly in 2011 were approved. The General Assembly received the triennial financial report, the report of the IYCr Project Manager and the reports of the Executive Committee, the Commissions, the Scientific Associates and Regional Associates and the Union Representatives on Other Bodies since the TwentySecond General Assembly in 2011. New officers of the Union, Chairs and members of Commissions and Union Representatives were elected; the full list of these people is given as an Appendix to the Report of the Twenty-Third General Assembly and Congress. The Commission on NMR and Related Methods was approved. The Commission on Crystallography of Materials would continue on an ad interim basis. Reports of the Chair of the Sub-committee on the Union Calendar, of the Chair of the Committee for the Maintenance of the CIF Standard and of the Editor of the $\mathrm{IUCr}$ Newsletter were received. The good progress of the IUCr/Oxford University Press book series was noted. The General Assembly approved the recommendation that the unit contribution remain unchanged at CHF 1000 for the years 2015-2017 inclusive. It reaffirmed its decision to hold the Twenty-Fourth General Assembly and Congress in Hyderabad, India, in 2017. It also accepted an invitation from the Czech and Slovak Crystallographic Association to hold the Twenty-Fifth General Assembly and Congress in Prague, Czech Republic, in 2020. The Executive Committee met for several days before and most days during the Congress, mainly to deal with matters directly related to the business of the General Assembly and the work of the Commissions.

\section{Other meetings}

The IUCr sponsored the following meetings held during 2014:

School of Crystallization and Polymorphism, San José, Costa Rica, 27-31 January.

Southern Africa Powder Diffraction Conference and Workshop, Johannesburg, South Africa, 27-31 January.

Powder Diffraction and Rietveld Refinement School, Durham, UK, 30 March - 3 April. 
Electron Crystallography School - Introduction to Electron Diffraction Tomography, Darmstadt, Germany, 7-11 April.

Macromolecular Crystallography School 2014: From Data Processing to Structure Refinement and Beyond, Sao Carlos, Brazil, 8-16 April.

RapiData 2014, Brookhaven, USA, 13 April - 2 May.

International School on Fundamental Crystallography 2014 (ISFC 2014), La Plata, Argentina, 27 April - 9 May.

Hot Topics in Contemporary Crystallography, Sibenik, Croatia, 10-15 May.

Annual Meeting of the American Crystallographic Association, Albuquerque, New Mexico, USA, 24-28 May.

4th International School on Crystallization: Drugs, Foods, Agrochemicals, Minerals, New Materials (ISC2014), Granada, Spain, 26-30 May.

Structural Basis of Pharmacology: Deeper Understanding of Drug Discovery Through Crystallography, Erice, Italy, 30 May - 8 June.

International Expo/Sir Workshop, Bari, Italy, 10-13 June.

1st International Symposium on Halogen Bonding (ISXB-1), Lecce, Italy, 18-22 June.

2014 Kuo Symposium on 3D Cryo-EM Molecular Imaging and the Seventh K. H. Kuo Summer School on Electron Microscopy and Crystallography, Shanghai, People's Republic of China, 28-30 July.

Second South African School on Fundamental Crystallography - satellite meeting of the 21st Meeting of the International Mineralogical Union, Bloemfontein, South Africa, 25-29 August.

Quantum Materials: New Crystals versus Novel Properties, Beijing, People's Republic of China, 26-28 August.

1st European Crystallography School, Pavia, Italy, 28 August - 6 September.

Crystallography in Materials Science: Novel Methods for Novel Materials (EMRS Symposium N), Warsaw, Poland, 1519 September.

Current Trends in Structural Biology and 7th International Conference of the Hellenic Crystallographic Association, Heraklion, Crete, Greece, 19-21 September.

The 6th AONSA Neutron School 2014, Kawasan Puspiptek Serpong, Tangerang, Indonesia, 12-17 October.

XVIII International Conference on Crystal Chemistry, X-ray Diffraction and Spectroscopy of Minerals, Yekaterinburg, Russia, 13-15 October.

2014: Crystal (cl-)Year, Turin, Italy, 16-17 October.

Symmetry Relationships Between Crystal Structures with Application to Structural Phase Transitions, Varanasi, India, 27-31 October.

Atomic Pair Distribution Functions Technique: Fundamentals and Applications, Mar del Plata, Argentina, 31 October - 1 November.

VI School of the Argentinian Crystallography Association, Mar del Plata, Argentina, 3-7 November.

Frontiers of Structural Biology: New Advances in X-ray Diffraction and Cryo-Electron Microscopy, New Delhi, India, 15-17 December.
Structural Biology: Using Synchrotron Radiation to Visualize Biological Molecules, Trieste, Italy, 15-19 December.

\section{Executive Committee}

The membership of the Executive Committee, including new members elected at the General Assembly in 2014, is as follows: President: Professor M. L. Hackert (USA); VicePresident: Professor A. M. Glazer (UK); General Secretary and Treasurer: Professor L. Van Meervelt (Belgium); Immediate Past President: Professor G. R. Desiraju (India); ordinary members: Dr H. A. Dabkowska (Canada), Professor W. Depmeier (Germany), Professor S. Garcia-Granda (Spain), Professor J. M. Guss (Australia), Professor R. Kuzel (Czech Republic), Professor M. Takata (Japan).

\section{Publications}

Volume 70 of Acta Crystallographica, Volume 47 of Journal of Applied Crystallography (JAC), Volume 21 of Journal of Synchrotron Radiation (JSR) and Volume 1 of IUCrJ were published.

\section{Adhering Bodies}

A list of Adhering Bodies of the Union, with names and addresses of the Secretaries of the National Committees for Crystallography, was published as Appendix D to the Report of the Twenty-Third General Assembly and International Congress of Crystallography [Acta Cryst. (2012), A68, 607664].

\section{Work of the Commissions}

\subsection{Commission on Journals}

\subsubsection{IUCrJ}

To coincide with the International Year of Crystallography (IYCr2014), the IUCr launched the comprehensive openaccess journal IUCrJ in January 2014. The journal has had an excellent first year, and has already started to establish itself within the wider scientific communities that use results obtained from diffraction methods. All the indications are good in terms of the journal making a strong impact in attracting high-quality science papers of wide scientific significance from these communities. First impressions from authors, readers, referees and commentators are very positive with a number of papers receiving high downloads in line with high-impact publications.

In addition to providing high-impact high-profile publication, IUCrJ also aims to provide fast publication for authors. Submissions undergo preliminary screening by a panel consisting of the five Main Editors (Ted Baker, Richard Catlow, Gautam Desiraju, Sine Larsen, John Spence) and the Editor-in-Chief (Samar Hasnain), and this has helped to 
provide a rapid and efficient review process. Preliminary screening is generally complete within 72 hours, and any articles that do not meet the journal's requirement for broad scientific significance are usually transferred, with the agreement of the authors, to one of our other journals. Such transfers are seamless and do not require any further work by the authors.

The six issues of IUCrJ published in 2014 have featured papers from a wide variety of areas including biology, chemistry, crystal engineering, materials, physics and FELs. The number of articles submitted to the journal in its first year was 130; this was well ahead of our target of 100 articles. A total of 72 papers have been published with an average turnaround time of 14 weeks. A number of papers have been highlighted via an in-depth commentary in a manner similar to other comprehensive journals such as Nature and PNAS.

$I U C r J$ has set out to become the natural home for reporting breakthroughs and 'full' science reports rather than simply reporting a structure or how it was determined. We welcome your impressions of the first year of IUCrJ and ideas of measures we should collectively take for its widest acceptance by the broadest possible community. We feel that we have made an excellent start and have attracted many highquality submissions in all of the areas we cover. To maintain this confident start we encourage continued pro-active engagement from the whole structural community in improving the rate of submission of high-quality papers across the board.

We wish IUCrJ to become the leading journal for highquality structure-based papers in the chemical and biological sciences. We remind these communities to consider IUCrJ as one of their first-choice journals for their work that may have broader appeal. In addition, we will continue to work closely with physicists, materials scientists, computational crystallographers and pioneering FEL scientists to ensure that IUCrJ is able to meet the expectations of these communities.

As mentioned above, in 2014, we set ourselves a target of attracting 100 papers to celebrate IYCr2014 and the 100 years of success following the first Nobel Prize related to crystallography, awarded in 1914 to Max von Laue. We are grateful to the community for helping us to exceed this target by a significant margin. We are planning to publish 100 high-quality papers in 2015 in celebration of the centenary of W. H. and W. L. Bragg who won the Nobel Prize in 1915 for the first use of X-rays to determine a crystal structure.

Throughout the year we plan to encourage a greater number of papers reporting advances in technologies and methods that underpin our structural science. In addition to advances associated with synchrotron sources and X-ray freeelectron lasers, we look forward to reporting major advances that are taking place in neutron sources, methods and applications.

In 2015, we will be present at many major conferences including SRI 2015 (USA), XAFS 16 (Germany), IUBMB (Brazil), IUPAC (Korea), ACA (USA) and ECM (Croatia). Please come and visit the IUCr Journals stand, meet the Editors and get involved in making IUCrJ one of the main- stream comprehensive science journals. We look forward to seeing you there.

S. S. Hasnain, Editor-in-Chief, and E. N. Baker, G. R. Desiraju, C. R. A. Catlow, S. Larsen and J. C. H. Spence, Editors

\subsubsection{Acta Crystallographica Section A}

We continue our efforts to increase the impact of Acta A through the publication of higher profile Advances, with and without accompanying commentaries, and by publicizing results through social-media outlets.

Four Advances were published in 2014:

Magnetic Pair Distribution Function Analysis of Local Magnetic Correlations by B. Frandsen, X. Yang and S. J. L. Billinge (January issue);

On the Temperature Dependence of $\mathrm{H}-\mathrm{U}_{\text {iso }}$ in the Riding Hydrogen Model by J. Lübben, C. Volkmann, S. Grabowsky, A. Edwards, W. Morgenroth, F. P. A. Fabbiani, G. M. Sheldrick and B. Dittrich (July issue);

Atomic Scale Study of Polar Lomer-Cottrell and Hirth Lock Dislocation Cores in CdTe by T. Paulauskas, C. Buurma, E. Colegrove, B. Stafford, Z. Guo, M. K. Y. Chan, C. Sun, M. J. Kim, S. Sivananthan and R. F. Klie (November issue);

Unconstrained and X-ray Constrained Extremely Localized Molecular Orbitals: Analysis of the Reconstructed Electron Density by L. H. R. Dos Santos, A. Genoni and P. Macchi (November issue).

Several of these papers featured in news articles on the main IUCr web site, http://www.iucr.org/. (Also by the end of 2014, three more Advances were already online as part of the January 2015 issue.)

We commissioned commentaries for two of these articles. We are still trying to decide on the impact of the commentaries. On the plus side, they raise awareness of the articles, but they also count against us in the citation metrics because they count as a citation object, but are rarely themselves cited. We would be interested to know others' experience on this. The commentaries were:

Reflections on the Magnetic Pair Distribution Function by W. Ratcliff (January issue);

New Capabilities for 'Colouring In' the Chemistry of Crystal Defects Atom-by-Atom by S. J. Haigh (November issue).

Another strategy for increasing impact is to commission Lead Articles. A number were commissioned in 2014, but none have been published so far. We will follow up with this strategy more aggressively in 2015.

2014 saw the publication of a Special Issue on Mathematical Crystallography (Guest Editors: Massimo Nespolo and Greg McColm). The issue comprised eight articles and an editorial published over the course of three issues, gathered together as a 'virtual' Special Issue at http://journals.iucr.org/special_ issues/2014/MathCryst/ (this attracted a lot of interest on social media).

Finally, a report of some housekeeping issues. Vladimir Dmitrienko retired after nine years of dedicated service as a Co-editor. We would like to take this opportunity to thank him 
for his hard work on behalf of Acta A. Three new Co-editors were appointed to replace Vladimir, and also to fill a number of vacancies from retirements in 2013. These were Professor David Keen, Professor Laurie Marks and Dr Angela Altomare. We are very excited at the quality and stature of our new Co-editors! The editorial board met at the Montreal Congress.

\section{S. J. L. Billinge and J. Miao, Editors}

\subsubsection{Acta Crystallographica Section B}

Among the notable events for the journal during 2014 were the publication of two substantial Special Issues. The first of these was on Crystal Engineering (Guest Editor: Andrew Bond) and it appeared in the February issue. The second covered Non-Ambient Crystallography (Guest Editors: Dave Billing and Andrzej Katrusiak) and appeared in the August issue. These Special Issues were designed to promote the message of the widening scope of the journal and were largely responsible for a $64 \%$ increase in the number of articles published from 63 in 2013 to 98 in 2014 - the number of pages published rose from 633 to 1036 . Interestingly, the Special Issues did not result in a drop in the number of submissions to the journal later in the year, suggesting that they do attract new papers. Special Issues require the commitment of substantial time and effort by the Guest Editors and we are extremely grateful to them for all their work. Further Special Issues are underway for 2015-2017, including Energy Materials (Guest Editors: Simon Parsons, Richard Walton and Karena Chapman), Crystal Structure Prediction (Guest Editors: Graeme Day and Carl Henrik Görbitz), Minerals and Related Materials (Guest Editors: Sergey Krivovichev, Stuart Mills and Janusz Lipkowski), and Ferroelectric and Multiferroic Materials (Pierre Bordet will be one of the Guest Editors), with others in earlier stages of planning.

In 2014 the journal introduced a new category of article, the Research Perspective, where the main or sole author is an established leader in a particular field, and such articles are expected to review the development of that field, with a strong focus on the author's own contributions to its development. The journal will normally publish one article in this category per annum. The 2014 Research Perspective article was Aperiodic Crystals and Superspace Concepts by Ewald Prize winners Ted Janssen and Aloysio Janner. For 2015, Michael Zaworotko has agreed to submit a Research Perspective in the general area of crystal engineering.

The journal published two Feature Articles in 2014, entitled Crystalline Metal-Organic Frameworks (MOFs): Synthesis, Structure and Function and Crystallographic Studies of Gas Sorption in Metal-Organic Frameworks. Upcoming Feature Articles include MOFs Under High Pressure by Stephen Moggach and Prospects for Crystal Engineering by Christer Aakeroÿ; the latter is envisaged as a follow-up to the Crystal Engineering Special Issue. We will also continue to publish invited articles such as Synergy Between Transmission Electron Microscopy and Powder Diffraction: Application to Modulated Structures by D. Batuk, M. Batuk, A. M.
Abakumov and J. Hadermann, by high-profile speakers at the Montreal Congress and subsequent meetings. We note that each of the three invited articles from 2013 (on charge flipping, invarioms and structure prediction) has so far been very well cited.

Commentaries on some outstanding articles are now appearing regularly at the front of the journal, and other articles have been highlighted by means of regular news features on the IUCr home page. The Acta B home page is being redesigned for 2015, to allow more extensive coverage of recent news items and to highlight outstanding articles and the most cited papers from the journal. We continue to look for new and better ways to promote these exceptional contributions.

Acta $B$ is a well established publication route for work in fields such as high-pressure crystallography and aperiodic structures, and we are working to expand our coverage, including crystal engineering and materials science. The journal will be represented at a number of scientific meetings in 2015, including at the 12th International Conference on Materials Chemistry (York, UK), a conference celebrating 50 years of the Cambridge Structural Database (Cambridge, UK), the Annual Meeting of the American Crystallographic Association (Philadelphia, USA) and the 29th European Crystallographic Meeting (Rovinj, Croatia).

We were delighted to welcome several new recent additions to the Acta B board: Radovan Cerný (University of Geneva, Switzerland), Miao Du (Tianjin Normal University, Tianjin, People's Republic of China), Janusz Lipkowski (Polish Academy of Sciences, Warsaw, Poland), Andrzej Katrusiak (Adam Mickiewicz University, Poznan, Poland) and Pierangelo Metrangolo (Politecnico di Milano, Italy). Several long-serving Acta B Co-editors retired at the Montreal Congress: Carl Henrik Görbitz, Jim Kaduk, Keiichiro Ogawa, Urszula Rychlewska and Mark Spackman, and we wish to record our thanks to them for all their efforts on behalf of the journal.

\section{A. J. Blake and M. de Boissieu, Editors}

\subsubsection{Acta Crystallographica Section C}

During 2014, Paul Raithby was appointed as a second Main Editor for Section $\mathrm{C}$ and the benefits of his influence are already being felt. Concurrently, Larry Falvello stepped down as Deputy Main Editor and we thank him wholeheartedly for his assistance with proof-reading over the last few years. At the Montreal Congress, six Co-editors retired and five new Coeditors were appointed. We express our appreciation to the retirees for their dedicated efforts over the last several years and warmly welcome the new Co-editors.

2014 was a year of consolidation for Section C. In 2013, the journal announced its strategy and new scope and now we are in the phase of reaching out to the structural chemistry community to make them aware of the new style and scope of the journal. Such efforts include promotions at key chemistry conferences and plans for publishing Special Issues on a 
regular basis. So far, we observe a very slight trend towards receiving papers of the kind we are hoping for, but few with the sort of science and depth that might parallel a Section B paper. There are still many submissions of the traditional style, so it is clear that the transition will take some time. Unfortunately, after the four Special Issues in 2013/2014 boosted the number of submissions to the journal for 2013 and decreased the rejection rate, the number of submissions in 2014 decreased to the same low levels as in 2011 and appear to be following a similar trend in 2015. Concomitantly, the rejection rate has climbed again.

In February 2014, a Special Issue on Computational Materials Discovery was published and attracted considerable attention and downloads. We hope this will soon be reflected in the citation statistics. A virtual issue on Coordination Polymers was also published in July 2014. Two more Special Issues are in the pipeline: one on The Structural Chemistry of Homogeneous and Heterogeneous Catalysts and one on NMR Crystallography. The latter is a rapidly emerging field and its importance to structural scientists was recently recognized by the establishment of the IUCr Commission on NMR Crystallography and Related Methods during the Montreal Congress. It is hoped that Section C can become a leading journal for the publication of results relating to this field.

As has been the case for a number of years, we receive many submissions that are on the borderline between what we would prefer to see in Section $\mathrm{C}$ and what might be more suitable for Section E, especially now that the new Research Communications paper style in $\mathrm{E}$ can cater for multi-structure submissions. Our Co-editors thus often have a hard choice to make: encourage the authors, if possible, to extend their submission to make it more science-facing and suitable for Section C, or reject it with a recommendation to submit the paper to Section E. Unfortunately, encouraging authors to extend their papers, even when potential is evident, often results in little more than cosmetic changes to the manuscript and Co-editors then have no choice but to reject the paper. These factors impact on the rejection rate for Section C.

One of the key requirements to make the journal more attractive is to increase its impact factor (IF) significantly (even if the wisdom of relying on such statistics is arguable, we cannot ignore their importance to some authors and funding bodies). The IF issue is a bit self-perpetuating because once the IF is up there, more papers tend to come in, thus (hopefully) keeping the IF up, while a low IF discourages submission of 'good' papers. We have been fortunate to have attracted and published two key papers in January 2015: one by George Sheldrick on the new version of SHELXL and one by Ton Spek on the SQUEEZE procedure in PLATON, which had never been published. Both these papers should be highly cited, even if just to cite the software, and we hope to see a substantial boost to the Section C IF when the 2016 rankings come out in 2017. It is hoped that this will attract more authors to submit more substantial papers to the journal and thereby keep the IF at a good level. However, the need for ongoing Special Issues to help keep the journal in a prominent position is also important.
Changes to the submission system during 2013 allowed papers for Section C to be submitted as Word documents, alongside the data CIF. Authors are now increasingly submitting the text of their papers in Word documents, which suggests that route is the method authors generally prefer, in line with normal procedures for other journals. We hope that this reduces the frustration expressed in some areas about preparing papers entirely in CIF format and encourages more authors to choose Section C.

\section{A. Linden and P. R. Raithby, Editors}

\subsubsection{Acta Crystallographica Section D}

In the International Year of Crystallography 2014, declared by the United Nations, Acta $D$ remains in a very good situation, being a primary venue not only for methods papers, but also analyses of biologically important structures, successfully competing with other journals publishing similar results. Ted Baker moved to take responsibility for biologically oriented papers of $I U C r J$, and Jenny Martin from the University of Queensland, Australia, joined the team of Acta D Section Editors. The impact factor is 7.23 , a relatively high value in comparison with other journals publishing results of crystal structure analyses of macromolecules. About one in three papers are now published with an open-access licence, continuing the rising trend from previous years.

The number of submissions was 429 and the rejection rate was $32 \%$, similar to the previous year, but the number of published articles rose to 297, mostly research papers, with a high proportion of very significant scientific value. Acta $D$ remains attractive to the community of macromolecular crystallographers. A number of papers presented results of structural analyses performed by methods complementary to $\mathrm{X}$-ray crystallography, such as small-angle scattering, NMR, computations in silico etc., in keeping with current trends in structural biology.

The methods papers constitute an important part of Acta D publications, and are usually highly cited. In 2014, exceptionally, there was no Special Issue dedicated to the CCP4 Study Weekend, since the proceedings of the 2013 meeting were published November 2013, and of the 2014 meeting in January 2015. Nevertheless, a number of important methods papers were published in 2014, including those on novel techniques of data acquisition and processing by the 'serial crystallography' approach using X-ray free-electron laser and synchrotron sources.

The high standing of Acta $D$ is in significant part due to the high professionalism and dedication of its Managing Editors in the Chester Office, Louise Jones and Simon Glynn, who deserve high acclaim and gratitude for their efforts.

\section{Z. Dauter, J. L. Martin, R. J. Read and S. Wakatsuki, Editors}

6.1.6. Acta Crystallographica Section E 2014 has been another challenging year for Acta E, with a further fall in submissions from 2123 in 2013 to 1478 in 2014. 
As for last year, authors from more than 70 countries continue to publish with Acta E. The six top contributors in 2014 were India $(18.7 \%)$, China $(12.0 \%)$, USA (11.0\%), Germany (6.4\%), South Korea (5.98\%) and Japan (4.4\%). Compared with 2013, the proportions of submissions from India and China have fallen but those from the USA, Germany, South Korea and Japan have risen.

The relaunch of Acta E in June 2014 heralded its transformation from Structure Reports Online to Crystallographic Communications and saw the publication of the first papers in the new Research Communication format designed to bring out the science behind the structure determination. Reports are no longer limited to a short description of a single structure and figures are no longer relegated to the supporting information. We are delighted to see that an increasing number of authors are choosing to publish their work as a Research Communication, with the numbers of these articles increasing every month. The November issue included the one hundredth paper to be published in this format. Authors are positively encouraged to report and discuss related structures in a single Research Communication rather than publishing a series of short structural reports. We were pleased to see that papers reporting two structures are a now regular feature and some three-structure papers have also been published along with one four- and one five-structure paper. Authors have made the most of the opportunity to include extra tables and figures in the published paper to illustrate their results and enhance the discussion of the underlying science. We are actively encouraging more of our authors to submit to the journal in the new format.

Overall, the proportion of organic (73\%), metal-organic $(22 \%)$ and inorganic (4\%) papers was approximately the same as in 2013. However, the proportions were different for the Research Communications with 52\% organic, 39\% metalorganic and $9 \%$ inorganic papers. The average length of a Research Communication was 3.7 pages. The average length of a Data Report was 1.7 pages, the change in format accounting for the increase from 1.3 pages for Structure Reports in 2013. Publication times still remain low with an average submission-to-publication time of 0.8 months.

An Advisory Board was established in 2014 and we appreciate and thank the various members for their confidence and support.

A large part of the success of the new Research Communication format is down to our dedicated team of Co-editors who are doing an excellent job in advising authors how to promote their science. The Section Editors of Acta E would like to take this opportunity to thank them for helping make Acta $E$ the obvious choice for disseminating the results of the excellent crystallography that is being carried out by our authors worldwide.

A number of Co-editors retired during the year, and it is our pleasure to record here our sincere appreciation of their sustained outstanding efforts and their support of the journal. The retirees are: Sylvain Bernès, Michael Bolte, Ivan Brito, Ray Butcher, Jan Fabry, John Gallagher, Ning-Hai Hu, Biserka Kojic-Prodic, Huub Kooijman, Christian Näther and
Georgina Rosair. We are pleased to welcome Luc Van Meervelt to the Section Editor team.

We are extremely grateful to all current Acta E Co-editors and the Chester Editorial Office staff for their dedicated support and contributions to the ongoing daily operations of the journal.

W. T. A. Harrison, H. Stoeckli-Evans, E. R. T. Tiekink, L. Van Meervelt and M. Weil, Editors

\subsubsection{Acta Crystallographica Section F}

In 2014, its tenth year of publication, Section $F$ has seen a small but steady increase in submitted papers for the third year in a row. Although the rejection rate nearly doubled compared with 2013, this increase in submissions still led to a slight increase in published papers: 339 original science articles in 1713 pages. With this Section $\mathrm{F}$ retains its status as an important journal for the macromolecular crystallography community. Section F is also important for structural biology as a whole and in 2014 the subtitle of the journal was shortened to Structural Biology Communications in order to emphasize this.

A positive development is that the average time from the submission of a paper to its publication stayed below 3 months. After a maximum of 3.9 months in 2011, the average publication time is now down to 2.9 months and we believe that as long as we stay below 3 months we are effectively fulfilling our mandate of rapid publication. Nevertheless, we will continue our efforts to investigate the factors lengthening publication time in order to develop measures to bring publication times down even further. An important tool, which certainly helped to bring the publication times down, is publBio, and we have been advocating its use among our authors. We finally decided to take a step further and make the use of it mandatory for papers covering preliminary characterizations of macromolecules.

A very important change concerning the content of our papers has been introduced. The journal has adjusted its expectations of what new material is required to justify publication and an editorial to this effect appeared at the end of the year. This move was made in essence to seek more detailed characterization of macromolecules under study and to limit preliminary reports on orthologues. There is a chance that this may lead to a reduction in the number of publications. However, we believe it is a necessary step in seeking to ensure that our journal finds the right balance between supporting our community and providing a home for interesting papers.

A word on impact factors. Our journal impact factor is still significantly below our target of 1.0, but has been slowly creeping up since 2011.

Finally, our colleague and Section $\mathrm{F}$ founding editor Howard Einsphar stood down in 2014 from his position as a Section Editor. We would hereby like to thank him for his dedication to the journal, his inputs, insight and hard work. However, Howard has not gone completely. In his role as editor of the IYCr crystallization series, he continues to 
support the journal by cajoling some very fine reviews out of researchers, and by keeping them mostly to schedule.

\section{S. Weiss and W. N. Hunter, Editors}

\subsubsection{Journal of Applied Crystallography}

The first year of 'online only' was a transitional year for $J A C$, in that the format remained much as it has been in recent years with a print edition. Only from the start of 2015 have changes been introduced to update the format for online-only publication.

It is clear $J A C$ continues to focus on the application of crystallography and crystallographic methods in all their forms (other than crystal structure determinations), and on the instrumentation, techniques and other factors involved. As stated in the journal's expanded scope statement, many research topics in condensed matter research, materials science and the life sciences make use of crystallographic methods to study crystalline and non-crystalline matter with neutrons, X-rays and electrons. All of these areas were reflected in the journal's papers during 2014. Developments of instrumentation and crystallographic apparatus, theory and interpretation, numerical analysis computer programs, and Teaching and Education papers also had a presence. Indeed, we note that the journal remains the primary place where crystallographic computer program information is published. Two computer program papers published in JAC in prior years [Kraulis, P. J. (1991). MOLSCRIPT: a Program to Produce both Detailed and Schematic Plots of Protein Structures. J. Appl. Cryst. 24, 946-950; Laskowski, R. A., MacArthur, M. W., Moss, D. S. \& Thornton, J. M. (1993). PROCHECK: a Program to Check the Stereochemical Quality of Protein Structures. J. Appl. Cryst. 26, 283-291] were included in the recently published listing of the 100 most cited scientific research papers of all time [Van Noorden, R., Maher, B. \& Nuzzo, R. (2015). Nature Explores the Most-Cited Research of All Time. Nature, 514, 550-553], each having been cited well over 13000 times. Occasional Feature Articles will now also appear in the journal, and the first of these was published in 2014.

We note that the latest impact factor of 3.95, published in 2014 for 2013, remains among the highest for crystallographic journals and that the number of published papers and pages continues to increase. We would welcome more high-quality papers focusing on industrial applications of crystallography. Furthermore, during 2014, some new Co-editors were appointed with expertise in the area of free-electron lasers, and we would welcome papers focusing on the deeper implications for applied crystallography raised by the new measurement paradigms that such facilities offer.

Although JAC no longer publishes conventional conference proceedings as Special Issues, 2014 did see the publication of a virtual Special Issue containing select full-length research papers associated with the 15th International Conference on Small-Angle Scattering (SAS2012) held in Sydney, Australia, in November 2012. Similar Special Issues are planned highlighting the 12th Biennial Conference on High-Resolution
X-ray Diffraction and Imaging (XTOP2014), expected to be published summer 2015, and the 16th International Conference on Small-Angle Scattering (SAS2015), expected spring/ summer 2016. Two subject-focused Special Issues are also being considered on Neutron Science and Technology and on Free-Electron Laser Software.

From 2014, JAC has had three Main Editors to provide greater efficiency in all editorial matters pertinent to the longterm health of the journal. While regular paper submissions were not pre-selected during 2014 (i.e. prior to assignment to a Co-editor), as remains the case in 2015, it may become necessary for the Main Editors to start pre-selecting papers for their suitability as the paper submission rate continues to increase in the future.

Starting in 2014, with the change to online-only publication, the cover art for the journal changes with every issue (or couple of issues). This is one way in which papers of particular interest within an issue have started to be highlighted. Another way significant papers can now be highlighted is by including a brief commentary on the paper, and its context in the current field, within the same journal issue. Commentaries (citable themselves and including relevant references) are solicited from authors other than the authors of the paper being highlighted, at the discretion of the Main Editors. These also started to appear in 2014.

The journal continues to welcome a small but strategically important category of papers in the area of Teaching and Education. For a number of years, Katherine Kantardjieff has served as our Co-editor for Teaching and Education, in addition to her normal Co-editor workload. We are deeply indebted and grateful to Katherine for her careful work in this area. As she comes towards the end of her term as Co-editor, we are pleased to announce that one of our other existing Coeditors, Juanma Garcia-Ruiz, has kindly agreed to succeed Katherine as Teaching and Education Co-editor.

We note that $J A C$ remains a hybrid journal. Authors of accepted papers have the option to retain access to their paper based on journal subscription or to secure open access to their paper on payment of a charge to the IUCr Editorial Office. The cost per article of open access for a paper published in $J A C$ (or any other IUCr journal) remains significantly less than that for articles published in most other journals of comparable impact. In 2014, open access papers made up about $5 \%$ of the total.

Many challenges lie ahead for scientific publishing, especially with regard to subscription-based access versus open access, the increasing demand to archive and provide access to research data, and the general demands placed on increasingly busy reviewers to provide the core support for a fair and rigorous review system. However, we believe that the journal is well-placed to meet the challenges ahead.

\section{A. J. Allen, J. Hajdu and A. R. Kaysser-Pyzalla, Editors}

\subsubsection{Journal of Synchrotron Radiation}

In $2014 J S R$ has seen a further growth of the number of submissions and published papers. This largely reflects the 
increasing number of beamlines at synchrotron light sources worldwide and a growing community of users. We note here that the number of 'beamline papers' has markedly increased in 2014. Moreover, existing beamlines have become more efficient in their use, thanks to increased brilliance of the light sources and the use of ever more sophisticated positionsensitive X-ray detectors. Therefore, the average number of experiments per beamline increases yearly. Photon science is a healthy activity and $J S R$ is the premier publication medium for scientists reporting new developments in X-ray instrumentation and methodology at large facilities. $J S R$ also serves as a publication medium for X-ray science results rather than just serving as a platform for science facilitators. Nonetheless, there is a need to attract more 'pure' science papers.

In the coming decade synchrotron-radiation facilities will be upgraded substantially. So-called multi-bend achromat (MBA) enabled storage-ring lattices will provide significantly higher brilliance and near-diffraction-limited conditions over a substantial wavelength range. In $2014 J S R$ has published a Special Issue entitled Diffraction-Limited Storage Rings and New Science Opportunities, with invited contributions from leading scientists in the field (Volume 21, Part 5, pp. 837-1216, 1 September 2014; Guest Editors: Mikael Eriksson and J. Friso van der Veen). It is hoped that the growing community building these sources or making use of them will see $J S R$ as their prime publication medium for communicating results, not only on instrumentation and methods, but also on applications.

In general, we believe that the publication of Special Issues with (invited) contributions written by leading experts on topics of current interest will not only enhance the readership of $J S R$ but also attract new authors. In 2014, preparations have been made for the appearance of Special Issues entitled X-ray Radiation Damage to Biological Crystalline Samples (Volume 22, Part 2, pp. 195-470, 1 March 2015) and X-ray FreeElectron Lasers (Volume 22, Part 3, pp. 471-866, 1 May 2015; Guest Editors: Ilme Schlichting, William E. White and Makina Yabashi). The advent of VUV and X-ray free-electron lasers provides a great opportunity for $J S R$ to attract new readers and authors. $J S R$ actively solicits papers in this category, and it is expected that the recent publication of the Special Issue on existing XFELs will act as a catalyst. A second Special Issue will report later about developments at XFELS that currently are still in the construction phase. A Special Issue is also being prepared on XFEL Photon Diagnostics. For soliciting more XFEL papers in the journal it is very helpful that $J S R$ has a number of leading experts in XFEL science on its Editorial Board. In 2014 we welcomed to the board Makina Yabashi from the XFEL Research and Development Division of RIKEN SPring-8.

In previous annual reports we have recognized the need for publications in the category 'beamline papers'. The purpose of these papers is to provide users of the beamline, notably in life sciences, with a good reference to be included in their publications. It is important that beamline parameters at which user experiments are performed are properly on record. In addition, inclusion of such references in user publications provides proper credit to the facilities and their staff for their services. Last but not least, 'beamline papers' have the potential to improve the journal impact factor. It is gratifying to see a marked growth of the number of beamline papers in 2014. But it is important that the editorial staff continues to stimulate colleagues at the facilities to submit more papers in this category. We would like to see at least a doubling of the number (12) reached in 2014.

We thank the readers of $J S R$ for their continued interest in the journal topics, the authors for publishing in our journal, the Co-editors for their great services to the community, the Editor-in-Chief, Samar Hasnain, for his unwavering support of the journal's activities, and the Managing Editor, Tony Weight, and other staff members of the IUCr office for their great support with the handling of manuscripts.

\section{G. Ice, I. Schlichting and J. F. van der Veen, Editors}

\subsection{Commission on International Tables}

International Tables for Crystallography is a book series published by the IUCr in conjunction with Wiley. Eight volumes designated $\mathrm{A}$ (and A1) through $\mathrm{G}$ are currently in print, a ninth $(\mathrm{H}$, on powder diffraction) is nearing completion, and a tenth (I, on XAS) is being developed. All can be purchased as printed volumes or accessed online by subscription. An affordable print edition of the Brief Teaching Edition of Volume A is also available.

Symmetry information is covered in Volumes A (SpaceGroup Symmetry), A1 (Symmetry Relations Between Space Groups), and E (Subperiodic Groups). Information about the influence of symmetry on the physical and tensor properties of crystals and on their structural phase transitions is found in D (Physical Properties of Crystals). Information on superspace symmetry is currently located in Volume C (Mathematical, Physical and Chemical Tables) but will almost certainly be moved to the next edition of Volume B. An extensive electronic Symmetry Database is available to subscribers to the online version of the series.

Additional information of a general type is included in Volumes B (Reciprocal Space) and C, which can be traced back to Volume II of the original series (1937) and Volumes II-IV of the series with red covers (1959-1974).

The other volumes of the series cover more specific areas. These volumes are F (Crystallography of Biological Macromolecules), G (Definition and Exchange of Crystallographic Data), and the nearly finished ninth Volume H (Powder Diffraction). The volume on XAS that is being developed (Volume I) also belongs in this group.

An article about this book series was published in the second issue of the 2014 volume of the IUCr Newsletter. That article was made into a flyer that was distributed during the Montreal Congress. The article is also available online at http://www.iucr.org/news/newsletter/volume-22/ number-2/international-tables. 
Descriptions of activities during 2014 for the individual volumes follow.

Volume A. The 6th edition of Volume A is being set in type; publication in 2015 is expected. The text has been extensively revised to improve its pedagogic value; new sections have been added to introduce topics treated in more depth in Volumes A1 and E. There is a new chapter on magnetic space groups and magnetic subperiodic groups. The layout of the space-group tables has been simplified because the sub- and supergroup data are now available in Volume A1. There are new general-position diagrams for the cubic space groups; also included are supplementary diagrams showing tilted, perspective views of the more complex cubic groups.

Enhancement of the Symmetry Database of the Online Edition of International Tables for Crystallography has focused on the development of computer tools for the analysis of group-supergroup relations between space groups of any index, on the implementation of a user-friendly interface, and on creation of a first set of basic tools for visualizing symmetry diagrams.

A revised version of the Brief Teaching Edition is in an advanced stage of development.

Volume B. The reorganization of Volumes B and C to give a more sensible grouping of topics has been discussed with the Editor of Volume C. Contact has already been made with various authors to define the topics to be reviewed in Volume B.

Volume C. Plans for a major revision have progressed steadily. Authors willing to write chapters on eight new topics have been formally invited to do so; authors willing to revise a number of the existing chapters have been identified. Some of the chapters in the current Volume $\mathrm{C}$ will be deleted because of coverage in the new Volume $\mathrm{H}$ (material on powder diffraction) or the new Volume A; other chapters will be moved to the revised Volume B (for example, material on modulated structures).

Volume D. The second edition of Volume D, which went online at the end of 2013, appeared in print during 2014. It included one completely new chapter, new sections in two other chapters, and updates of a number of additional chapters.

Volume E. The possible standardization of Seitz symbols [see Acta Cryst. (2014), A70, 300-302] in the online edition is being considered.

Volume G. James Hester was appointed Joint Main Editor to replace Syd Hall, who retired from the position in 2013; Brian McMahon continues as the other Joint Main Editor. Planning for a new edition of Volume $\mathrm{G}$ began. The revised edition will include detailed coverage of new and updated CIF foundational standards developed over the past decade, including CIF2, DDLm and dREL. Descriptions of new data dictionaries and updates of the software catalogue will be added.

Volume $\mathrm{H}$. The new Volume $\mathrm{H}$ on powder diffraction is progressing well. Of the $c a 55$ expected chapters four have already been typeset and 28 are ready for typesetting. Eighteen more are under review.
Volume I. The Editors of the new volume on XAS have conferred with other interested parties, have agreed on a detailed outline, and have begun to identify authors.

Volumes A1 (2011) and F (2012) have been so recently updated that there was no activity during 2014.

Further information about the volumes can be found at the home page of the Commission, http://www.iucr.org/resources/ commissions/international-tables. The Guided Tour available at http:/it.iucr.org/services/guidedtour/ is highly recommended because it shows what is available electronically. Access to the tables of contents of all the volumes is free, as are sample pages (including author lists and prefaces); see the home pages for the individual volumes (e.g., http://it.iucr.org/ $\mathrm{Fb} /)$.

It is a pleasure to thank the staff in Chester, especially Nicola Ashcroft, for all they do to help editors and authors plan, produce, revise and advertise the volumes of this series. Their careful work and wise counsel are indispensable.

\section{P. Brock, Chair}

\subsection{Commission on Aperiodic Crystals}

The year 2014 was another active and exciting year for the Commission (CAC). The International Year of Crystallography provided a framework for activity aimed at promoting crystallography to the public; examples of related events are an IYCr meeting in Belo Horizonte, Brazil, in November 2014 organized by Carlos Pinheiro, in which Ted Janssen and Gervais Chapuis were main speakers, and public lectures by Ron Lifshitz and Dan Shechtman at McGill University about quasicrystals as part of the IYCr activities in conjunction with the Montreal Congress. The award of the 2011 Nobel Prize in Chemistry to our colleague Dan Shechtman for his discovery of quasicrystals continues to provide a great inspiration and inspired further special meetings, honorary awards and Plenary Lectures on aperiodic crystals, promoting the notion of aperiodic crystals to the wider scientific community as well as to the general public. With the award of the 10th Ewald Prize to our colleagues Aloysio Janner and Ted Janssen for their development of superspace crystallography, aperiodic crystals took centre stage at the Congress, followed by Dan Shechtman's Plenary Lecture the next day. We hope that the award of the Ewald Prize will also have a lasting effect in promoting the study of aperiodic crystals within the wider community. There is also a vibrant community working on the mathematics of aperiodic crystals with which the Commission is involved; for instance, a workshop in Oberwolfach, Germany, on Dynamical versus Diffraction Spectra in the Theory of Quasicrystals in December 2014 was co-organized by the Chair.

The Montreal Congress was preceded by the very successful satellite workshop Introduction to Aperiodic Crystals, organized by Ron Lifshitz (as the then Chair of CAC). Leading experts in the field provided an excellent exposition of research on aperiodic crystals, attracting a large audience of crystallographers, many new to the topic. Given the success of 
this event, the Commission is planning to organize a similar day at the next Congress in 2017. The satellite workshop was followed by the opening of the Congress and the Ewald Prize ceremony with Ted Janssen's Ewald Prize lecture. Aperiodic crystals remained a strong thread throughout the Congress, with no fewer than twelve Microsymposia and five Keynote Lectures related to aperiodic crystals, which the Commission helped to organize. The Keynote Lectures and Microsymposia were very well received, attracting large audiences and inspiring discussions among delegates. The CAC would like to acknowledge the excellent work of the Programme Committee and the constructive and fruitful collaboration with many other Commissions, and we are looking forward to continue this synergetic approach in the future.

The CAC held an official meeting at the Congress. The main items for discussion were the forthcoming events, in particular the 8th International Conference on Aperiodic Crystals in Prague, Czech Republic, 30 August - 4 September 2015, which is organized by Michal Dusek and Lukas Palatinus, with Vaclav Petricek chairing the International Programme Committee composed of the members of the CAC. In 2015, the 8th Workshop on Structural Analysis of Aperiodic Crystals will take place in Bayreuth, Germany, 12-15 March, organized by Sander van Smaalen. Following on from the successful previous schools, another forthcoming event is the Third International School on Aperiodic Crystals, which will take place in Antwerp, Belgium, 4-9 July 2016, organized by Joke Hadermann and Artem Abakumov. We also discussed the Commission's web site, which is now integrated with that of the Special Interest Group on Aperiodic Crystals of the ECA (SIG3). The web site http://aperiodic.iucr.org/ is administered by Michal Dusek, who has joined the Commission as a member. Other Commission business was conducted via e-mail. As always, the Commission continues actively to promote aperiodic crystallography, in organizing, supporting and promoting meetings, workshops and educational activities worldwide. In doing so, CAC continued its ongoing coordination of interaction between the various sub-communities and disciplines involved in the different aspects of research in aperiodic crystals. In particular, we are continuing our close collaboration with SIG3, which among other events is offering a series of ad hoc workshops on the software Jana2006. Further forthcoming events with direct involvement of the Commission are the 29th European Crystallography Meeting in Croatia in August 2015, where two Microsymposia are coChaired by Commission members, and the XXIII Conference on Applied Crystallography in Poland in September, with invited presentations by Ron Lifshitz, Vaclav Petricek, Dan Shechtman and Janusz Wolny.

\section{U. Grimm, Chair}

\subsection{Commission on Biological Macromolecules}

The aim of the Commission (CBM) is to support macromolecular crystallography worldwide through scientific exchange, training, and promotion of policies that encourage the generation and dissemination of knowledge and technologies.

International Year of Crystallography (IYCr2014). As described below, during 2014 the CBM participated actively in IYCr2014.

Participation in the annual national conference of the Society for Structural Biology: XII Discussions in Structural Molecular Biology in March 2014 where the International Year of Crystallography was celebrated. The highlight was the Plenary Lecture by David Stuart: Challenges of Virus Crystallography. The meeting was attended by about 120 people, mostly from the Czech Republic and Slovakia, with a few guests from Germany, Spain etc. Details of the event are at http://www.structbio.org/xii-discussions-2014.

The Worldwide Protein Data Bank (wwPDB) created a 2014 calendar that illustrates how X-ray crystallography enables our understanding of biology at the atomic level (http://wwpdb.org/iycr2014.html). The RCSB (Research Collaboratory for Structural Bioinformatics) PDB promote IYCr stories and events on social media at https://www. facebook.com/RCSBPDB (1550 likes) and https://twitter.com/ buildmodels (1183 tweets; 1031 followers).

Membership of the Organizing Committee of the Italian meeting Crystal (cl)Year, Turin, Italy, 16-17 October, to celebrate the International Year of Crystallography: http:// bioinfo.igst.it/.

A summit meeting in the IYCr was held in Campinas, Brazil, in September 2014. All three summit meetings were held in developing countries and the theme for the LatinAmerican summit was Biological Crystallography and Complementary Methods. The meeting took place 22-24 September and united about 100 researchers from the region as well as guest representatives of the IUCr and expatriate Latin Americans working in Europe and the USA. Representatives from Brazil, Argentina, Uruguay, Paraguay, Chile, Peru, Venezuela, Colombia and Mexico took part in an enthusiastic and highly enjoyable event.

Participation at the IYCr Opening Ceremony in Paris, 2021 January 2014.

Co-organization of and Participation in the IYCr Innsbruck Symposium Celebrating 100 Years of Crystallography, Innsbruck, Austria, 8-9 September 2014.

Guest Editorship of FEBS Special Issue celebrating the IYCr2014.

Standards for information to be provided to reviewers of macromolecular structures. The CBM has worked with the American Crystallographic Association, the Asian Crystallographic Association, the European Crystallographic Association and the Worldwide Protein Data Bank to begin the development of standards for information that reviewers of macromolecular structures should receive. The key ideas in these draft standards are that for a macromolecular crystal structure, reviewers should receive (1) the PDB validation report and (2) pictures of omit maps for any ligands and unusual structural elements. Additionally, the draft standards suggest the idea of making the data (structure factors, coor- 
dinates) available to reviewers. These draft standards are under continued development in consultation with all the groups listed above.

IUCr Diffraction Data Deposition Working Group (DDDWG). The CBM has worked with the DDDWG to evaluate theoretical and practical reasons for the deposition of raw diffraction images that constitute the primary data in a macromolecular X-ray diffraction experiment. During 2014 a set of four papers were published in Acta D that examine this idea in detail. An introduction to the papers can be found on the Acta $D$ web site at http://journals.iucr.org/d/ issues/2014/10/00/me0551/index.html (Archiving Raw Crystallographic Data). An extensive discussion of the issues is available on the DDDWG forums page at http://www.iucr.org/ forums/dddwg.

Meetings, workshops and other outreach activities. Coorganization of a school on protein crystallography mostly directed at students coming from countries that are members of the SESAME consortium; the school was generously supported by the IUCr, via the CBM: Structural Biology: Using Synchrotron Radiation to Visualize Biological Molecules. A joint initiative between Elettra and SESAME. ICTP Advanced School. 15-19 December 2014, Adriatico Hotel, Trieste. Directors: S. Onesti and Z. Sayers. http://indico.ictp.it/ event/a13194/.

Macromolecular Crystallography School 2014: From Data Processing to Structure Refinement and Beyond, São Carlos, Brazil, for the first time. This event was supported by CCP4, the IUCr, Brazilian funding agencies and a South American initiative, CeBEM, which promotes training and interchange visits in the field of structural biology. This is the second edition (the first having been held in Montevideo, Uruguay, in 2013) and it is now our intention to make this a regular annual event alternating between Uruguay and Brazil. This year's event in Montevideo will take place in April.

Organization of the Laue Symposium and dedication of Laue Memorial Plaque on the school in Poznan, Poland, attended by Max Laue as a schoolboy. The unveiling ceremony was attended by Professor Gautam Desiraju, President of the IUCr. (Included in the IYCr2014 calendar.)

Co-organization of a biocrystallography school: Biocrystallography for the High-Throughput Era, Bialystok, Poland, 1-5 July 2014, as part of the IYCr2014 calendar.

The CBM frequently recommends support from the IUCr for meetings and workshops that can provide a teaching or major dissemination role for macromolecular crystallography. Some letters of support written in 2014 include:

2014 Kuo Symposium on 3D Cryo-EM Molecular Imaging and the 7th K. H. Kuo Summer School of Electron Microscopy and Crystallography, Shanghai, People's Republic of China, 26-30 September 2014.

Current Trends in Structural Biology and 7th International Conference of the Hellenic Crystallographic Association, Heraklion, Crete, Greece, 19-21 September 2014.

\section{T. Terwilliger, Chair}

\subsection{Commission on Charge, Spin and Momentum Densities}

At the Montreal General Assembly, the Commission membership was partially renewed. Beatrice Gillon concluded her three-year term as Chair of the Commission and became a consultant. Her work was extremely productive as testified by the very rich report on the triennial activity, published in 2014. All new and former Commission members thanked Beatrice for her valuable service.

D. Jayatilaka, T. Koritsanszky, U. Pietsch and M. Takata left the Commission and are also thanked for their activity over one or two terms. Masaki Takata was elected to the Executive Committee of the IUCr and he is the now acting as a liaison member. The new Commission members are P. Dominiak (Poland), A. Gukasov (France), J. Kozisek (Slovakia), E. Nishibori (Japan) and W. Scherer (Germany), who joined E. Espinosa (France), L. J. Farrugia (UK), J. M. Gillet (France) and Y. Sakurai (Japan), members confirmed for a second term.

At the Montreal Congress, the Commission organized or co-organized five scientific Microsymposia (MS19, MS35, MS65, MS89, MS106). Most of the sessions received a large audience. The discussions mainly concerned new methods to compute electron-density distributions from X-ray diffraction, combined refinement to determine simultaneously the charge and the spin density, new sources and detectors, and new opportunities at large-scale research facilities.

The Commission was also represented by Wolfgang Scherer (Germany) who gave a Keynote Lecture, where he reported on recent advances in charge-density studies for inorganic materials. Mark Spackman (Australia) also gave a Keynote Lecture on application of charge-density partitioning for crystal-engineering purposes, invited by the Commission on Structural Chemistry.

After the meeting, the new Commission started working on the organization of one of the main events of the triennium, namely the XVIII Sagamore Conference, scheduled to be held in Santa Margherita di Pula, Sardinia, Italy, 7-12 June 2015. Carlo Gatti, previous Commission member and Chair, is the President of the Organizing Committee and he has worked very intensively in order to prepare an attractive programme, following the suggestions of the Commission.

The Commission has also supported the first Asian Charge Density Workshop in Bangalore, India, scheduled for February 2015 and organized by L. J. Farrugia (Commission member) and T. N. Guru Row (Commission consultant).

Meanwhile, other meetings and schools are forthcoming and the Commission has started all due activities to help the organizers. In particular, the 9th International Conference on Inelastic X-ray Scattering will be held in Taiwan in 2015 and received the support of the Commission. The 7th European Charge Density Meeting will take place in Warsaw, Poland, in June 2016 and is also fully supported by the Commission. A charge-density school is planned in Nancy, France, in August 2016 as satellite of the European Crystallographic Meeting in Basel, Switzerland.

Moreover, the Commission has renewed its interest in two important projects that started during the previous term and 
will be completed this term. The first project concerns the electron distribution in the metallic bond, measured by QCBED techniques and X-ray diffraction. P. Nakashima (Australia) is the leader of this project and coordinates the preparation of the samples and the measurements. The second project is a round-robin test on charge-density determination using synchrotron and home-laboratory radiation sources. The project is led by J. Overgaard (Denmark) and involves three synchrotron groups at SPring-8 (Japan), APS (USA) and Soleil (France), and four groups working with conventional sources in France, Germany, UK and Canada. All the groups have received the samples for the measurements and they will provide data sets according to a protocol written by J. Overgaard and E. Espinosa. J. Overgaard will carry out the refinement and will report the results.

\section{P. Macchi, Chair}

6.6. Commission on Crystal Growth and Characterization of Materials

The activities of the Commission in 2014 were dominated by the occurrence of the International Year of Crystallography (IYCr) and the Montreal Congress.

Concerning IYCr, the Commission supported different activities at a national level. Moreover, with the help of the IUCr webmaster, Brian McMahon, and of Michele Zema, the Commission realized a web site with the purpose to collect crystal images from crystal growers worldwide. The web site (http://www.iycr2014.org/participate/crystal-growing) is active and keeps on growing with new images.

In 2014 the members of the Commission collaborated actively but mostly via the internet. However, in August, at the Montreal Congress, there was an official Open Meeting of the Commission on 6 August and most of us had the opportunity to meet in person and exchange opinions about the future of crystal growth around the world. Several Commission members/consultants were present at the meeting: Tom Keuch, Tatyana Bekker, Detlef Klimm, Andrea Zappettini. Also, we had the participation of Edmondo Gilioli, from Parma, Italy, Garcela Diaz De Delgado, from Venezuela, and Vera Gribanova, from Russia. Also, further discussions were carried out with Commission members/consultants who arrived in Montreal in the following days: Juanma Garcia Ruiz, Koichi Kakimoto, Elias Vlieg, Joseph $\mathrm{Ng}$ and Janet Newman.

I underlined my intention to ask members/consultants to help me at least on these topics: (1) cooperation with IUCr journal editors; (2) improvement of our Commission web site; (3) connection with the Commission on Crystallographic Nomenclature.

We also discussed the international schools on crystal growth for the coming years. Two international schools on crystal growth were expected to be organized in Europe in 2015 (in Granada, Spain, in May and in Bologna, Italy, in September). The International Summer School on Crystal Growth ISSCG-16 will be held in Otsu, Shiga, Japan, 1-6
August 2016. Organization of schools in Africa would always be welcome, but the lack of local contacts and the difficult political situation in many countries makes this not easy at the moment.

All the Microsymposia organized by the Commission at the Montreal Congress were quite successful. I wish to take the chance to thank Edmondo Gilioli, Tatyana Bekker, Antoni Dabkowski, Joseph Ng, Janet Newman, Detlef Klimm and Y. Mori for their enthusiastic efforts in the organization of these sessions. Also, Juanma Garcia Ruiz and Peter Rudolph gave excellent Plenary and Keynote Lectures.

Concerning the membership, the Commission was partially renewed by the General Assembly, with three new members (Janakiraman Kumar, Haosu Luo and Tom Keuch). Juanma Garcia Ruiz and Jiyang Wang accepted to continue to help the Commission as consultants. We thank Christine Klemenz for her contribution to the Commission in the last six years.

Of course, the organization of the Congress catalyzed many energies of the Commission and of the crystal-growth community. However, other events were organized and supported by the IUCr with the backing of the Commission:

4th International School on Crystallization: Drugs, Foods, Agrochemicals, Minerals, New Materials (ISC2014), Granada, Spain, 26-30 May 2014.

1st International School of Crystallization and Polymorphism, San José, Costa Rica, 27-31 January 2014.

It must be underlined that these events, even if not directly organized by the Commission, were all organized and supported by many members and consultants of the Commission.

Moreover, the Commission in 2014 was asked for several letters of support for other events:

5th International School on Biological Crystallization (ISBC2015), Granada, Spain, 24-29 May 2015.

Fifth European Conference on Crystal Growth (ECCG5), Bologna, Italy, 9-11 September 2015.

European School on Crystal Growth 2015 (ESCG 2015) Fundamentals of Crystal Growth, Bologna, Italy, 5-8 September 2015.

Finally, I wish to express my great honour and pleasure to continue chairing this Commission for the next three years. I hope I am giving my own contribution to all the work done up to now by the Commission to bring more understanding of the role of crystal growth and influence of crystals on many aspects of life and technology.

\section{A. Zappettini, Chair}

\subsection{Commission on Crystallographic Computing}

The main event proposed by the Commission for 2014 was a Computing School to be held at La Cité collégiale in Ottawa during the week before the Montreal Congress. However, due to low registration the School was cancelled.

A number of the Microsymposia suggested by the Commission were adopted by the International Programme 
Committee; several joint Microsymposia with other Commissions were also adopted (see Annual Report for 2013).

A new Chair of the Commission was appointed by the General Assembly in Montreal. A Secretary (Dr Martin Lutz, Utrecht University, The Netherlands) and webmaster (Dr Arie van der Lee, University of Montpellier, France) were also appointed.

Two new members of the Commission were appointed: $\mathrm{Dr}$ Patrick Mercier (National Research Council, Ottawa, Canada) and Dr Lukas Palatinus (Institute of Physics, Prague, Czech Republic). Dr Robert Von Dreele stood down as Chair and became a member of the Commission. Benedetta Carrozzini (CNR, Bari, Italy) and Jordi Rius (CSIC, Barcelona, Spain) retired as members of the Commission and became consultants.

The Commission was invited by Professor B. Gopal of the Indian Institute of Science, Bangalore, India, to hold a Computing School before the Hyderabad Congress in 2017. A Local Organizing Committee [Professor Gopal, Dr Santosh Pajikar (Australian Synchrotron) and Dr Garib Murshudov] and a Scientific Programme Committee [Dr Patrick Mercier (NRC Ottawa), Dr Arie van der Lee (University of Montpellier) and Dr Garib Murshudov] were appointed to oversee the organization of the School.

To date the venue has been decided (subject to approval by the Institute's authorities) along with provisional dates (15-20 August 2017); a list of potential sponsors is being prepared. The aim is to be able to have preliminary advertising material in place ready for the AsCA meeting in Kolkata, India, in December 2015. The two Committees will keep in contact via regular e-mail and videoconferencing. Professor Sekar has been inivited to join the Local Organizing Committee.

\section{H. R. Powell, Chair}

\subsection{Commission on Crystallographic Nomenclature}

In 2014 André Authier resigned after more than 12 years as Chair of the Commission. We thank him for his many years of good judgment and wise counsel. After the Montreal Congress Carol Brock became Chair.

Under André's leadership the Commission prepared three formal reports that were published in Section A of Acta Crystallographica, the most recent in 2014 (see below). André was also the Founding Editor (and first General Editor) of the Online Dictionary of Crystallography, which was established according to distributed authorship principles similar to those of Wikipedia.

The other members of the Commission are the Editors of the Union's journals and the Editors of the Volumes of International Tables, the Chair of the IUCr/OUP Book Series Committee, the Chair of the Commission on Crystallographic Teaching, the Chair of the Committee for the Maintenance of the Crystallographic Information File Standard, the President of the IUCr and the General Secretary of the IUCr. The total number of members and appointed consultants exceeds 50 .
There was an Open Meeting of the Commission during the Montreal Congress.

During 2014 the report on the standardized Seitz notation for symmetry operations (referenced in the Commission's 2013 Annual Report) was published in Acta Cryst. [Glazer, A. M., Aroyo, M. I. \& Authier, A. (2014), Seitz Symbols for Crystallographic Symmetry Operations. Acta Cryst. A70, 300302]. This paper is available on the Commission's web page.

The compendium of definitions in the Online Dictionary of Crystallography was published in paperback form by the Commission as its contribution to the International Year of Crystallography $[A$ Little Dictionary of Crystallography, edited by A. Authier \& G. Chapuis (2014), xiv + 238pp; IUCr Commission on Crystallographic Nomenclature - Lulu Press (http://www.lulu.com)]. About 150 copies of this book have been sold at conferences and via the web; others have been given away as poster prizes and promotional items. A review by Gaston Garcia appeared in Crystallography Reviews (doi:10.1080/0889311X.2014.998660). This book is, of course, only a snapshot in time of an online resource that is always changing.

At the 2014 Commission Meeting in Montreal, Massimo Nespolo described work by Michael O'Keeffe and associates on a graph-theoretic description of bonding in crystal structures. This group had developed a full terminology to be approved by IUPAC, and it was suggested that the IUCr should also consider approving this terminology. This work had some overlap with the description of lattice complexes in crystallography. Massimo suggested establishing a Working Group of the CCN, perhaps as a joint IUCr/IUPAC project, to identify the overlap and similarities/differences between these two approaches. During early 2015 the CCN asked Massimo to set up a Working Group to consider these matters and to then submit a report to the Commission.

\section{P. Brock, Chair}

\subsection{Commission on Crystallographic Teaching}

Since filing its last annual report in April 2014 and last triennial report in May 2014, the Commission (CCT) has continued its efforts to reach out to the crystallographic community, the scientific community and the community at large by using social media. The CCT Facebook page (http://www.facebook.com/IuCrCommissionOnCrystallographic Teaching) has 513 'likes' (227\% increase), and our Twitter feed (@IUCrTeach) has 78 followers (300\% increase). The CCT continues to increase activity on both social media outlets better to disseminate exciting findings and important information, particularly in the afterglow of the International Year of Crystallography and the Montreal Congress and General Assembly. CCT members were surveyed with regard to their skills, time and interest with various social media. A member will be assigned along with the CCT Chair to specific social-media feeds to make more frequent posts reporting the latest news and information, and to moderate more discussions among followers. We are also reviewing our web pages 
on the IUCr web site, examining resources for utility and audience, reorganizing content as appropriate, and updating information. Our objective is to make all our communication channels and information more targeted and relevant to specific audiences.

The CCT sponsored three Microsymposia at the Montreal Congress:

Eric Reinheimer (USA) and Juanma Garcia-Ruiz (Spain) co-Chaired Spreading the Word. Introducing Crystallography to the Public, MS 68, scheduled on 10 August 2014 in the morning session. A manuscript reporting on this symposium is in final preparation for submission to the Journal of Applied Crystallography, Teaching and Education section.

Clyde Smith (USA) and Tim Gruene (Germany) coChaired Crystallography Education and Training in the 21st Century: New Pedagogies, New Paradigms, MS 84, scheduled on 11 August 2014 in the morning session. A manuscript reporting on this symposium is in preparation for submission to the Journal of Applied Crystallography, Teaching and Education section.

Saulius Grazulis (Lithuania) and Amy Sarjeant (USA) coChaired Crystallography Education and Training in the 21st Century: New Pedagogies, New Paradigms, MS 92, scheduled on 11 August 2014 in the afternoon session. A manuscript reporting on this symposium should have been submitted at the time of this report to the Journal of Applied Crystallography, Teaching and Education section.

The published transactions of these symposia will elaborate on the wide variety of topics presented in Montreal, from technology, to K-16 education and outreach, to community engagement, to post-baccalaureate innovations. We hope that these articles will benefit wider audiences and be cited by the STEM education community.

The CCT also co-sponsored a Microsymposium on Beginners Guide to Validation of Crystallographic Results sponsored by the Commission on Crystallographic Computing. The status of the published report from this symposium is unknown, but we believe that a review manuscript is planned.

In the past year, the CCT has reviewed and written supporting letters for several proposals of variable quality and made recommendations for workshops and summer schools focused on areas relevant to the discipline. Since the Montreal Congress and General Assembly, the CCT now reviews and writes recommendation letters for all workshop and summer school proposals. We are very pleased by this development implemented by the Executive Committee. The CCT hopes that the Executive Committee continues to require a letter from the appropriate subject-matter Commission with these applications. This year, we have also had very lively discussion concerning the primary language to be used for conducting workshops and summer schools that are classified as international'. We have made our concerns known in our most recent recommendation letters.

The proposals received by the CCT continue to vary considerably in quality. Proposers often send in documents at the last minute, which are vague in details, missing supporting data, and/or do not justify the funds requested. Proposers also expect immediate response and automatic endorsement at full funding levels. The CCT this past year has attempted to develop and implement more formalized rubrics for evaluating proposals, along with criteria and guidelines to be presented to those individuals or groups making proposals to the IUCr for support. These guidelines will enable proposers to make the best possible case in their request. Rubrics will enable the CCT to determine more easily whether the proposals meet the mission and goals of the IUCr, to better compare and contrast the proposals, and to provide more useful feedback to the Executive Committee so that precious funds can be invested wisely and with maximum return. We had hoped to have our refined guidelines and rubrics drafted by the time of this report for proposal to the Executive Committee, but these guidelines and rubrics will not be ready until later this summer.

\section{K. A. Kantardjieff, Chair}

\subsection{Commission on Crystallography in Art and Cultural Heritage}

The Commission continues to pursue the mission of diffusing the crystallographic knowledge related to artworks and ancient materials. The mission was especially important during IYCr2014, to show to the general public the link between crystallographic symmetry and art, and the role of crystallographic techniques in archaeometry and conservation.

The following IYCr2014 actions were completed through the effort of the Commission members:

Preparation of calendars for the International Year of Crystallography IYCr2014. The official calendar printed by the IUCr and distributed during the Opening Ceremony of IYCr2014 was an initiative of the Commission (CrysAC) (Alicja Rafalska-Lasocha, Bernardo Cesare). This calendar as well as other calendars prepared by the Commission can be downloaded from http://crysac.visual-chemistry.net/downloads.html.

Several public exhibitions were organized:

October 2013 - March 2014: Padova, Italy - Exhibition CRISTALLI (organized by Gilberto Artioli). More at http:// 147.162.183.151/cristalli/welcome.html, http://www.iycr2014. org/photos/italy/cristalli. The panels, the text and the iconographic part of the exhibition traveled through Italy as part of other events: http://www.iycr2014.it/eventi.

May 2014 - May 2015: Krakow, Poland - Exhibition In The Unusual World of Crystals (organized by Alicja RafalskaLasocha in cooperation with the Faculty of Chemistry, Jagiellonian University) was shown 14 times in various places in Poland. More at http://www2.chemia.uj.edu.pl/ krysztaly_wystawa/.

Juan Manuel Garciía-Ruiz \& Fermín Otálora, from the Laboratorio de Estudios Cristalográficos (IACT, CSIC/UGr) developed the exhibition CRISTALES to increase the awareness of students and the general public about crystal- 
lography. All materials are available at the web site http:// cristales2014.org.

Special conferences, sessions, lectures:

During the Opening Ceremony of IYCr2014 (Paris, France, 20-21 January 2014), two members of CrysAC delivered lectures:

Abdelmalek Thalal - Symmetry in Art and Architecture of the Western Islamic Golden Age;

Emil Makovicky - Highlights of Eastern Islamic Ornamental Art As Seen Through Crystallographers' Eyes.

Organization of the international scientific conference: 5 th Meeting of X-ray and Other Techniques in Investigations of the Objects of Cultural Heritage Celebrating the International Year of Crystallography and the 650th Anniversary of Jagiellonian University, Krakow, Poland, 14-17 May 2014 (organized by A. Rafalska-Lasocha; G. Artioli and P. Bezdicka lectured). More at http://www.chemia.uj.edu.pl/nauka-ibadania/konferencje/X-ray.

Organization of the scientific session Role of Crystallography in Science, Art and Everyday Life in cooperation with the Faculty of Chemistry, Jagiellonian University in Krakow, Poland, 14 May 2014 (A. Rafalska-Lasocha).

5th ALMA interdisciplinary conference 2014: Interpretation of the Fine Art Analysis in Various Contexts, Dominican Monastery of St Giles, Prague, Czech Republic, 20-21 November 2014 (Petr Bezdicka, David and Janka Hradil, ALMA Laboratory).

294th edition of the one-day Rozhovory seminar: Discussions on Problems of X-ray and Neutron Structure Analysis, 23 April 2014. See http://www.xray.cz/xray/csca/r294_en.htm (Petr Bezdicka, Radek Kuzel, Silvie Svarcova).

Colloquium Struktura 2014 of the Czech and Slovak Crystallographic Association and Regional Committee of the IUCr, Kutna Hora, Czech Republic, 9-12 June 2014 (Petr Bezdicka).

Presentation at Montreal Congress: Crystallography on Stage: Presenting the Concepts and History Dramatically (Celerino Abad-Zapatero).

Lecture Diagnostics in Art and Archaeology: Concepts and Case Studies, GABEC-GNM International School on Innovative Methodologies for Characterization, Diagnosis and Conservation of the Cultural Heritage, Catania-Siracusa, Italy, 1-4 July 2014 (Gilberto Artioli).

Lectures on Crystallography and the International Year of Crystallography delivered in Krakow, Madrid, Warsaw etc. (Alicja Rafalska-Lasocha).

IYCr2014 OpenLab Ghana, University of Ghana, Accra, 912 June 2014 (G. Artioli, PANalytical).

IYCr2014 OpenLab Turkey, Bilkent University, Ankara, 19-22 January 2015 (G. Artioli, PANalytical), contained a full day on cultural heritage.

Crystallography contest:

The Commission, in cooperation with the Faculty of Chemistry of Jagiellonian University, organized a contest entitled The Role of Crystals in Human Life for secondaryschool, high-school and University students in Poland (Alicja Rafalska-Lasocha). More about the contest and most of the contributions (in Polish) can be found at http://www2. chemia.uj.edu.pl/konkurs_krysztaly/. A photo gallery is available at http://www2.chemia.uj.edu.pl/konkurs_krysztaly/ ?page_id=525.

Participants in the contest were asked to prepare a poster, a presentation or a video clip. Prepared contributions were sent to the organizers by e-mail. The deadline was 28 February 2014. We received 99 contributions: (61 from secondary-school students, 33 from high-school students, and 5 from University students). The judging was carried out in two stages: online voting and after that experts' evaluation. In online voting, 8819 votes were received.

Continuing project. Celerino Abad-Zapatero continued collaboration with Mr Painton Cowen to incorporate scientific content into the Rose Window web site (http:/therose window.com/TheRoseWindow2/Rose-numbers.htm).

\section{G. Artioli, Chair and A. Rafalska-Lasocha, Secretary}

\subsection{1. ad interim Commission on Crystallography of Materials}

Summary. Our ad interim Commission was approved at the meeting of the Executive Committee of the IUCr in Boston (July 2012). This is the newest and in many ways a unique Commission covering a high-impact and deeply crystallographic topic that has not been covered by other IUCr Commissions.

Activities. Active participation in the Montreal Congress in Montreal through the participation in the International Programme Committee and organization of two Keynote Lectures and two Microsymposia:

Keynote Lecture - Michele Parrinello (ETH Zürich): Novel Computational Methods for Materials Science and Biochemistry.

Keynote Lecture - Evgeny Antipov (Moscow State University): Li Batteries of Energy Storage.

Microsymposium - Crystallography and Physics of LowDimensional Systems: Fullerenes, Carbon Nanotubes, Graphene, Topological Insulators and Superconductors.

Microsymposium - Crystal Structure Prediction and Materials Design Workshop - Crystal Structure Prediction (Q. Zhu).

The Commission also co-sponsored a number of Microsymposia with other Commissions.

A Special Issue on Computational Materials Discovery in Acta C has been published (February 2014), with Guest Editor A. R. Oganov. This Special Issue has set records for download rate in this journal.

A Conference on New Approaches in Computational Materials Design was organized by A. R. Oganov in Moscow, Russia, 11-12 December 2014 (Lecturers - R. Dronskowski, M. Tuckerman, V. Perebeinos, D. Proserpio, P. Sorokin, A. R. Oganov, V. Tsirelson, A. Aleksandrova, A. Laio, K. Litasov, L. Slipchenko, Q. Zhu, O. Isayev, U. Uspensky).

The Conference was oversubscribed ( 100 participants) and Nature sent its senior Editor to attend the meeting. The 
programme and pdf files of the lectures are available at http:// s.mipt.ru/material.

The following workshops were organized to disseminate knowledge and technical skills:

Crystal Structure Prediction, Northwestern Polytechnical University, Xi'an, People's Republic of China, 11-12 January 2014.

Quantum Materials: New Crystals versus New Properties. Beijing, People's Republic of China, 24-28 August 2014. (Organizer: Professor C. Q. Jin.)

The 18th International Conference on Reactivity of Solids was held in St Petersburg, Russia, 9-13 June 2014. (Programme Chair E. V. Antipov.)

\section{A. R. Oganov, Chair}

\subsection{Commission on Electron Crystallography}

The major event of 2014 was the Montreal Congress. One of the major parts of the Congress was electron crystallography, in both physical and biological sciences. There were several sessions related to improvements in structural determination based on technical advances. One of the crucial steps forward was the invention of direct electron detectors (DE) that enable scientists to obtain stunning results, regardless of DE application: in situ TEM, STEM (scanning), DTEM (dynamic), ETEM (environmental), HRTEM (highresolution), electron holography and others. The last year has demonstrated that since the new imaging systems have become commercially available, a tremendous number of possibilities, both in material and biological structural studies, have opened up. This year several cameras were available on the market: K2 (Gatan), Falcon II (FEI), and DE20 (Direct Electron). The Gatan K2-IS direct detector (in situ camera to resolve dynamic details in heating, catalysis, mechanical deformation, STEM diffraction, electrical testing and chemical reaction experiments) was used for 4D-STEM probe diffraction patterns. The development and application of new electron-microscopy techniques to study the structural and functional properties of a variety of materials were reported on at the Congress by T. Gonen and P. Midgley [Nature Methods (2014), 11(9), 927-930; IUCrJ (2015), 2(1), 126-136]. Progress has also been made in developing software to process the huge amounts of information collected using these new detectors (Wacker \& Schröder, 2015; Ishizuka, 2013; Midgley \& Thomas, 2014). Another important development is the usage of Cs correctors that allow us to improve the point resolution in the images, thus decreasing distortions induced by electron microscopy. These new developments stimulate novel approaches in crystallographic studies \{see the review The Correction of Electron Lens Aberrations [P. W. Hawkes (2015), Ultramicroscopy, doi:10.1016/j.ultramic.2015.03.007].

The 2014 Gjønnes medal in electron crystallography was awarded to two scientists: John Steeds, Emeritus Professor in Physics at the University of Bristol, UK, and Michiyoshi Tanaka, Emeritus Professor at Tohoku University, Sendai, Japan, for their outstanding contributions to convergent-beam electron diffraction, which has revolutionized electron crystallography. The work of Professor Steeds, Professor Tanaka and colleagues at Bristol and Sendai has had a major impact on the design of transmission electron microscopes for the study of crystalline materials. Professor Tanaka gave the lecture The Large-Angle Technique and Lattice Defect Identifications and Professor Steeds gave a lecture entitled $A$ Convergence of Beauty and Utility.

The Commission has been actively involved in a number of workshops/schools that were held in 2014:

Ute Kolb. Electron Crystallography School - Introduction to Electron Diffraction Tomography, Darmstadt, Germany, April 2014. The course covered the following topics: electron microscopy, formation of image and diffraction in TEM and STEM, electron scattering theory with the emphasis on kinematical and dynamical diffraction, different methods in experimental procedures, and methods of structural analysis. (http://www.staff.uni-mainz.de/kolb/ECSchool2014/ECS.htm.)

J. Briggs. Cryo-Electron Microscopy and 3D Image Processing. EMBO Practical Course, Heidelberg, Germany, 31 August - 9 September 2014. The course was dedicated to methods of cryo-electron microscopy: sample preparations, images analysis - both single particles and thin protein crystals, methods of data collections and image processing. (https://www.embl.de/training/events/2014/CRY14-01/index. html.)

Advanced Imaging Techniques For Scanning Electron Microscopy, Westmont, Illinois, USA, 13-15 July 2014. The major topics covered were very high resolution imaging and low voltage imaging. (http://www.hookecollege.com/courses/ course.asp?COURSE_ID=127.)

Alexander Eggeman. ESTEEM2 Electron Crystallography Workshop, Cambridge, UK, 22-25 July 2014. This workshop covered the latest developments in the theory and application of electron crystallography such as precession electron diffraction, convergent beam electron diffraction, ptychography, structure solution and structure refinement methods. (http://www.ecryst2014.msm.cam.ac.uk/.)

H. Li. Kuo Symposium on 3D Cryo-EM Molecular Imaging and 7th K. H. Kuo Summer School of Electron Microscopy and Crystallography, Shanghai, People's Republic of China, 26-30 July 2014. The symposium included lectures on structural analysis of protein single molecules and thin crystals and advances in cryo-electron microscopy imaging. (http:// www.ncpss.org/newsConference.action.)

International Symposium on Crystallography, Fortaleza, Ceará, Brazil, 12-15 October 2014. The symposium will be the first scientific event on crystallography to be held in the Northeast of Brazil (http://www.sic100.ufc.br/site/index.php/ sic/sic100).

Ano Internacional da Cristalografia na UFMG, Universidade Federal de Minas Gerais, Belo Horizonte, Minas Gerais, Brazil, 27-28 November 2014. The UFMG has had research groups engaged in crystallography since 1980 and was involved in celebration of the International Year of Crystallography in Brazil. (http://www.labcri.ufmg.br/iycr/ index.html.) 
2014, VIII Micromat, Campinas, São Paulo, Brazil, 1620 November 2014. (http://www.eventus.com.br/micromat/ programacao.html.)

International Workshop on Advanced and in situ Microscopies of Functional Nanomaterials and Devices IAMNano, Rio de Janeiro, Brazil, 6-8 July 2014.

\section{E. Orlova, Chair}

\subsection{Commission on High Pressure}

The main event in 2014 was the Montreal Congress. The Commission was represented on the Programme Committee by $\mathrm{P}$. Dera.

The following Keynote Lecture and Microsymposia were sponsored (fully or partly) by the Commission:

Keynote Lecture: Polymorphism and Electronic Transformations of Deep Earth Minerals, presented by Leonid Dubrovinsky, University of Bayreuth, Germany.

MS17: High-Pressure Crystallography of Periodic and Aperiodic Crystals (Chairs: Vasily Minkov and Clivia Hejny).

MS27: Advances in Experimental Techniques and Data Analysis for Science at Extreme Conditions at Synchrotron and Neutron Sources (Chairs: Simon Redfern and Stanislav Sinogeykin).

MS41: Electronic and Magnetic Phenomena at Extreme Conditions (Chairs: Karen Friese and Stefan Klotz).

MS49: High Pressure Solid State Chemistry and Materials Synthesis (Chairs: Vladimir Solozhenko and Tetsuo Irifune).

MS88: Liquids, Amorphous and Nanocrystalline Solids at Extreme Conditions (Chairs: Yoshinori Katayama and Dennis Klug).

MS80: Biomolecular Systems Under Pressure - in Memory of Roger Fourme (Chairs: Thierry Prange and Nick Brooks).

Four Microsymposia were co-sponsored by the Commission with expected significant high-pressure component:

MS1: Phase Transitions in Functional Inorganic Materials and Minerals (Chairs: Pam Thomas and Vladimir E. Dmitrienko).

MS58: From Exo-Planets to Explosives: Ices and Other Molecular Compounds under Pressure (Chairs: Werner Kuhs and Hiroyuki Kagi).

MS66: Multiferroics and Other Multi-Functional Materials: Synthesis, Properties and High-Pressure Behavior (Chairs: Edmondo Gilioli and Lars Ehm).

MS99: Non-Ambient Crystallographic Studies of Nanoporous Materials (Chairs: H.-C. Zhou and Stephen Moggach).

The role adopted by the Commission in this multidisciplinary and dynamically evolving field is to facilitate and enable the exchange of new ideas and developments. The main tools available to the Commission to achieve this goal are annual workshops on high-pressure crystallography. The Commission also helps to shape a strong high-pressure programme at the triennial IUCr Congresses. In addition, Commission members and consultants are involved in organizing summer schools dedicated to high-pressure crystal- lography and in other forms of disseminating high-pressure techniques in crystallography and material sciences.

The new and old Commission members present in Montreal held several closed meetings during the Congress. We discussed the priorities for this triennium. The following initiatives were then envisaged for the triennium:

Dissemination of high-pressure techniques to new applications in crystallographic X-ray laboratories;

A diamond-anvil cell in every laboratory - sharing of expertise through all stages of experiments on one's own equipment in the laboratory.

A round robin for high-pressure experiments, in order to determine possible systematic errors in high-pressure results.

Developing guidelines for depositing high-pressure crystallographic diffraction data from various high-pressure techniques. This project is led by Dr Kamil Dziubek who will represent the Commission at ECM-29 in Rovinj, Croatia, 2015. Before ECM-29 all Commission members should communicate their support for small-scale local high-pressure workshops.

The annual Commission Workshop was scheduled for Campinas, Brazil, 12-16 September 2015. The Chair of the Local Organizing Committee was chosen - Dr Narcizo Souza Neto. This will be first Commission Workshop in Latin America and in the southern hemisphere, where considerable development, including the construction and operation of a powerful synchrotron with beamlines dedicated to highpressure research takes place. This workshop was scheduled for the next meeting of the Commission. An application for supporting young scientists to attend the Campinas Workshop was submitted to the IUCr.

\section{A. Katrusiak, Chair}

\subsection{Commission on Inorganic and Mineral Structures}

Members and consultants of the Commission (CIMS) discussed various issues by e-mail. Other forms of communication were in person at occasional meetings or conferences (in particular, a meeting was held in Montreal during the Congress), or by using the web site. The latter is kindly maintained by M. Nespolo (http://www.crystallography.fr/ cims/).

The Commission on Structural Chemistry (CSC) and CIMS maintained their links. P. Mercier is now the liaison person representing CSC in CIMS and vice versa.

P. Mercier continues to act as liaison officer of CIMS with the IUCr Newsletter.

D. Pandey and F. Paz were appointed Co-editors of, respectively, Journal of Applied Crystallography and Acta C.

Strong links exist between CIMS and the European Crystallographic Association: O. Yakubovich (CIMS member) is a member of the Executive Committee; the Secretary of the Special Interest Group SIG5 is O. Siidra, the Chair S. Krivovichev (CIMS consultant) and F. Hatert Vice-Chair (CIMS member) (ECA - SIG5, http://sig5.ecanews.org/). 
There are very good relationships between CIMS and the European Mineralogical Union (EMU, http:// eurominunion.org/); R. Oberti (EMU Past President) is a member of CIMS and also Commissioning editor of the EMU Notes in Mineralogy. In 2014, EMU organized the school Planetary Mineralogy (Glasgow, 25 August - 3 September, main organizers M. Lee and H. Leroux), which was supported by an Erasmus Intensive Programme grant. The accompanying book of the EMU Notes in Mineralogy, Vol. 15, will be published shortly. Volume 16 on Mineralogical Crystallography, co-edited by J. Majzlan, Sergey Krivovichev (CIMS consultant) and J. Plasil, is presently under production.

CIMS also collaborates with the Geochemical Society and the European Association of Geochemistry: R. Oberti was Co-editor of the Special Issue of the Mineralogical Magazine that focused on the contribution to the session GEOLIFE Geomaterials for Environment, Technology and Human Activities, convened during the 2013 Goldschmidt Conference.

The main activity of CIMS in 2014 was the preparation and running of the following events at the Montreal Congress:

MS1 Phase Transitions in Functional Inorganic Materials and Minerals (Chairs P. Thomas and K. Sugiyama);

MS15 The Role of Defects in Crystal Structure Formation, Organization and Stability (Chairs O. Yakubovich and S. Pereira);

MS74 Mineralogical Crystallography (Chairs P. Mercier and R. Peterson); D. Pandey delivered the Keynote Lecture The World of Perovskites: Phase Transitions and Exotic Properties.

R. Oberti co-Chaired the Organizing Committee of the first European Crystallographic School (ECS) held in Pavia, Italy, 26 August - 6 September 2014 to celebrate the International Year of Crystallography. Some 120 students from 30 countries (selected from among 200 applications) and more than 20 internationally renowned teachers (including the Nobel laureate V. Ramakrishnan) contributed to the success of a tenday school for masters and PhD students and a six-day school designed for students with expertise. The school was supported by an Erasmus Intensive Programme grant to a consortium of nine European Universities and provided students with three ECTS credits. The successful request for sponsorship to the IUCr was supported by CIMS.

M. Nespolo and S. Krivovichev represented CIMS on the International Advisory Board of the 2014 Meeting of the International Mineralogical Association, held 1-5 September 2014 in Gauteng, South Africa, where CIMS was in charge of the session Modular Aspects of Mineral Structures in the theme Mineralogical Crystallography.

J. Rocha was a member of the Organizing Committee of SMARTER4, Durham, UK, 1-4 September 2014 (http:// www.ccpnc.ac.uk/smarter4/).

Joint IUCr MaThCryst-CIMS Workshop: D. Pandey was workshop coordinator, and M. Nespolo and J. Rocha were members of the International Programme Committee of the Workshop on Symmetry Relationships Between Crystal Structures with Application to Structural Phase Transitions, Varanasi, India, 27-31 October 2014. (Dhananajai Pandey,
Massimo Nespolo, Mois Aroyo and Juan Carvazal were lecturers.) (http://iitbhu.ac.in/conferences/mst/IUCr/.)

G. Ferraris and R. Oberti were members of the scientific committees for the organization of two meetings celebrating IYCr in Italy: (1) Impact of Crystallography on Modern Science was organized by the Accademia delle Scienze di Torino and held in Torino on 25 June 2014; a talk was given by Robert Hubert, Nobel laureate 1988: Beauty and Fitness for Purpose, the Architecture of Proteins, the Building Blocks of Life. R. Oberti talked on the impact of crystallography and crystal chemistry on petrology and geochemistry. (2) Challenges in Crystallography was organized by the Accademia Nazionale dei Lincei and held in Rome, 13-14 October 2014. CIMS Chair, J. Rocha, gave an invited talk.

O. Yakubovich was a member of the Organizing Committee of the XVIII International Conference on Crystal Chemistry, X-ray Diffraction and Spectroscopic Studies of Minerals, held in Ekaterinburg, Russia, 2014.

CIMS has been involved in the organization of the following meetings:

R. Oberti is a member of the scientific committee of the 8th European Conference on Mineralogy and Spectroscopy to be held in Rome, 9-11 September 2015 (http://www.ecms2015. $\mathrm{eu} /$ ). This event will deal with mineralogy, spectroscopy and related fields, with a special focus on the interplay between short-range and long-range information to account for crystalline and amorphous materials' physical properties.

S. Krivovichev and R. Oberti are members of the scientific committee of the 2nd European Mineralogical Conference to be held in Rimini, Italy, 11-15 September 2016 (http:// emc2016.socminpet.it/). The focus will be on the impact of crystallography on the mineralogy and petrology of the Earth and extraterrestrial bodies. C. Ling is chairing the Organizing Committee of the 2nd Asia-Oceania conference on Neutron Scattering (AOCNS-2015), Sydney, Australia, 19-23 July 2015 (http://aocns-2015.com).

O. Yakubovich is a member of the Programme Committee of the 29th European Crystallographic Meeting, to be held in Rovinj, Croatia, August 2015.

CIMS supported the application for funding by the IUCr of the following meetings to be held in 2015:

8th USPEX Workshop on Computational Materials Discovery Using the USPEX Code, Shiv Nadar University, India, 20-24 January 2015, promoted by Artem O. Oganov; D. Pandey will give the opening lecture.

8th European Conference on Mineralogy and Spectroscopy, Rome, Italy, 9 September 2015, promoted by R. Oberti (scientific committee).

\section{J. Rocha, Chair}

\subsection{Commission on Magnetic Structures}

In 2014, the IUCr magCIF working group, which includes members of our Commission, and also members of COMCIFS, completed a first draft of the new magCIF dictionary, which includes support for both commensurate and incommensurate 
magnetic structures. The dictionary proposes to extend three existing dictionaries (core, symmetry, modulated structures), adhering as closely as possible to the existing structure, so that the extensions appear to be both natural and minimal. This draft is being actively debated and revised in hopes that a final draft can be agreed upon next year. This intensive effort has been driven by the immediate need for communication amongst multiple software packages and online resources. Early adopters of the prototype magCIF format in 2014 include FullProf, JANA, the Bilbao Crystallographic Server, and the ISOTROPY suite.

Eight Commission members and consultants conducted a two-hour internet-video meeting on 11 February 2014. Plans and preparations for the sponsorship/support of several upcoming meetings were determined. But most of the time was dedicated to detailed discussions of which coordinate systems, settings, symmetry operations and fundamental description types to support in the new magCIF format. The Minutes of this meeting were influential in guiding the development of a prototype magCIF tag set.

At the Montreal Congress, ten members and consultants of the Commission met in person on 9 August. Wieslawa Sikora was appointed as Secretary of the Commission. Danny Litvin will serve as our liaison to the Commission for Crystallographic Nomenclature. Maria-Teresa Fernandez-Diaz will continue to be our liaison to the Commission on Neutron Scattering, Taku Sato will manage the Commission's web resources and Alexander Pirogov will lead the effort to contribute entries relevant to magnetic structure to the IUCr's Dictionary of Crystallography. Annalisa Guerri (University of Florence, Italy) visited the meeting to assist with our plans for an International School of Crystallography on the topic of Magnetic Crystallography in Erice in 2019. David Brown (McMaster, Canada) and James Hester (ANSTO, Australia) of COMCIFS joined the meeting for an extended discussion of the development of the new magCIF dictionary. Most of the meeting was devoted to debating these technical details, and also to plans for sponsoring and otherwise supporting upcoming meetings and Microsymposia.

J. M. Perez-Mato and his colleagues at UPV/EHU in Bilbao have constructed and released a substantial collection of over 200 commensurate and incommensurate magnetic structures via the new MAGNDATA utility of the Bilbao Crystallographic Server. These structures have been extracted from both new and old scientific literature, and from the book Magnetic Structures Determined by Neutron Diffraction by Andrzej Oles, and also the structure collection of Wieslawa Sikora. We note the recent passing (18 January 2014) of Professor Oles with sadness. Owing to significant variations in the presentation styles and standards of different research communities, the extraction and modern presentation of each structure is a minor research project. For each structure in the collection, the server provides a magCIF data file and visualization output for Jmol and Vesta.

The extensive efforts of our Commission members in planning, organizing, advertising, attending and presenting at the Montreal Congress made it a hugely successful venue for the magnetic-structure community. The scientific programme included 14 directly relevant Keynote addresses and Microsymposia (http://magcryst.org/meetings/iucr-congress-2014/), 8 of which were co-sponsored by our Commission, and nearly all of which were supported in some way (e.g. organizer, Chair, presenter etc.) by Commission members. These sessions were well attended (completely full in some cases), and the presentation quality was generally very high.

To celebrate the International Year of Crystallography, the Commission conducted a three-day workshop on The Role of Magnetic Symmetry in the Description and Determination of Magnetic Structures (http://magcryst.org/meetings/ cmsworkshop2014) on 14-16 August 2014 at the Brockhouse Institute for Materials Research, McMaster University, which is located in the city of Hamilton, Canada. This satellite meeting of the Montreal Congress was filled to capacity and had truly global reach, with 46 participants (including 8 presenters) from 29 institutions in 15 countries and 6 continents (Argentina, Australia, Belgium, Canada, Czech Republic, France, Germany, India, Norway, South Korea, Spain, Sweden, Switzerland, UK, USA). The workshop combined the practical aspects of magnetic structural analysis (e.g. analytical software tools and neutron-scattering instruments) with the theoretical foundations of magnetic crystallography (e.g. magnetic symmetry groups, tensor properties and matrix representations). Hands-on tutorials emphasized new magnetic-structure capabilities of the JANA, FullProf, TOPAS, Bilbao Crystallographic Server and ISOTROPY Suite tools and resources. Lectures demonstrated the application of these novel capabilities to a variety of interesting structures. One common theme throughout the workshop was the use of the new magCIF format for the unambiguous description of a magnetic structure.

In addition to promoting the Montreal Congress and the satellite workshop in Hamilton, the Commission's new web site at http://magcryst.org was used to promote meetings that give attention to high-quality magnetic-structure research. At many of these events, our Commission members gave featured presentations, developed workshop components, organized or hosted workshops and Microsymposia, and presented lecture courses. Highlights include the following:

20th ad hoc JANA2006 Workshop on Magnetic Structures, Prague, Czech Republic, 16-17 January 2014 (Vaclav Petricek).

17th International Seminar on Neutron Scattering Investigation in Condensed Matter, Faculty of Physics, Adam Mickiewicz University, Poznan, Poland, 21-23 May 2014 (Wieslawa Sikora).

Magnetic Diffraction from Single Crystals at the ESS, Paris, France, 26-27 May 2014 (Juan Rodriguez-Carvajal).

American Crystallographic Association meeting, MS 2.1.5, Albuquerque, USA, 24-28 May 2014 (Branton Campbell).

Workshop on Magnetic Structure Determination from Neutron Diffraction Data, Knoxville TN, USA, 5-8 June 2014 (Juan Rodriguez-Carvajal).

Lecture course on Determination of Magnetic Structure from Neutron Diffraction Experiment, for young scientists, 
Korea Atomic Energy Research, Daejon, Korea, August 2014 (Alexander Pirogov).

Montreal Congress (KN7, KN13, KN34, MS08, MS18, MS26, MS33, MS41, MS81, MS90, MS98, MS105), 5-12 August 2014 (all Commission members).

CMS Workshop on Magnetic Structures, McMaster University, Hamilton, Canada, 14-16 August 2014 (all Commission members).

Lecture and practical workshop on Neutron Diffraction and Magnetic Structures, Thematic School on Crystallography and Neutrons, French Society of Neutron Scattering, Oléron, France, 21-24 September 2014 (Juan Rodriguez-Carvajal).

Russian Conference on Neutron Diffraction, Russia, October 2014 (Alexander Pirogov).

Lecture course on Magnetic Neutron Diffraction, Ural Federal University, Ekaterinburg, Russia, NovemberDecember 2014 (Alexander Pirogov).

25th ad hoc JANA2006 Workshop on Magnetic Structures, Prague, Czech Republic, 1-2 December 2014 (Vaclav Petricek, Branton Campbell).

\section{B. Campbell, Chair}

6.16. Commission on Mathematical and Theoretical Crystallography

Organizational issues. During the Montreal Congress, the renewal of the Commission (MaThCryst) was approved. M. I. Aroyo became Chair. The Commission wishes to thank its outgoing Chair, M. Nespolo, for his many years of service and promotion of mathematical and theoretical crystallography, and especially for his dedicated and exceptional work as Commission Chair.

Apart from active communications between the members of MaThCryst via the internet, in August 2014, at the Montreal Congress, there was an official Open Meeting of the Commission. Some of the new and outgoing members and consultants had the opportunity to meet in person and exchange opinions about the various aspects of future MaThCryst activities. Several actions were agreed for the forthcoming triennium - in particular, the reinforcement of links with other Commissions and the promotion of education in all fundamental aspects of mathematical and theoretical crystallography.

Following the recommendation of the Executive Committee and to encourage greater participation of individual members within Commissions, members were assigned to different aspects of the work of the Commission: M. L. De Las Peñas accepted to serve as Secretary of MaThCryst; M. Aroyo as liaison to Commissions on International Tables, Crystallographic Nomenclature and Magnetic Structures; J. Hadermann as liaison to the Commissions on Electron Crystallography and Aperiodic Crystals, and also to the ECA (being a member of its Executive Committee); L. Suescun as liaison to the Commission on Crystallographic Teaching and LACA; E. Rams as liaison to LACA; K. Momma as liaison to AsCA; S. Hyde as liaison to World Database of Crystal- lographers; G. McColm as liaison to AMS and SIAM; M. Nespolo as liaison to the Commission on Inorganic and Mineral Structures; and D. Litvin as liaison to the Commission on Magnetic Structures. MaThCryst's home page is maintained by M. Nespolo, and can be found at http://www. crystallography.fr/mathcryst/index.php. G. McColm is maintaining a blog on mathematical crystallography, called Crystal Mathematician at http://blogs.iucr.net/crystalmath and devoted to mathematics of crystal design and analysis.

Educational and scientific activities. All the activities of MaThCryst during 2014 were dedicated to the celebration and promotion of the International Year of Crystallography.

Montreal Congress. The central activity for the Commission in 2014 was its active participation in the Montreal Congress. M. Nespolo was the representative of MaThCryst on the International Programme Committee. MaThCryst organized one Keynote Lecture (KN13 Mathematical Crystallography in the 21st Century, Marjorie Senechal, Smith College, USA), suggested two Microsymposia [MS72 Methods, Algorithms and Software for Powder Diffraction (co-Chairs R. OishiTomiyasi, J. Wright) and MS95 Symmetry and its Generalisations in Science and Art (co-Chairs M. L. De las Peñas, E. Makovicky)] and co-organized four Microsymposia proposed by other Commissions [MS01 Phase Transitions in Functional Inorganic Materials and Minerals (co-Chairs P. Thomas, K. Suglyama); MS33 Symmetry Constraints in Magnetic Structure Determination: Experiment and Theory (co-Chairs B. Campbell, M. I. Aroyo); MS34 Crystals and Beyond (coChairs S. I. Ben-Abraham, J.-Y. Lee) and MS42 Diffuse Scattering and Partial Disorder in Complex Structures (coChairs R. Welberry, M. de Boissieu)].

Together with the Commission on Magnetic Structures, MaThCryst co-organized a satellite workshop of the Montreal Congress on The Role of Magnetic Symmetry in the Description and Determination of Magnetic Structures, at the Brockhouse Institute for Materials Research at McMaster University, Hamilton, Canada, 14-16 August 2014. The workshop was attended by 46 participants (including 8 presenters) from 29 institutions in 15 countries (Argentina, Australia, Belgium, Canada, Czech Republic, France, Germany, India, Norway, South Korea, Spain, Sweden, Switzerland, UK, USA). The main subjects of the workshop programme included practical aspects of magnetic structural analysis combined with the theoretical foundations of magnetic crystallography. Hands-on tutorials emphasized new magnetic-structure capabilities of the JANA, Fullprof, TOPAS, Bilbao Crystallographic Server and ISOTROPY Suite computer tools and resources.

International schools. During 2014 MaThCryst continued with the support and organization of international schools following the idea of the importance of improving the teaching of fundamental aspects of crystallography, especially to graduate students and young researchers in countries where nowadays the subject is overlooked in common University courses. This mission is accomplished through a series of schools and meetings in a wide range of regions. 
(a) The IV MaThCryst School in Latin America was held in La Plata, Argentina, 27 April - 3 May 2014 (MaThCryst coordinators: E. E. Rams and L. Suescun). This was the fourth school in Latin America organized by the Commission, after those in Havana, Cuba (2007), Montevideo, Uruguay (2010), and Uberlandia, Brazil (2012). The 37 selected participants (from more than 80 applications) included post-docs, $\mathrm{PhD}$ and MSc students and even three undergraduate students. The participants came from Universities and research centres of Argentina (20), Bolivia (2), Brazil (4), Colombia (3), Costa Rica (1), Mexico (2), Peru (2), Uruguay (2) and USA (1). Four members of MaThCryst (Nespolo, Rams, Suescun and Aroyo) were among the international team of lecturers and instructors. Financial support from the IUCr for the school was greatly appreciated. Details of the programme of the school, didactic material etc. are available at the web site http:// www.crystallography.fr/mathcryst/laplata2014.php.

(b) II South African School on Fundamental Crystallography, Bloemfontein, South Africa, 25-29 August 2014 (MaThCryst coordinators: M. Nespolo and M. I. Aroyo). The second school organized by the Commission in Bloemfontein was also run as a Satellite Meeting of the 21st Congress of the International Mineralogical Union. The school was attended by 36 participants from 9 different institutions and six countries. Participants with backgrounds in chemistry, physics, materials science and mineralogy ranged from Masters students to post-docs and University professors. The programme included basic and advanced topics from fundamental crystallographic group theory to applications in phase transitions, twins and modular structures. Each lecture was accompanied by a series of guided exercises. The school closed with a session where most of the participants gave short oral presentations followed by discussions of their research projects. Details of the programme of the school, didactic material, photos etc. are available at the web site http:// www.crystallography.fr/mathcryst/SouthAfrica2014.php.

(c) The International Scientific School Topological Methods for Expert Systems in Materials Science was held in Samara, Russia, 12-16 August 2014 (MaThCryst coordinators: D. Proserpio and V. Blatov). Twenty young researchers and professors from Russia, Poland, Brazil, India, China and Saudi Arabia participated in the school. Among the school participants were students, postgraduate students, candidates of sciences and professors, who work in various fields of chemistry. The school programme included lectures and practical training applying the TOPOS software package under the supervision of D. Proserpio and V. Blatov. The practical training was aimed at understanding the basics of topological analysis and nanocluster analysis of intermetallic compounds, as well as the search for new electrolytes based on the analysis of crystal structures by means of Voronoi-Dirichlet polyhedra.

(d) Second International PhD School on Geometry and Topology of Liquid Crystals and Related Ordered Materials, RMIT University, Melbourne, Australia, 12-16 August 2014 (MaThCryst coordinator: S. Hyde). The school was an intense five-day immersion in newer aspects of (mainly) two-dimensional (generalized) crystallography and structure, focusing on nets and tilings, surface topology and differential geometry, orbifolds, and point, plane (wallpaper) and hyperbolic discrete groups. Each day comprised four daytime sessions, with handson exercises following short presentations, and evening research lectures, highlighting materials science applications involving the material explored during the day (including lyotropic liquid crystals, metal-organic frameworks, crystalline membranes in vivo and pharmaceutical delivery materials). Stephen Hyde was the principal lecturer, assisted by Gerd Schroeder-Turk (Erlangen), Jacob Kirkensgaard (Copenhagen), Elisabetta Matsumoto (Princeton), with evening talks also by Charlotte Conn (RMIT), Yuru Deng (Changzou) and Liliana de Campo (ANSTO). Eleven students, mainly materials scientists, ranging from $\mathrm{PhD}$ students to mature researchers from Australia and Europe, attended the school. A suite of new concepts was introduced, and the week closed with self-directed projects, ranging from computer constructions of grain boundaries in bicontinuous cubic mesophases, to explorations of non-orientable orbifolds and associated 2D glide operations.

Workshops, courses and meetings. In 2014 MaThCryst was also involved in the organization of, and its members actively participated in, several workshops, courses and meetings:

(i) Workshop on Symmetry Relationships Between Crystal Structures with Application to Structural Phase Transitions, Varanasi, India, 27-31 October 2014. The workshop was successfully organized in cooperation with the Commission on Inorganic and Mineral Structures. D. Pandey was the main local organizer and also the MaThCryst coordinator. About 40 participants (apart from the lecturers and organizers) attended the workshop. The lectures of the workshop included topics on crystallographic groups, their representations and applications in structural and magnetic phase transitions. There were hands-on practicals on space-group descriptions in Volume A of International Tables for Crystallography, online training for the analysis of crystal structure relations and phase transitions using the Bilbao Crystallographic Server and practical exercises on refinement of magnetic and nuclear structures using the FullProf suite. More details on the programme of the workshop and the related didactic material can be found on the web site of the workshop (http:// www.crystallography.fr/mathcryst/banaras2014.php). Thanks to the IUCr support of the meeting, a number of young scientists had the opportunity to participate.

(ii) Training Course on Symmetry and Group Theory, Tsukuba, Japan, 15-17 August 2014 (MaThCryst coordinator: M. Nespolo). The main organizer of the course was the Photon Factory, co-organizer the Crystallographic Society of Japan, with support from the Japanese Society for Synchrotron Radiation Research, the Japanese Society for Neutron Science and MaThCryst. The course was held in the campus of the Photon Factory at Tsukuba and was attended by 35 participants coming from various places in Japan: from Hokkaido to Hiroshima. The training course spanned three full days. An optional pre-school day was organized on 14 August for those needing to revise general concepts about matrix algebra and general introduction to group theory. The lecturer of the 
course, M. Nespolo, gave the lectures in Japanese. A detailed programme is available at http://www.crystallography.fr/ mathcryst/Tsukuba2014.php, and photos at http://www. iycr2014.org/photos/japan/tsukuba-training-course.

(iii) Spring Eastern Sectional Meeting of the American Mathematical Society, University of Maryland, Baltimore, USA, 29-30 March 2014 (MaThCryst coordinator: G. McColm). Three special sessions on Discrete Geometry in Crystallography were co-organized by the Commission. Among the different lectures treating various aspects of mathematical crystallography, one should highlight the excellent contributions of three members of MaThCryst: M. Nespolo on pseudosymmetry analysis and its applications in twin studies; B. Souvignier on relations between icosahedral polytypes induced by group ring elements; and G. McColm on generation of crystal nets in Euclidean space.

\section{I. Aroyo, Chair}

\subsection{Commission on Neutron Scattering}

The Commission promotes the use of neutron scattering by encouraging the publication of information on the capabilities of neutron sources and instrumentation and by supporting symposia, schools and workshops that educate researchers on the unique information that can be provided by neutron scattering. Several members of the Commission are actively involved in developing neutron sources and new neutron scattering technologies and methods. Notable developments in 2014 included the start of construction of the European Spallation Neutron Source in Sweden, which is projected to produce the first neutrons in 2019, operation of the Spallation Neutron Source (SNS) in the USA at a world-record level of 1.4 MW, installation of the first accelerator components for the Chinese Spallation Neutron Source (CSNS), which is expected to be operational in 2018, and the continued ramp up in power of the accelerator at J-PARC in Japan toward 1 MW. Further, several new neutron scattering instruments were brought into user programmes at neutron scattering facilities across the world.

Commission members were also involved in organizing several meetings that took place in 2014, including the Montreal Congress and various annual meetings of regional crystallographic associations. A notable neutron conference in 2014 was the 7th American Conference on Neutron Scattering, which was held in Knoxville, USA. This conference was hosted by Oak Ridge National Laboratory (ORNL) and sponsored by the Neutron Scattering Society of America. The programme included several tutorials, satellite meetings, user group meetings for national neutron user facilities (Lujan User Group, the SNS/HFIR User Group and the NCNR User Group), industrial exhibits, and a tour of ORNL, which operates two advanced neutron scattering research facilities: the SNS and the High Flux Isotope Reactor (HFIR).

Several neutron schools were supported by Commission members, including the 16th National School on Neutron and X-ray Scattering (NXS), jointly organized by Argonne and
Oak Ridge National Laboratories in the USA, the 6th AsiaOceania Neutron Scattering Association (AONSA) school held in Serpong, Indonesia, and the 20th annual Center for High Resolution Neutron Scattering summer school on methods and applications of neutron spectroscopy, NIST Center for Neutron Scattering in the USA. The Spanish neutron society meeting organized its biennial school in Pamplona, Spain, VII Reunión de la Sociedad Española de Técnicas Neutrónicas (SETN), with about 80 national and international participants.

Commission members were involved in planning activities for several important neutron conferences in 2015, including a Gordon Research Conference (GRC) on Neutron Scattering, which is a new series featuring several world-leading neutron scattering scientists. The inaugural GRC will take place in Hong Kong and will focus on the effect of disorder and disordered materials. Other planned conferences include the 6th European Conference on Neutron Scattering, which will take place in Zaragoza, Spain, and the triennial International Symposium on Diffraction Structural Biology (ISDSB2016), which will be held in Knoxville and ORNL. In India a conference on Neutron Scattering and a Neutron School were organized at Bhabha Atomic Research Centre at Mumbai with participation of several colleagues from abroad. In both of these events crystallography, magnetic structures and mesoscopic structures (using small-angle neutron scattering) were very important topics related to the objectives of the IUCr.

Public outreach related to the International Year of Crystallography continued to the end of 2014 and beyond. There was an exhibition entitled Representations of Matter in Real and Reciprocal Space: Images and Objects from Crystallography at the Verge Gallery of the University of Sydney (http://verge-gallery.net/2014/07/31/crystallography-august-1522/). This was coordinated by Althea Ling, the wife of the present ANBUG (Australian Neutron Beam Users Group) President, Chris Ling, and included 3D-printed crystal structures, dramatic colourful images of diffraction patterns, both $\mathrm{X}$-ray and neutron, and a selection of the photographs from the IUCr's competition Crystallography in Everyday Life. Dr Helen Maynard-Casely of ANSTO continued her popular blog Crystallography365: Blogging a Crystal Structure a Day in 2014. Dr Maynard-Casely herself wrote upwards of half the entries. This blog has now been picked up by the IUCr as a permanent item on their web site (http://www.iycr2014.org/ learn/crystallography365).

The International Year of Crystallography was celebrated in an article for Australian Physics, the house journal of the Australian Institute of Physics. Crystallography at ANSTO's Jewel, the OPAL Reactor, by Dr Helen Maynard-Casely (again!) and Professor Garry McIntyre, described the contributions that Australia has made to neutron diffraction from the formative years of the subsidiary programme of neutron scattering at the materials-testing reactor HIFAR to the ground-breaking experiments possible now at the state-of-theart OPAL reactor. Nature produced a special Nature Milestones collection on crystallography with part sponsorship 
from ANSTO (http://www.nature.com/milestones/milecrystal/ index.html).

With ANSTO also operating the Australian Synchrotron, it was straightforward to morph into the International Year of Light in 2015 (http://www.ansto.gov.au/AboutANSTO/ MediaCentre/News/ACS068854), but neutron diffraction has not been left out. A series of banners has been installed around the ANSTO site marking the IYL2015 with falsecolour images of neutron scattering patterns, including Laue diffraction, which would show a range of wavelengths if only we had wavelength-sensitive area detectors (http://www.ansto.gov.au/ResearchHub/Bragg/CurrentResearch/ ScientificHighlights/HigherDimension/index.htm).

\section{P. Langan, Chair}

\subsection{Commission on NMR and Related Methods}

A proposal to establish the Commission was formally presented by Professor Francis Taulelle (with support from Rod Wasylishen and Manish Mehta) to the Executive Committee of the IUCr on 1 August 2014, at its meeting in Montreal prior to the triennial Congress. Following a brief discussion, the Executive Committee gave a warm formal approval to the existence of the Commission with an amended title: Commission on NMR Crystallography and Related Methods, to emphasize the inclusion of such techniques as EPS/ESR. The formation of the Commission was confirmed by the General Assembly.

R. K. Harris and M. A. Mehta have been appointed as joint Secretaries, whilst liaison with the IUCr Executive is maintained through G. R. Desiraju. Details of the membership, objectives and activities of the Commission can be found on the IUCr web site at http://www.iucr.org/iucr/ commissions/nmr-crystallography. The Commission's web site will be developed further and new members of the Commission are currently being sought (especially to broaden the geographic representation and to add expertise in ESR spectroscopy).

A series of SMARTER conferences has been established on the topic of NMR crystallography, with participants from both the NMR and diffraction communities. The fourth of this type was held in Durham (UK) in September 2014; these meetings are now sponsored (inter alia) by the IUCr. The next SMARTER meeting will be in Bayreuth, Germany, in 2016 (organizer J. Senker).

Discussions are underway to determine how research papers involving NMR crystallography will be incorporated into Acta Crystallographica. Initially, it has been decided to publish a Special Issue of Acta $C$ with a submission deadline of August 2015 and publication in January 2016.

Establishment of the new Commission is not before time! Although new to the IUCr, NMR has been known as a method of obtaining detailed molecular-level information on crystalline materials for about 60 years. For instance, in 1948 (only three years after the discovery of the NMR phenomenon) Pake reported the measurement of the internuclear distance between protons in water molecules involved in gypsum. A year later, Gutowsky et al. commented that 'the development of experimental methods for observing nuclear magnetism has provided a means of investigating certain aspects of molecular and crystal structure'. However, much higher resolution was attainable for solutions than for solids, so for several decades, the former dominated NMR work and the latter languished. This situation changed with the development of cross polarization, magic-angle spinning and high-power proton decoupling in the mid-1970s. This combination of techniques resulted in much higher resolution for solids, so that applications to crystalline materials have become common. The crystallography community in general has been slow to adopt NMR as one of its key techniques, so NMR and diffraction methods have largely involved separate communities until recently. However, it has become obvious that the complementarity of these methods requires a closer interaction of their practitioners, so the formation of a new IUCr Commission at this point makes sense. The development of computational methods for refining structures from NMR data has added urgency to this matter.

The requirement for closer integration of NMR with other methods of studying crystalline materials was highlighted by a short article in the IUCr Newsletter in 2005, following an International School on Crystallography at Erice the previous year, which had included lectures on NMR. It should be noted that the Commission will also deal with other magnetic resonance techniques, such as ESR/EPR, NQR and muon spin resonance. A link has been established with developments in connecting chemical shifts with crystal structure via computation, carried out by the Collaborative Computational Project for NMR Crystallography (funded by EPSRC in the UK). The Commission has been invited to plan a one-day meeting on NMR Crystallography.

It is worth summarizing here just a few of the salient points about NMR crystallography for the benefit of newcomers to the subject:

NMR is generally used to study microcrystalline samples and does not require single crystals.

It gives information about short-range environments of atoms in a complementary fashion to diffraction techniques, which rely on long-range order.

Motion in solids can be monitored and investigated.

Crystallographic disorder can be detected and evaluated.

Amorphous systems yield detailed information about molecular-level structure.

The structure of heterogeneous materials can also be evaluated by NMR.

Since the technique is based on nuclei not electron density, the correct positions of hydrogens are relevant.

It can be used in combination with powder diffraction (and even, in some circumstances, on its own) to obtain full structural information.

The sheer versatility of NMR should also be emphasized. This arises from $(a)$ the fact that nearly all the elements of the Periodic Table have a suitable isotope for study (and the frequency ranges for their signals do not in general overlap) 
and $(b)$ there is are wide variety of experiments that can be performed by varying the radiofrequency pulse sequences used. Further details can be seen in a number of books and themed issues of several journals. There is, for example, a recent (2009) handbook on NMR Crystallography (ISBN 9780-470-69961-4).

\section{F. Taulelle, Chair}

\subsection{Commission on Powder Diffraction}

2014 was dominated by the International Year of Crystallography and the Montreal Congress. The Commission was represented in Paris at the Opening Ceremony of the IYCr by a past-Chair and long-term member of the CPD, Bill David. The year started in earnest with a CPD-organized workshop in Africa held 27-31 January, spear-headed by Dave Billing, as one of the first official IYCr events. The decision to hold a workshop in Africa was intended to support IUCr efforts to expand crystallography in the region. The 2014 Southern African Powder Diffraction Workshop was a success in no small part due to the efforts of Dave, the rest of the Organizing Committee and the South African Crystallographic Society. A strong lineup of invited speakers ensured a highquality programme covering a broad range of applications of powder diffraction.

Personally, the Montreal meeting was quite an event as one of the people involved in the original bid in Osaka. Powder diffraction was well represented in the programme, and it was satisfying to see many sessions very well attended. In a glass half-full/half-empty situation some people could not get into some sessions (myself included) owing to overcrowding. The quality of the sessions was high and a good variety of topics were covered, from the oft-neglected texture and reflectometry applications to the latest developments in structure solution from powder data.

As always happens at the triennial Congresses, a certain turnover of the CPD membership occurs, although I find myself still Chair of the Commission. Come the Congress in Hyderabad in 2017 this will change as I will have been Chair as long as the IUCr rules permit. Unfortunately, the deadline for publication of Volume $\mathrm{H}$ of International Tables in time for the Congress was not met. The powder diffraction community has been understandably impatient for the publication of such a definitive text.

Given the location in the centre of Montreal and excellent weather the Commission meeting was held in an unusual (but not unprecedented) location in the form of a roof-top hostelry overlooking the city. A mixture of retiring, continuing and new members were present to discuss progress and future plans.

Discussions have been ongoing through the year with regard to an update to the Rietveld refinement guidelines and the form that this will take. Although the fundamentals of the guidelines are just as correct now as when originally published, developments in hardware and software have made certain aspects somewhat dated. They would benefit from a change in emphasis required in some areas and a higher profile in the literature to increase their relevance and impact.

\section{P. Whitfield, Chair}

\subsection{Commission on Small-Angle Scattering}

Commission meetings and communication. During 2014, members of the Commission (CSAS) communicated by e-mail or during personal meetings at national and international conferences. Most of the members and consultants contribute to the various activity categories on an ongoing basis. What follows is a summary of highlights for calendar year 2014 . Following the Montreal Congress, Andrew Allen stepped down as Chair, and was succeeded by Jill Trewhella.

Commission activities. During 2014, Commission activities focused on planning for SAS-related activities at the Montreal Congress and planning for SAS2015 to be held in Berlin, Germany, September 2015. CSAS activities also supported the International Year of Crystallography, IYCr2014.

Following initial publication of papers associated with the SAS2012 Conference in the Journal of Applied Crystallography in late 2013 and early 2014, these 24 selected papers were collected together and the SAS2012 Special Issue was published in Spring 2014. While still a little early to make too many conclusions, citation data to date suggest that the SAS2012 papers more than match the journal impact of regular papers. The SAS2012 Special Issue presented a good cross section of cutting-edge SAS papers that represented the state-of-the-art in the field for IYCr2014. This selected publication model will be followed for SAS2015 with A. Allen (CSAS and JAC Editorial Board) and M. Gradzielski (SAS2015 Conference organization) proposed as Guest Main Editors. Other Guest Co-editors will be appointed as appropriate. CSAS members have been very active in planning for SAS2015, with D. Svergun on the Scientific Programme Committee, and A. Allen, E. Gilbert, D. McGillivray, J. SkovPedersen and J. Trewhella on the International Advisory Board. In addition, CSAS has collaborated with the SAS2015 Organizing Committee to develop and publish calls for the Guinier Prize and for bids for hosting SAS2021.

CSAS members and consultants worked with E. Gilbert, the CSAS nominated member of the Montreal International Programme Committee (IPC), to develop a programme that included a Keynote speaker and an unprecedented number of SAS-related Microsymposia, including six dedicated Microsymposia plus three further Microsymposia jointly organized with other Commissions. The Microsymposia ranged over broad areas of interest: SAS of biological macromolecules; SAS for magnetism and magnetic structures; grazing incidence surface techniques; simultaneous methods with SAS; in operando and structure evolution - from atomic to micrometre scale; industrial and technological applications of SAS (organized by CSAS members U. Jeng and R. Serimaa); and applications of anomalous SAXS. Unfortunately, E. Gilbert was unable to attend the Congress, and so the outgoing CSAS Chair, A. Allen, had the privilege of chairing the SAS-related 
Keynote Talk: Applications of Small-Angle Scattering to Macromolecules and Polymer Physics, given by Takeji Hashimoto. The development of a robust scientific programme in Montreal with significant presence from CSAS demonstrated the breadth of applications for SAS and also the broad complementarities between SAS and areas of interest with other IUCr Commissions.

A. Allen chaired an Open Meeting of the Commission during the Montreal Congress to report on CSAS activities over the past three years - see the Triennial Report and other activities mentioned in this Annual Report. In addition, A. Allen and J. Trewhella met with the IUCr Executive Committee to provide a verbal report on CSAS activities and recommendations for CSAS membership and consultants.

Various CSAS members were active in marking the celebration of IYCr2014. These included active involvement in symposia and sessions at conferences held around the world during 2014. A. Allen took part in IYCr2014-themed symposia at both the TMS Annual meeting in San Diego, CA, USA, in February 2014, and the MRS Fall meeting in Boston, MA, USA, in November 2014. T. Kanaya was co-organizer of a Special Seminar on Polymer Crystals in the annual meeting of the Fiber Society, Japan, celebrating IYCr2014 in Tokyo, June, 2014, and also gave an invited lecture on SAS dedicated to IYCr2014 at the International Union of Materials Research Societies International Conference in Asia 2014, Fukuoka, Japan, August, 2014. Finally, David Babonneau acted as regional representative to serve as a bridge with the French steering committee of IYCr2014.

Finally, the CSAS evaluated and recommended support for the application from N. Yagi (SPring-8/JASRI) for IUCr sponsorship and financial support for the 9th AOFSRR Cheiron School.

Educational activities. In 2014, CSAS members and consultants contributed to and organized a large number of courses, tutorials and lectures to improve awareness of SAS methods and applications, and also to increase the expertise in SAS and its applications broadly.

The European Molecular Biology Organization (EMBO)supported Global Exchange Lecture and Practical Courses are growing in popularity among those aspiring to learn about SAS applications in structural biology. A feature of these is that they generally do not focus exclusively on SAS, rather they put SAS in the context of what have been traditionally more main-stream techniques, including crystallography, and thus are able to emphasize the complementarity of SAS among the suite of modern structural biology tools. Courses that were held or planned for in 2014 included:

EMBO Global Exchange Lecture Courses with a focus on SAS:

(i) Structural and Biophysical Methods for Biological Macromolecules in Solution, Sao Paulo, Brazil, 19-26 January 2014 (main organizer D. Svergun and main local co-organizer C. Oliveira from Sao Paulo University). The course was the first event of this kind in South America, with 56 students selected from 115 applications, mostly from Brazil and other Latin-American countries. Fourteen international lecturers and tutors presented on SAXS, SANS, NMR, biophysical and computational methods and their synergistic use. Hands-on tutorials enabled students to interact with the tutors and engage with the material presented, and the course finished with a workshop where selected students presented their own research.

(ii) Structural and Biophysical Methods for Biological Macromolecules in Solution, Taipei, 4-10 May 2015. D. Svergun is the main organizer and U. Jeng one of the main local organizers.

EMBO Practical Courses:

(i) Solution Scattering from Biological Macromolecules, Hamburg, Germany, 27 October - 3 November 2014, covering SAXS and SANS analysis of bio-macromolecular solutions. This was the seventh such course in Hamburg, and attracted 200 applicants for just 20 regular places and an additional seven applicants were selected to attend lectures only. A team of 16 tutors and speakers from Hamburg plus a number of international lecturers provided the lectures and practicals.

(ii) Small-Angle Neutron and X-ray Scattering From Proteins in Solution, Grenoble, France, 18-22 May 2015. J. Trewhella and D. Svergun will contribute Keynote talks.

J. Trewhella and B. Vestegaard gave lectures at the above courses that took place in Sao Paulo and Hamburg and will also lecture in the Taipei course.

CSAS members from the Asia-Pacific region were very active promoting SAS methods and teaching the required skills to students and researchers in the region. In particular:

U. Jeng gave invited lectures on SAS applications with a focus on soft materials at: the Taiwan Neutron Science Society (TWNSS) Annual Meeting and Summer School and International Neutron Conference, Kaohsiung, Taiwan, 9-12 October 2014; the annual meeting of the Biophysical Society of ROC, Tainan, Taiwan, 5-7 May 2014; and the International Symposium on Frontier Technology for the Future, Hsinchu, Taiwan, 24-27 June 2014.

T. Kanaya acted as an advisor to the AONSA Neutron School, Indonesia, October 2014, and gave a number of tutorial lectures on SAS applications, including at the annual meeting of the Chemical Society in Japan, Nagoya, March 2014, in Nanjing (People's Republic of China), June 2014, and in Hsinchu (Taiwan), September 2014.

E. Gilbert gave an invited talk at the International Union of Food Science and Technology, Montreal, 17-21 August 2014, to describe how SAS methods may be applied to study foodbased systems.

For the Russian research community, V. Volkov was very active in contributing SAS expertise to training courses and providing specialist lectures, with a number focused on condensed-matter applications and nanoscience, including:

(i) extending a lecture course on Supra-Atomic Structures in Nanomaterials to include applications of SAS/GISAXS/ diffraction tomography to understand the structure of disordered systems;

(ii) contributing a lecture on mathematical methods in SAS data treatment at the meeting on the Use of Neutron Scat- 
tering and Synchrotron Radiation in Condensed Media, St Petersburg, October 2014;

(iii) a 10-hour course of lectures on SAS methods was included for students in the course X-ray Methods for Investigation of Matter;

(iv) six-hour training courses entitled Investigation of Structure of Nanoscale Disperse Systems by Small-Angle Scattering Methods were included in the programme of the Moscow State University;

(v) a training course on SAXS instrumentation and data treatment was carried out for young scientists from Moscow Institute of Physics and Technology and Moscow State Institute of Electronics and Mathematics.

Community-building activities. CSAS members and consultants served on various SAS-related Committees and panels and editorial boards in 2014:

A. Allen served on the SANS beam-time allocation Committee at the NIST Center for Neutron Research.

A. Allen became one of the three Main Editors of the Journal of Applied Crystallography.

E. Gilbert joined the editorial boards of the Journal of Applied Crystallography and Food Structure (Elsevier).

J. Trewhella became one of four Co-editors of the Biology and Medicine area for IUCrJ.

Consultant activities. Several CSAS members and consultants served on SAS-related proposal and design evaluation committees:

A. Allen served as a technical consultant for the new ISO 17867 SAXS (best practice) international standard: Particle Size Analysis - Small-Angle X-ray Scattering, developed in connection with particle-size measurements by ISO/TC 24/SC 4 Particle Characterization. Standard issued in 2015.

A. Allen also acted as informal consultant to parts of the canSAS effort in 2014 - acting as liaison with canSAS on SAS publication issues (i.e. IUCr journals), data and metadata requirements for SAS (imminent call on this likely to all nonpublishing IUCr Commissions), NIST SRM (see below), and ISO standards activity.

N. Yagi was advisor for design of proposed LIX (High Brightness X-ray Scattering for Life Sciences) beamline at NSLS-II, Brookhaven Laboratory, NY, USA, and attended a Beamline Advisory Team meeting (April 2014).

N. Yagi was adviser for Advanced Soft Material Beamline, SPring-8 (a dedicated SAXS beamline for industry-oriented polymer and soft-materials science).

David Babonneau continued to serve on Peer Review Committee 3: Matter and Material Properties: Structure, Organization, Characterization, Elaboration for beam-time allocation at SOLEIL synchrotron, France.

V. Volkov continued to consult on SAS methods for scientists from scientific and engineering institutes in Russia.

Organizational activities. SAS Commission members and consultants served on several programme or organization Committees for SAS-related conferences and workshops in 2014:

U. Jeng organized the National Synchrotron Radiation Research Center (NSRRC) SAXS interest group meeting,
Hsinchu, Taiwan, 11-13 September 2014. N. Yagi presented a Plenary talk at the meeting. U. Jeng also organized an international BioSAXS workshop at the meeting.

T. Kanaya was Co-organizer of the annual meeting of Frontier Soft Matter Beamline (FSBL) in SPring-8, Kyushu, Japan, January 2014; Co-organizer and invited lecture in the 6th Taiwan-Japan Joint Meeting on X-ray and Neutron Scattering, Tokai, Japan, March 2014; Co-organizer of Special Session on Flow-induced Polymer Crystallization at the International Conference on Fiber Science and Technology, Tokyo, Japan, September/October 2014.

David Babonneau as co-Chair planned for the 3rd International GISAS Meeting to be held as a satellite conference of SAS2015, Berlin, Germany.

E. Gilbert represented SAS interests for the Polarized Neutrons for Condensed Matter Investigations Conference, Sydney, Australia, 15-18 September 2014.

Technical activities. A major initiative supported by CSAS members relates to the continued work of the Worldwide Protein Data Bank (wwPDB) SAS Task Force (SAStf) on data requirements for biomolecular modelling. The SAStf is Chaired by J. Trewhella, and D. Svergun is a member. In accordance with the recommendations of the SAStf [Trewhella et al. (2013), Structure, 21, 875-881], D. Svergun's group developed and made publicly available a Small Angle Scattering Biological Data Bank (http://www.sasbdb.org) [Valentini et al. (2015), Nucleic Acids Res. 28, 43 (Database issue), D357-363], a curated repository for SAS data and models made public in October 2014, and currently containing 187 models of biomolecules derived from SAS data. The future strategy of wwPDB foresees federated systems of interconnected databases similar to that which exists presently for the PDB (RSCB, PDBe, PDBj). At present, two SAS databases exist, SASBDB and BIOISIS (http://www. bioisis.net, presently 99 models). At the 2014 meeting of the SAStf in Rutgers, it was agreed that a data-exchange mechanism between databases that were maintained and curated by different communities was desirable and could be achieved by utilizing a Crystallographic Information Framework (CIF). A SAS extension for CIF was created over a decade ago [Malfois \& Svergun (2000), J. Appl. Cryst. 34, 812] and has been extended through a collaboration between D. Svergun and the PDB. The extended sasCIF dictionary is linked to SASBDB, which provides a framework to facilitate seamless exchange of data with other repositories. This principle of data exchange can be extended to support the deposition of the hybrid modelling results as recommended by the new wwPDB Hybrid Methods task force (HMtf) that had its inaugural meeting at the European Bioinformatics Institute, Hinxton, UK, 6-7 Ocober 2014. The meeting was cochaired by A. Sali, T. Schwede and J. Trewhella, and D. Svergun was one of a select group of 35 leaders in structural biology methods invited to consider the future direction and needs for hybrid modelling, and a report from the meeting has been written and is under review for publication in Structure.

Other technical activities that CSAS members and consultants took part in include: 
A. Allen continued development of NIST standard reference material (SRM 3600) for SAXS intensity calibration, based on glassy carbon (in collaboration with others at NIST and at the Advanced Photon Source, Argonne National Laboratory). Final documentation is being assembled for release during 2015.

A. Allen completed a chapter on heterogeneous materials for the new IUCr International Tables for Crystallography Volume H. The chapter has been accepted but Volume H will not now be released until 2016.

U. Jeng led the construction of a new dedicated highbrilliance biological SAXS/WAXS beamline at the new $3 \mathrm{GeV}$ synchrotron of NSRRC, Taiwan, planned to be operational in 2018.

David Babonneau continued development of FitGISAXS (software package for modelling and analysis of GISAXS data using Igor Pro).

In summary, it is fair to say that CSAS had a busy and productive 2014 and we look forward to continuing to support and promote the application of SAS techniques in a broad range of scientific fields.

J. Trewhella, Chair

\subsection{Commission on Structural Chemistry}

The Commission met in Montreal and had robust discussions on a number of matters, including increasing support from chemical crystallographers for IUCr journals and direction and strategy of these journals, and the need for the Commission actively to encourage and support crystallography schools and regional meetings, particularly in developing countries. It is expected that these discussions will continue within the Commission (via e-mail).

Since Montreal, the Commission has supported a number of meetings. The SAGAMORE XVIII Conference on Charge, Spin and Momentum Densities, organized by the Commission on Charge, Spin and Momentum Densities, will be held in Sardinia, Italy, in June 2015 (http://www.sagamorexviii.org). The 22nd International Conference on the Chemistry of the Organic Solid State (ICCOSS XXII) will be held in Niigata, Japan, the following month (http://www.iccoss2015.org). These are both long-running and well established meetings, which have good support in the chemical crystallography community. The 2015 meeting of the excellent Zürich School of Crystallography, held in June 2015, was also supported.

Looking forward to the Hyderabad Congress, it is important that chemical crystallography is well represented and supported. To this end, an extensive list of potential advisory committee members was provided to the organizers, with the aim of having a good chemical crystallography programme at the meeting, and thus good support for the meeting from the chemical crystallography community.

\section{S. Batten, Chair}

\subsection{Commission on Synchrotron and XFEL Radiation}

The aim of the Commission (CSXR) is to promote access and awareness of crystallographers worldwide to the world's synchrotron radiation (SR) and X-ray free-electron laser (XFEL) facilities. To this end, the Commission broadly promotes the development of crystallographic instrumentation, technology and standards, and the synergies between storage-ring-based and LINAC-based next-generation sources such as X-FELs and Energy Recovery Linacs (ERLs). The bulk of the Commission's work is carried out via e-mail, with occasional face-to-face meetings held at selected conferences attended by sufficient of the Commission members.

In recognition of the increasing significance of free-electron laser sources to crystallography, the Commission proposed in 2013 to modify its name to the Commission on Synchrotron and XFEL Radiation. This change was discussed and unanimously supported by the Commission members in 2013, and was ratified by the Executive Committee and approved by the General Assembly at the Montreal Congress.

The International Year of Crystallography. The synchrotron community in general embraced the IYCr in a number of capacities, with 15 directly sponsoring IYCr2014 and all hosting special events, including dedicated sessions at their user meetings and events aimed at furthering public understanding of the impacts and benefits of crystallography. Examples include:

The one-day symposium Celebrating 100 Years - A Journey Through the World of Crystallography, held by the Canadian Light Source on 14 September and co-organized by Commission member Pavel Grochulski. This symposium combined a hands-on introduction workshop for local highschool students, and a general public session featuring the role of crystallography in HIV/AIDS research.

SOLEIL and LLB jointly hosted a satellite symposium composed of four Plenary Lectures dedicated to crystallography on 23 January, before their 2014 Users' meeting. Commission member Jean-Louis Hodeau was involved in the organization.

Additional activities associated with Commission members include a collaboration between the Polish Synchrotron Radiation Society (Commission consultant Maciej Kozak is President of the Society) and Polish Mail to issue a limited set of four postal stamps to mark IYCr2014 (http:// www.iycr2014.org/events/postage_stamps/postage-stamp-issue2). The IYCr2014 activities were also sponsored and celebrated by national laboratories such as the Australian Nuclear Science and Technology Organization (ANSTO).

Commission member Jean-Louis Hodeau has been particularly involved in planning a number of European activities to celebrate IYCr2014 and the associated centenary of the Laue-Bragg discoveries. This includes the development of the travelling exhibition Journey into the Crystal, which takes visitors on a journey of the discovery of matter - but also on a journey through time to the beginnings of crystallography. An important contribution was made by several large light-source facilities (such as ESRF, ILL, SOLEIL and ALBA) to its 
translation into English and Spanish, to allow an international distribution of this travelling exhibition during 2014. The first showing of this exhibition was at UNESCO in Paris, in January 2014, where the complete exhibition (39 panels) was on display at the Opening Ceremony for the International Year of Crystallography. A condensed version (12 panels) was subsequently produced in additional languages: Arabic, English, Spanish, Dutch-Flemish, French, Russian, Slovakian, Portuguese-Brazilian, German, Catalan, Finnish, Swedish, Turkish. (See http://www.iycr2014.org/resource-materials/ voyage.)

Jean-Louis was also instrumental in producing crystallography-themed games in French and English, with the aim of disseminating an understanding of basic crystallography concepts to students and pupils. The games are symmetry games with mirrors, quiz cards etc.

Commission involvement in the 2014 Montreal Congress. The Commission worked with other Commissions to hold a number of joint Microsymposia:

High-Resolution Charge Density using SR, jointly proposed with the Commission on Charge, Spin and Momentum Densities (MS-CCSMD-7).

Advances in Experimental Techniques and Data Analysis for Science at Extreme Conditions at Synchrotron and Neutron Sources, jointly with the Commission on High Pressure (MS-CHP-5).

Applications of Anomalous Small-Angle X-ray Scattering to Soft Materials and Bimolecular Systems, jointly with the Commission on Small-Angle Scattering (MS-CSAS-2).

Time-Resolved Spectroscopic Studies with Synchrotron Radiation and Free Electron Laser Sources, jointly with the Commission on XAFS (MS-CXAFS-1).

XFEL Macromolecular Crystallography, jointly with the Commission on Biological Macromolecules (MS-CSR-1).

X-ray, Muon and Neutron Studies of Magnetic Structure in Materials, jointly with the Commissions on Neutron Scattering and Materials Science (MS-CNS-5).

In addition, the Commission organized the following Microsymposia:

Advances in X-ray FEL Coherent Scattering and Diffraction (MS-CSR-2);

Advances in X-ray, Neutron and Electron Detectors (MSCSR-3);

and successfully proposed two Keynote presentations: Future Light Sources and their Impact on Structure Studies, by Edgar Weckert (DESY), and Use of Two Colour XFEL Modes for SAD/MAD Phasing and Improved Intensity Measurements for de novo Macromolecular Structure Determination, by Commission consultant Soichi Wakatsuki (SLAC).

In recognition of the increasing impact of the XFEL facilities in crystallography, and of the need to inform the world community of crystallographers of what is possible and how to access these sources, the Commission organized a one-day workshop at the Montreal Congress. Held on 5 August and titled Crystallography at XFEL Sources, the aim of the workshop was to introduce Congress participants to the new capabilities of the XFEL sources, and to provide information and advice on how best to carry out a successful XFEL experiment. While crystallography was the main focus of the workshop, other applications of these new sources were introduced in the opening presentations.

Supported meetings, schools and workshops. The Commission provided letters of support and endorsement for the following funding requests:

Structural Basis of Pharmacology: Deeper Understanding of Drug Discovery through Crystallography, Erice, Italy, May/ June 2014.

RapiData 2014, Stanford Synchrotron Radiation Laboratory, SLAC, USA, April 2014, to support participation of Latin-American students.

Applications of In-Situ Synchrotron Radiation Techniques in Nanomaterials Research, held as part of the Materials Research Society spring meeting in San Francisco, USA, April 2014.

Funding for a Visiting Professor for Atomic Pair Distribution Functions Technique: Fundamentals and Applications, Mar del Plata, Argentina, beginning on 31 October 2014.

Sixth School of the Argentinian Crystallography Association, Universidad Nacional de Mar del Plata, Mar del Plata, Argentina, November 2014.

Asia-Oceania Forum for Synchrotron Radiation Research (AOFSRR). This Forum is an international network whose mission is to foster collaboration among synchrotron-radiation facilities and user communities in Asia and Oceania, as well as promoting collaborations with facilities and communities in America and Europe. The eight facility-operating nations in the region are full members of the AOFSRR, and the Forum's mission includes promotion of synchrotron-based science throughout the region. To this end Malaysia, New Zealand and Vietnam are associate members of the AOFSRR. Several members of the Commission play active roles in the organization, including Richard Garrett (Executive Committee member and Treasurer), Shih-Lin Chang (past representative of Taiwan on the AOFSRR Council) and Soichi Wakatsuki (represented the Photon Factory to 2012).

The eighth annual AOFSRR Conference was held 15-18 September 2014 at the National Synchrotron Radiation Research Center (NSRRC) in Hsinchu, Taiwan. The number of participants was 283, including 166 international and 117 from Taiwan. The program included a special session devoted to the International Year of Crystallography, consisting of three Invited Lectures:

What Brings IYCr 2014 to Japan? - Activities for Celebrating IYCr 2014 in Japan - Masaki Takata (JASRI/SPring-8, Japan). Crystallography in Taiwan - Yu Wang (Academia Sinica, Taiwan).

The International Year of Crystallography and Its Legacy Michele Zema (IUCr, UK).

One of the core activities of the AOFSRR is the Cheiron School, a two-week international synchrotron school, which has been held annually at SPring- 8 since 2007 . The curriculum is very broad, covering both the fundamentals of synchrotronradiation generation and the various applications, including 
all the common crystallography applications. In 2014 the AOFSRR cooperated with the IUCr, UNESCO and the International Year of Light to bring three students from Africa to the Cheiron School - the first time that students from outside the Asia-Oceania region had been admitted to the school. The students were Ariste Bolivar Voufack from Dschang University, Cameroon, Mohamed Abdellatif Bensegueni from University Mentouri, Algeria, and Mashikoane Wilson Mogodi from the University of the Witwatersrand, South Africa.

Following the success of this initiative the Cheiron School, with the support of the Commission, will apply for IUCr support in 2015 to allow two students from Africa or the Middle East to attend the 2015 school.

\section{R. F. Garrett, Chair}

\subsection{Commission on XAFS}

(1) Duties of Commission members. The following responsibilities of Commission members have been assigned:

Krystyna Jablonska and Giuliana Aquilanti: Secretaries;

Farideh Jalilehvand: Liaison with the International Programme Committee;

Giuliana Aquilanti and Masao Tabuchi: Responsibility for the web site;

Peter Glatzel: IXAS liaison;

Jesus Chaboy: IUCr dictionary of XAFS terminology;

Steven M. Heald and Sofia Diaz-Moreno: Coordinators for new editions of the Q2XAFS workshop;

Bruce Ravel and Steven M. Heald: Working Group on Databases.

(2) Consolidation of the achievements of the Commission with the Montreal Congress.

Tutorial Workshop at Congress. The Commission-organized tutorial workshop on XAFS on 5 August had a record number of attendees with 165 registrants from 28 countries (compared to 56 in Madrid). Key discussion about the XAFS tutorial workshop led to the suggestion to make this hands-on for the next edition. This should be considered by $\mathrm{C}$. Chantler and $\mathrm{B}$. Bunker as co-Chairs and an additional co-Chair from India acting as local coordinator. This should be a 'zero-cost' workshop that encourages and emphasizes the outreach nature of the activity.

Microsymposia at the IUCr Congress. A record number of six Microsymposia (MS) were organized or co-organized by CXAFS.

MS06: Time-Resolved Spectroscopic Studies with Synchrotron Radiation and Free Electrons, co-Chairs: Federico Boscherini, Christian Bressler. The symposium covered time-resolved spectroscopic techniques at storage rings and FELs. Time-resolved XAFS experiments have gained momentum at SRs and FELs and now offer time resolution in the $100 \mathrm{fs}$ time frame, which is of high relevance for many chemical systems.

MS14: Electronic Structure and Chemical Bond Information by High-Energy Resolution X-ray Spectroscopy, co-
Chairs: Richard Strange, Pieter Glatzel. The symposium was devoted to resonant inelastic X-ray scattering (RIXS) and hard X-ray emission spectroscopy (XES), which provide information on electronic structure that is complementary to $\mathrm{X}$-ray diffraction. These can identify ligands, determine the chemical state of the metal site and some ligands and are very sensitive to X-ray damage. XES unlike XAS does not require a monochromatic X-ray beam and is thus compatible with a diffraction setup. This property is particularly interesting for crystallography at X-ray free-electron lasers. The MS reviewed the state of the art, introduced the technique, presented recent experiments (also at LCLS) and discussed future applications.

MS38: X-ray Techniques for Innovation in Industry, coChairs: Krystyna Jablonska, Jeffrey Cutler. Utilization of various X-ray techniques in material characterization is becoming increasingly important in science and technology, leading to innovation and commercialization efforts for industry, and this was highlighted in the Microsymposium. Topics ranged from life science to material science and included how industry engagement is being facilitated by dedicated industry support programmes at various light sources.

Fabia Gozzo from Excelsus (a spin-off of the Swiss Light Source) described how powder diffraction is important for drug development, including the detection of contamination at sub-per-cent level. Takeyuki Kawaguchi from Kyoto University presented work on improving our understanding of lithium nickel oxide battery material by applying diffraction anomalous fine-structure (DAFS) - site-selective spectroscopy. Wieslaw Lasocha from Jagiellonian University described the development of various polyoxometalate catalysts for application in green chemistry and the production of adipic acid from cyclohexane. Anthony Phillips from Queen Mary University highlighted an example in metal-cyanide framework chemistry where neutrons and X-rays coupled with DFT calculations allowed for the characterization of metals in the framework. Along with industry examples, Thomas Wroblewski from DESY and Stephanie Monaco-Malbet from ESRF highlighted their respective industrial liaison programmes and described how they have benefited smalland medium-sized enterprises and large multinational corporations. Overall, the attendees of the Microsymposium received a broad overview of how industry can benefit from access to novel X-ray tools.

MS46: XAS of Hydrated Metal Ions and Protein Active Centres in Aqueous Solutions, co-Chairs: I. Persson, R. Sarangi. The symposium presented the real possibilities and limits of XAS analysis (combined with molecular dynamics, for example) in the study of the solvation structure of metals. This includes inorganic and organometallic metal ions, solvation effects on metalloproteins and high-pressure interactions.

MS64: EXAFS Analysis at the Nanoscale and in Highly Disordered Materials, co-Chairs: Sofia Diaz-Moreno, Jesus Chaboy, Alexei Kuzmin. The symposium presented the real possibilities and limits of EXAFS analysis at the nanoscale. To date, different papers have mainly addressed the existence of 
surface effects in terms of the reduction of the coordination number. This is a controversial issue that needs clarification coupled with the analysis of disorder effects. Finally, what EXAFS (XANES) can really say regarding the existence of vacancies should also be an interesting topic.

MS103: Spectroscopic Approaches (XAFS, XANES, NMR ... ) in Crystallography, co-Chairs: M. Tabuchi, Carlo Lamberti. The symposium presented the spectroscopic approach to crystallography. Many spectroscopic techniques are naturally complementary to crystallographic methods. Multiple-wavelength anomalous dispersion is intrinsically a combined XRD/XAS technique, for example. XAFS and XANES combine to give detailed information on dynamical bonding, dynamical versus static disorder, oxidation and coordination number of active or intermediate states, which complement other techniques extremely well. Further, XAFS and XANES combine well with IR to probe detailed molecular dynamics.

(3) International Tables for Crystallography, Volume I, $X$-ray Absorption Spectroscopy and editorial activities. Procedures for a new volume of International Tables for Crystallography dedicated to XAFS have been progressed. C. T. Chantler, F. Boscherini and B. Bunker have been approved by the Executive Committee as Editors. The current draft outline was revised and final approval of the volume should occur soon. The three Editors encouraged CXAFS members to provide input for the contents of this volume. A preliminary contents list has been circulated.

The aim is for this to be a stand-alone volume, but it will necessarily have some overlap with Volume $\mathrm{C}$, and possibly also Volumes $\mathrm{H}$ and F. One possible way to market Volume I would be to offer delegates at relevant meetings the chance to pre-order the volume when registering for the conference.

(4) $Q 2 X A F S$ organization. It was proposed that the next Q2XAFS meeting be held in 2016 at Diamond, UK, after XAFS16 in Karlsruhe, Germany, 2015. The co-Chairs would be S. Diaz-Moreno, R. Strange, C. Chantler and B. Bunker. A sequel to this should be held at some period between 12 months and 36 months after that in Diamond, to be coordinated by Steven Heald and tentatively to be held at APS/ Chicago, USA.

(5) IXAS Newsletter and links to IUCr journals. Richard Strange and Steven Heald act as a link to IUCr journals. CXAFS encourages the IXAS Conference organizers to publish Proceedings in a Special Issue of JSR. CXAFS also encourages high-quality submissions related to XAFS.

(6) Joint CXAFS IUCr/IXAS Database Working Group. Progress was made on the format and content of the database and it was agreed that a report (status or otherwise) will be presented regularly every six months. The current Chairs of the Commission (Bruce Ravel and Steven M. Heald) and IXAS will work together to define the Chair and membership of the new Working Group, and to appoint jointly and to clarify the outcomes of the past cycle.

(7) Conference support and proposals. An application for support of XAFS16 to be held in Karlsruhe, Germany, August
2015, was submitted to the IUCr. The Commission endorsed the application.

(8) Development of data overlap and format with Japanese $X A F S$ Society. The report/summary of the status of the Japanese XAFS Society and their current initiatives, especially including that relating to a database, in collaboration with Hiroyuki Oyanagi, Asakura and others, was prepared by Masao Tabuchi.

(9) IUCr XAS dictionary definitions. Jesus Chaboy is recovering from health issues but will undertake this when he is able to do so.

\section{T. Chantler, Chair, and K. Jablonska and G. Aquilanti, Secretaries}

\section{Sub-committee on the Union Calendar}

The Sub-committee receives and considers requests for IUCr sponsorship and nominal financial support, and makes recommendations to the Executive Committee. Acting on the recommendations made by the Sub-committee, during 2014 the Executive Committee approved sponsorship of various schools and meetings, mostly with financial support. Those held in 2014 are listed at the beginning of this Report of the Executive Committee. Those scheduled for 2015, but approved in 2014, are listed below.

Computational Materials Discovery Using the USPEX Code, Shiv Nadar, India, 20-24 January 2015.

Asian XD Charge Density Workshop, Bangalore, India, 1618 February 2015.

Fifth Winter School on Soft X-rays in Macromolecular Crystallography, Athens, GA, USA, 28 February -3 March 2015.

XV Intensive Teaching School in X-ray Structure Analysis, Durham, UK, 21-29 March 2015.

Macromolecular Crystallography School 2015: From Data Processing to Structure Refinement and Beyond, Montevideo, Uruguay, 6-15 April 2015.

3rd School on Crystal Structure Determination From Diffraction Data: Application to Powder Samples, Sousse, Tunisia, 9-12 April 2015.

RapiData 2015, Stanford, USA, 26 April - 1 May 2015.

5th International School on Biological Crystallization, Granada, Spain, 24-29 May 2015.

To.Sca Lake: Total Scattering Analysis of Nanoscaled Materials, Como, Italy, 25-28 May 2015.

Engineering Crystallography: From Molecules to Crystal to Functional Form, Erice, Italy, 5-14 June 2015.

Sagamore XVIII Conference on Charge, Spin and Momentum Densities, Sardinia, Italy, 7-12 June 2015.

Zürich School of Crystallography 2015: Bring Your Own Crystals, Zürich, Switzerland, 7-20 June 2015.

22nd International Conference on the Chemistry of the Organic Solid State (ICCOSS XXII), Niigata, Japan, 12-17 July 2015. 
6th International Conference on X-ray Absorption Fine Structure (IXAS-16), Karlsruhe, Germany, 23-28 August 2015.

Aperiodic 2015, Prague, Czech Republic, 1-6 September 2015.

13th School on Synchrotron Radiation, Grado, Italy, 14-25 September 2015.

Organizers of meetings wishing to seek IUCr sponsorship should submit applications at least nine months in advance of the meeting, writing to the Chair of the Sub-committee. For up-to-date contact information, application procedures and rules, see http://www.iucr.org/iucr/sponsorship/meetings.html.

Requests from satellite meetings may be submitted, and possible financial support requested, separately or through the Organizing Committee of the main meeting.

Meetings (other than satellite meetings) scheduled to be held within one month before or after an IUCr Congress will not be considered for sponsorship. For any meetings scheduled to be held between one and two months before or after a Congress, the application for sponsorship will be sent to the Chair of the Congress Programme Committee for approval, or otherwise. For meetings (other than satellite meetings) scheduled to be held, in the respective region, within one month before or after a meeting of a Regional Associate (American Crystallographic Association, Asian Crystallographic Association, European Crystallographic Association, Latin-American Crystallographic Association), the applicants for sponsorship must seek approval of the Chair of the Regional Associate Organizing Committee.

IUCr sponsorship can only be given to meetings that are international in character and open to participants from all countries. For international meetings the membership of the Programme Committee is a good indication of this. National meetings are only supported if held in developing countries.

Explicit support from the relevant IUCr Commission(s) is required for any international meeting (except for the meetings of Regional Associates) and from the Commission on Crystallographic Teaching for any international schools (except for those organized by an IUCr Commission).

The IUCr continues to support and uphold ICSU's policy of non-discrimination and adheres to its decisions and procedures concerning the free circulation of scientists. Organizers of any meetings seeking IUCr sponsorship or support must assure the Sub-committee on the Union Calendar that the authorities of the country in which the meeting is to take place guarantee free entrance of bona fide scientists from all countries.

Visiting Professorships. The IUCr Visiting Professorship Scheme aims to support some of the costs of having internationally recognized scientists as lecturers for short courses at workshops or schools organized in developing countries. These schools or workshops may have national or international character. Up to a maximum of three Visiting Professorships can be granted for a single event. Travel and insurance costs will be met by the IUCr, while the local organizers cover the accommodation/subsistence expenses. Visiting Professorships can be requested in conjunction with the application for IUCr funding of a meeting, or independently as a single action to obtain highly qualified international teaching support within a teaching programme of local character. Support from at least one IUCr Commission is required. Full details may be found at http://www. iucr.org/iucr/sponsorship/vp.html.

\section{Committee for the Maintenance of the Crystallographic Information File Standard (COMCIFS)}

As part of its remit to maintain and develop the Crystallographic Information Framework (CIF) on behalf of the IUCr, COMCIFS has spent considerable time over the last decade discussing the upgrade of the set of standards that underpin CIF. Final agreement was reached on the new CIF2 syntax specification at the Montreal Congress, and an ISO/ IEC 14977 conformant EBNF syntax description was agreed on soon after. It was also emphasized that CIF2 is an alternative rather than a replacement for CIF1, and that the $\mathrm{IUCr}$ remains committed to supporting CIF1 in perpetuity. At Montreal it was also decided that any new dictionaries submitted to COMCIFS for approval would have a canonical DDLm version and that current DDL1 dictionaries would be progressively rewritten in DDLm. This requirement does not extend to DDL2 dictionaries; it was resolved to work to improve the match between DDLm and DDL2 to the point that it would be possible for a DDL2 dictionary to be written in DDLm without loss of information.

Late in the year a fully featured $\mathrm{C}$ software library for reading and writing both $\mathrm{CIF} 1$ and CIF2 files, written by $\mathrm{J}$. Bollinger, was released for beta testing. It is planned to release this software under an open-source licence, significantly simplifying the task of program authors in implementing CIF2-aware software.

New dictionaries. A long-awaited twinning dictionary was finalized and published in 2014, after several years' work by V. Young. A dictionary for describing magnetic structures is in the early stages of development, and will be the first domain dictionary written using DDLm. COMCIFS members are working closely with the Commission on Magnetic Structures as they develop this dictionary, and several COMCIFS members have volunteered to help other IUCr Commissions as they respond to the IUCr Executive Committee's request to identify and codify metadata requirements.

Macromolecular developments. The wwPDB continues its successful programme of transitioning the macromolecular community to use mmCIF-based infrastructure, and is now routinely receiving submissions in $\mathrm{mmCIF}$ format. Both $\mathrm{CCP} 4$ and Phenix program systems produce $\mathrm{PDBx} / \mathrm{mmCIF}$ files for deposition. The wwPDB PDBx Working Group on Deposition continues to expand and refine recommended content for deposition with a recent emphasis on chemical and structural descriptions of monomers and ligand refinement targets, intermolecular refinement restraints, and unmerged intensities. 
Interaction with other data-management initiatives. As noted in previous reports, other scientific communities are beginning to standardize data transfer and archiving practices. Where these scientific areas overlap with areas covered by $\mathrm{IUCr}$ dictionaries, harmonization of definitions is desirable in order to minimize the work required when translating or ingesting foreign data files, and to avoid confusion. In 2013, COMCIFS and the NeXus International Advisory Committee (NIAC) agreed to work together on harmonizing datanames. After making considerable progress on software and specifications, in December 2014 NIAC formally adopted CIF-style axis definitions, making this overall harmonization easier, and a major X-ray detector vendor, DECTRIS, agreed to adapt their output HDF5 format to conform (HDF5 is the format targeted by the NeXus standard). Progress on a similar harmonization in the presentation of XFEL data from the Cornell-SLAC Pixel-Array Detector (PAD) was achieved, with a $\mathrm{CBF}$ version already in use and the HDF5 version to follow shortly. It was also agreed at the December NIAC meeting that, at least for macromolecular crystallography, a reasonably complete set of NeXus fields equivalent to the CIF tags long used for processing macromolecular crystallography (MX) diffraction images needed to be included in NeXus ' $N X m x$ ' files, i.e. the NeXus files for macromolecular crystallography.

Future plans. A previously foreshadowed project to improve checkCIF handling of powder data files has been held over until 2015 owing to the need to finish Volume $\mathrm{H}$ of International Tables. The work of COMCIFS members in the near future is likely to be focused on transitioning DDL1 dictionaries to DDLm, and providing tools and documentation for the community to allow easy adoption of CIF2. A new edition of Volume $\mathrm{G}$ of International Tables is planned to document properly the new standards.

\section{J. Hester, Chair}

\section{IUCr Newsletter}

All issues of Volume 22 were 24 pages in length. As in previous years, the content covered topics such as activities of the IUCr, its Regional Associates and Commissions, letters to the editor, news concerning crystallographers and crystallography in general, awards, book reviews, election results, resources, meeting reports, obituaries, future meeting announcements, and a general meeting calendar.

Each issue carried a President's column - those in issues 1 and 2 were written by Gautam Desiraju and those in issues 3 and 4 were written by Marv Hackert. Bill Duax handled all editorial responsibilities. Patti Potter was responsible for layout and all phases of production and distribution.

Each issue devoted two pages to brief summaries of selected articles recently published in IUCr journals. All four issues contained several pages of articles pertaining to IYCr2014: issues 1 and 2 ran announcements for the IUCr Congress and issues 3 and 4 contained reports from the Congress.

Additional meeting and workshop reports were published covering activities in Argentina, Austria, Australia, Costa
Rica, Croatia, Japan, Russia and the USA. Future meeting announcements included the Montreal Congress as well as meetings in Croatia, Germany and Switzerland.

Distribution was done electronically for all four issues. Messages were sent to an average of 12570 people for the electronic version. Print copies went to 558 libraries and individuals, and copies went to several meetings, including the annual meetings of the Regional Associates.

\section{W. L. Duax, Editor, and P. Potter, Production Manager}

\section{IUCr/Oxford University Press (OUP) Book Series}

It may seem a contradiction that no new book was published in 2014, the IYCr, but it is accidental that finally none of the several books that were examined and are in the pipeline happened to be ready during this year.

I would also like to point out something that I find somewhat disappointing: we need more books in the burgeoning field of protein crystallography. There have been books recently (by OUP and other publishers), but not all of them were published in this series. I have already pointed out this fact to Dr Adlung asking him to try to have a better coordination of the publishing activities across OUP, involving all sectors of crystallography. At the same time, I would also encourage the Committee to commission new proposals in this area explicitly for the IUCr series if such opportunities arise.

There are nine books in the pipeline and some of them are in the final stages of the production phase. The Committee and the OUP editing staff reviewed a number of proposals and there are well established contacts with authors about possible new volumes.

The Committee is very interested in proposals for new volumes and encourages prospective authors to contact the Chair of the Committee (davide.viterbo@mfn.unipmn.it). Readers and Committee members may suggest topics and/or authors as they know the subjects that are not well covered in the literature. Manuscripts covering important aspects of crystallography and related fields are very welcome.

D. Viterbo, Chair of Book Series Selection Committee

\section{Regional Associates and Scientific Associates}

\subsection{American Crystallographic Association (ACA)}

The American Crystallographic Association, Inc. is a nonprofit, scientific organization of more than 1200 members.

The 2014 ACA Council consisted of Martha Teeter (President), Christopher Cahill (Vice-President), Cheryl Stevens (Past-President), S. N. Rao (Chief Financial Officer and Interim Treasurer), Jim Kaduk (Treasurer), Patrick Loll (Secretary) and Eric Montemayor (ex officio, as YSSIG representative). Michael James serves as the Canadian representative, Bill Duax as Chief Executive Officer, and - as IUCr Representatives - Marvin Hackert (until Montreal Congress) and Hanna Dabkowska (after the Congress). The 
ACA paid membership was 1221 by end of 2014 (down from 1571 in 2013).

ACA Albuquerque. The ACA Annual Meeting in 2014 was held in Albuquerque, New Mexico, 24-28 May. At this meeting 450 participants presented 128 posters and 221 lectures within the newly renovated Albuquerque Convention Center. Thirty-one vendors participated in the Exhibit Show. The Programme Chairs were Christine Beavers and Peter Zwart; Ilia Guzei served as the Poster Chair. Yulia Sevryugina and her fellow young scientists were all responsible for outstanding sessions and great social events. More information about this venue and details about the programme and about three adjacent workshops (Joint Neutron and X-ray Structure Refinement using Joint Refine in PHENIX organized by Pavel Afonine, Marat Mustyakimov, Zoe Fisher and Andrey Kovalevsky; Grazing Incidence SAXS Theory and Data Analysis organized by Alex Hexemer and Chenhui Zhu; and Reciprocal Space Visualization MAX3D organized by Jim Britten) can be found at http://www.amercrystalassn.org/2014.

The picture gallery from the whole meeting can be found at http://web.mit.edu/pmueller/www/ACA2014/.

Three of the ACA's major awards were presented at the meeting in Albuquerque: the Patterson Award to John Helliwell, University of Manchester, UK, the Etter Early Career Award to Borden Lacy, Vanderbilt University, USA, and the Wood Writing Award to Dan Rabinovich, University of North Carolina. The details are to be found at http:// www.amercrystalassn.org/2014-award-winners.

IYCr2014. Considerable effort was devoted to celebrating the International Year of Crystallography 2014 (IYCr2014). ACA strongly and efficiently supported this initiative. Martha Teeter, the head of the ad hoc Committee coordinating regional celebrations and activities for IYCr2014, was very pleased with the outcome.

IYCr Activities funded and co-funded by the ACA were as follows:

(1) US Crystal Growing Competition, organized by Jason Benedict. This attracted 200-300 students.

(2) US/Canada IYCr Facebook Video Contest, organized by Amy Alexis Sarjeant, Louise Dawe and Christine Beavers. Elementary and high-school students had their teachers submit videos to Facebook. Eight videos were submitted, some of which received more than 2000 views.

(3) WI Crystal Growth Contest and Lecture Tour, by Ilia Guzei. Two hundred students from 18 schools participated in growing crystals of copper sulfate. Very successful event, the 2015 competition is already on its way.

(4) RCSB PDB's Art of Science Traveling Exhibit, by Christine Zardecki. Two to three thousand high-school and college students have seen the exhibition. This will continue into 2015.

(5) University of Illinois Chicago Symposium for IYCr, by Constance Jeffery, Gerd Prehna and Bernard Santarsiero. This served 130 minority-diverse undergraduates and graduate students.

(6) Crystal Growth Contest for Valley Central High School, by Terri Campbell. Forty-five students grew crystals and gave poster presentations. One hundred attended the poster event.

(7) NSTA Presentation to Science Teachers in Long Beach Regional Meeting, organized by Martha Teeter. This included a crystal-growth demonstration (borax), crystal packing/ properties (face-centred cubic and hexagonal close packed), lego building face-centred cubic (2X), VESTA visualization and diffraction basics with ICE slides. Twenty-five teachers attended.

More information about the IYCr activities can be found at http://iycr2014.org/countries/usa.

Cora Lind-Kovacs and Ilia Guzei are ACA delegates to the IYCr Legacy Meeting entitled Crystallography for the Next Generation: the Legacy of IYCr, organized in Rabat, Morocco, 22-24 April 2015. Both have been very active in outreach activities in IYCr and both are committed to enhancing crystallography's image in the USA.

ACA journal. The new ACA potentially profitable online journal Structural Dynamics (http://sd.aip.org) is co-published with the AIP (American Institute of Physics). It boasts an impressive average time of 76 days from submission to publication. Journal topics include structural dynamics of molecular systems, biological systems, solid materials, liquids and solutions, surfaces and interfaces studies using highly coherent sources. The journal has interesting plans for upcoming special topic issues for further developments.

AIP and ACA. Chris Cahill is the ACA member representative (normally a three-year term) to AIP. Tom Terwilliger will take over from him from September 2015. In his report Chris discusses how the ACA can best exploit the resources available through the AIP, including media services, assistance with logistics etc. He stresses that there is a potential for a new and different relationship between the ACA and its parent organization (AIP).

If the proposed governance rules changes in AIP go into place, Charlie Carter will become a member of the AIP board.

Strategic planning. A strategic planning committee consisting of Cheryl Stevens (Chair), Bill Duax, Judy FlippenAnderson, S. N. Rao, Martha Teeter, George Phillips and Marcia Colquhoun have met a few times since its creation. A survey of the membership about the strategic plan has been prepared and will be implemented in Philadelphia in 2015.

Summer schools. The ACA Summer Course in Small Molecule Crystallography for the period 2012-2015 alternates between Northwestern (odd years) and Notre Dame (even years). The 2014 summer school was held from 7-16 July at Notre Dame. No ACA course in macromolecular crystallography is currently approved, but there are other macromolecular workshops that fill much of this void.

Future meetings. The next ACA Meeting is the 2015 Annual Meeting in Philadelphia, PA, 25-29 July, with Louise Dawe (University of Waterloo, Canada) and Kraig Wheeler (Eastern Illinois University, USA) as Programme Chairs. More information about the meeting can be found at http://www. amercrystalassn.org/2015-mtg-homepage.

The 2016 Annual Meeting will be held at the Sheraton Hotel in Denver, Colorado. It will begin on Friday 22 July and 
end on Tuesday 26 July. Amy Sarjeant (Northwestern University) and Eddie Snell (Hauptman Woodward MRI) are the Programme Chairs.

The 2017 (IUCr Congress Year) Annual Meeting will be held at the Hyatt Regency Hotel in New Orleans, Louisiana. The meeting will begin on Friday 26 May and it will end on Tuesday 30 May.

2014 ACA Fellows - a title that recognizes a high level of excellence in scientific research, teaching and professional duties, but also service, leadership, and personal engagement in the ACA and the broader world of crystallography and science - are Eddy Arnold, Abe Clearfield, Larry Dahl, George Philips, Ned Seeman, John Spence, Ron Stenkamp and Winnie Wong-Ng.

Elections. The fall 2014 elections resulted in introducing Tom Terwilliger (as Vice-President) Diana Tomchick (as Secretary) and Yulia Sverugina as YSSIG representative to the Council.

\section{H. A. Dabkowska, IUCr Representative}

\subsection{Asian Crystallographic Association (AsCA)}

(1) AsCA Executive officers. The current Executive officers for the term 2013-2016, elected at the annual meeting in Hong Kong, are: Pinak Chakrabarti (President, India), Jennifer Martin (Vice-President, Australia), J. J. Vittal (Secretary/ Treasurer, Singapore), and Se Won Suh (Immediate PastPresident, Korea).

(2) $A s C A$ 2013. The 12th meeting of the Asian Crystallographic Association was held 7-10 December 2013. The venue was the campus of the Hong Kong University of Science and Technology, Clear Water Bay, Hong Kong, People's Republic of China.

All major aspects of crystallographic sciences were covered with seven Plenary and Keynote speakers, including former IUCr President Sine Larsen. A total of 19 Microsymposia were held with about 100 speakers and 200 poster presentations. In addition, the one-day workshop South China Structural Biology Symposium was held in conjunction with the meeting, along with a number of workshops for small molecule and protein crystallographic software, by Olex, Bruker and CCP4.

Around 20 commercial sponsors exhibited at the meeting. The IUCr had a prominent booth to help advertise the upcoming IYCr2014 and a special Microsymposium was held to give attendees information about the plans of the IUCr and various regional associations for the upcoming year. Gautam R. Desiraju provided a video tape of a short message at the conference to introduce the IYCr2014 for its upcoming launch.

Actual attendance at the meeting and associated symposia and workshops was 413. The total number of countries represented at the meeting was 30 , with most delegates from Japan, followed by China, Korea and Hong Kong.
(3) $A s C A$ 2015. The 13th Conference of the Asian Crystallographic Association will be held at Science City, Kolkata, India, 5-8 December 2015. P. Chakrabarti is Chair of the Local Organizing Committee and A. Vrielink Chair of the International Programme Committee.

\section{Takata, IUCr Representative}

\subsection{European Crystallographic Association (ECA)}

The main ECA event - the ECM (European Crystallographic Meeting) - was not organized in 2014 because of the Montreal Congress. However, a number of activities and events connected with the IYCr were organized, the Executive Committee held two meetings and there was also an ECA council meeting during the Congress.

The Executive Committee consists of the following members: Andreas Roodt (President), Santiago GarciaGranda (Past President), Alessia Bacchi (Vice-President), Georgina Rosair (Secretary), Christian Lehmann (Treasurer), Udo Heinemann, Joke Hadermann, Olga Yakubovich (officers) and Fermin Otalora (education coordinator). As the IUCr representative Elena Boldyreva took part in all Executive Committee meetings in 2014. Election of a new Committee should be during the ECA council meeting at ECM-29 in Rovinj, Croatia, August 2015. It was decided to have the regular winter Committee meeting always in the place of the next ECM in order to see the venue in advance, and this was realized first in February 2014 in Rovinj. The winter meeting is usually a full working environment since the whole weekend is dedicated to the meeting, unlike the summer meeting, usually held during the ECM or IUCr Congress, as it was in Montreal in 2014. Two sessions of the ECA council meeting also took place there.

The ECA has become a member of ISE (Initiative for Science in Europe). The ISE is an independent platform of European learned societies and scientific organizations whose aims are to promote mechanisms to support all fields of science at a European level, involve scientists in the design and implementation of European science policies, and to advocate strong independent scientific advice in European policy making. Member organizations of ISE span 19 scientific organizations and more than 330000 individual members. In January 2014, the President and Past President attended the Council Meeting of ISE in Leuven to discuss details and some future actions to interact proactively in an over-arching manner with decision makers to influence positively scientific decisions of the European Community. It was decided to nominate Sine Larsen as President of ISE.

Many activities of the IYCr took place in the region of the ECA. A large contingent of ECA members and representatives of ECA member countries attended the Opening Ceremony of IYCr2014 in Paris, France, 20-21 January 2014. Although the ECA was not formally represented at the ceremony as a Regional Associate, Russia and South Africa as ECA members of the BRICS countries participated formally by invitation. 
OpenLabs were held twice in Turkey, then Morocco, Ghana, Algeria and Tunisia. A summit meeting was hosted in Bloemfontein, South Africa (12-14 October), and brought together government representatives from a large number of countries in Sub-Saharan Africa and North Africa, and finished with a summit declaration (appeal letter) signed by 73 people and addressed to several addressees including the IUCr President.

In July 2014, in Santander, Spain, there was a formal presentation of ECA activities for IYCr2014, together with other regional associations and the IUCr representatives, as well as UNESCO. This event was organized by Santiago Garcia-Granda and Fermin Otalora. It coincided with the completion of the Spanish Masters in Crystallography thesis evaluation and presentation.

In recent years, the activities of the ECA have been increasingly directed to the education of crystallography. The 1st European Crystallography School was organized in Pavia, Italy, 28 August - 6 September (http://ecs1.azuleon.org/). There were 24 lecturers from ten countries and 120 students selected from 30 countries among 200 applications; 50 students were supported by full or partial bursaries. The level of sponsorship has been also quite successful (11 sponsors plus ten supporting institutions).

The 2nd European Crystallography School will take place in Oviedo, Spain, 31 August - 5 September 2015. It is being prepared by a steering committee (Santiago Garcia-Granda, Mois Aroyo and Fermin Otalora). The third school is proposed by the Croatian Association of Crystallographers.

A European Crystallography Masters programme is being defined. This programme will be based on four semesters (120 credits). On the basis of experience with the Spanish national master, that registered students come from widely different fields and have equally different scopes for their future work, the structure of the master will include four different modules.

The ECA has over 300 individual members (fee EUR 10 per year), about 20 corporate members (fee EUR 250 per year), 33 national members and three observers. This generates some income. There are continuing discussions as to how to increase the number of individual members. Collection of fees is mainly by credit-card payments but the possibility of collection with the registration fee for the ECM is also discussed. The auditors recommended adopting a policy of a free ECA membership fee for students and retired people. The free membership allows more people to stay active in the ECA, especially when they cannot afford extra costs from their own pocket. The main financial contribution to the ECA budget usually comes from the ECM.

The last ECM was in Warwick, UK, in 2013. 855 delegates from 50 countries were registered, of which 196 were students. The organizers were able to donate $c a$ EUR 25650 to both the ECA and the BCA.

The ECA supported the Adhering Body of the IUCr consisting of Algeria, Latvia, Morocco, Tunisia, Turkey and the Ukraine. However, since at the Montreal Congress three of these were accepted independently, now the Regional Committee of Crystallographers at the IUCr represents
Latvia, Tunisia and the Ukraine only. The ECA Executive Committee is trying to involve other countries like Armenia, Belarus, Estonia, Moldova, Romania, Lithuania, BosniaHerzegovina, Iran and Albania, but this proves to be difficult.

The ECA usually supports schools or conferences by an amount of around EUR 7000. In 2014, this was more nearly EUR 10000 and went to the Master in Crystallography and Crystallization (Spain), Electron Crystallography School (Germany), Hot Topics in Crystallography (Croatia), Erice School and Structural Biology (Italy), International Conference on Crystal Chemistry, X-ray Diffraction and Spectroscopy of Minerals (Russia) and Strategic Pipeline Planning: From Sample Preparation to 3D Structure Determination with Bio SAXS and Other Biophysical Techniques (Greece).

No prizes were awarded in 2014 because of the Montreal Congress.

The ECA has currently two internet domains - http:// crystallography.eu and http://ecanews.org - and also created links in the main social networks [@social_eca (Twitter) and ecanews (Facebook)]. A completely new design of the web page has been shown by F. Otaloro but the page is not yet live.

A new version of the ECA leaflet has been prepared and printed. The leaflet has been designed to show clearly the ECA activities and to encourage membership. The main message is 'Being a member of ECA shows your commitment with the development of crystallography in Europe, Africa and the Middle East, and helps the association in supporting educational and scientific activities.'

The ECA now has 12 SIGs (Special Interest Groups) and 2 GIGs (General Interest Groups - young crystallographers and senior crystallographers). All are intensively involved in the preparation of the ECM programme and have other activites, and organize their own schools, seminars and conferences of different sizes. Probably the largest one is EPDIC, the European Powder Diffraction Conference, which is prepared by SIG8 and usually has more than 300 participants. This was held in Aarhus, Denmark, in June 2014 and the introductory lecture was given by Sine Larsen.

In 2014, the focus of the ECA Executive Committee work was largely devoted to preparation of the next ECMs, i.e. mainly ECM29 in Rovinj, Croatia, 23-28 August 2015. The work done by local organizers, mainly Aleksandar Visnjevac and Marijana Dakovic, seems to be excellent and hopefully this will be a very successful meeting. The next, ECM30, will take place in Basel, Switzerland, at the end of August 2016. The ECA council in Montreal also accepted two bids for 2018 and 2019. The former was presented by Santiago GarciaGranda for Oviedo, Spain, and the latter by Klaudia Hradil for Vienna, Austria.

\section{R. Kuzel, IUCr Representative}

\subsection{Latin-American Crystallographic Association}

At the Montreal Congress, the Latin-American Crystallographic Association (LACA) became the fourth Regional Associate of the IUCr. Also in Montreal I was appointed to be 
the IUCr representative to LACA and a member of the LACA Council. The LACA Provisional Executive Committee is currently formed by the following members: Marcia Carvalho de Abreu Fantini, President (Brazil), Diego German Lamas, Vice-President (Argentina) and Lauro Bucio Galindo, Secretary (Mexico).

The countries of the North, Central and South American regions, historically bound by the Luso/Hispanic heritage and language, have constantly made efforts to work together promoting the advance of science and education in all countries. The formation of LACA was approved in Cordoba, Argentina, to gather all the already consolidated crystallographic groups in the region. The region involved in the LACA initiative comprises important scientific communities and well established crystallographic societies, associations and consolidated crystallographic groups: starting with Mexico (SBCr), Venezuela (consolidated groups), Brazil (ABCr), Chile (consolidated groups), Argentina (AACr), Colombia (consolidated groups), Peru (consolidated groups) and Uruguay (consolidated groups). Other existing groups have started their own national societies, like Costa Rica (UCRC), or recently established collaborative projects to become a united group of countries. The mere existence of this very dedicated and scientifically productive crystallographic community in the Latin-American countries contributed significantly to support the construction of a synchrotron facility in Campinas, Brazil, in operation since 1997, and crystallographers represent the majority of its users. Some LACA countries have been affiliated to the IUCr for more than three decades, and are very aware of the importance of linking the regional scientific community acting in the crystallographic area with the activities and aims of the IUCr.

Through its association with the IUCr as a Regional Associate, LACA expects to increase the international interaction among the countries of the LACA region with the rest of the world. As a Regional Associate, LACA will configure the consolidation of the science of crystallography in the Latin-American countries and acquire an international institutional level that will greatly help the development of new laboratories, student exchange and financial support from governmental institutions in all countries of the region. A newsletter dedicated to reporting all activities related to crystallographic research in Latin America will be published. This will contribute to improving the level of interaction among students and researchers in all areas of science where crystallography plays a key role.

The Statutes and By-laws of LACA, as a non-profit organization, were discussed in November 2013 at the First Meeting of LACA in Cordoba, Argentina. The Statutes will be legally registered in Brazil, under Brazilian laws. There are versions in Portuguese, Spanish and English. The legalization process of the LACA Statutes is currently underway. The Brazilian National Synchrotron Laboratory (LNLS), in Campinas, Brazil, is the legal address of LACA.

The main objectives of LACA are (i) to contribute to the advancement and the dissemination of crystallography in accordance with the aims of the IUCr; (ii) to promote Latin-
American cooperation in crystallography; (iii) to promote the teaching of crystallography in Latin America; (iv) to facilitate the mobility of students and researchers across Latin America and between this region and others; and (v) to promote the formation of national associations or committees of crystallography in all countries of Latin America.

Currently crystallography in Latin America includes seven countries: Argentina, Brazil, Costa Rica, Chile, Mexico, Uruguay and Venezuela that are members of the IUCr. Two countries, Colombia and Peru, are in the process of organization and two countries, Cuba and Puerto Rico, are participating in LACA activities. The rest of the countries have not yet organized crystallography groups.

The most relevant activities in Latin America related to the IYCr2014 are the Latin-American Summit Meeting (Brazil) and four OpenLabs (Argentina, Uruguay, ColombiaVenezuela and Mexico). In parallel, many educational and promotional activities were also organized: the UNESCO Schools Science Teachers Meeting, São Paulo, Brazil, the Agilent OpenLabs in La Plata and Buenos Aires, Argentina, the Bruker OpenLab in Montevideo, Uruguay, the Rigaku OpenLab in Bucaramanga, Colombia (collaboration with Venezuela), and the PANanalytical OpenLab in Mexico City, Mexico.

Several National Meetings of the National Crystallographic Associations took place in 2014 in Latin America: the Mexican Crystallographic Association (SMCr), the Asociación Argentina de Cristalografia (AACr), the Red Uruguaya de Cristalografia (RUCr) and the Grupos Peruanos de Cristalografia Peru.

Advanced Schools on different crystallographic topics also took place in 2014: the School on Crystallization and Polymorphism (San José, Costa Rica, January 2014), the School on Macromolecular Crystallography (São Carlos, Brazil, April 2014), the course on Protein Crystallization (Concepcion, Chile, May 2014), the course on Single Crystal Diffraction for undergraduate students (Merida, Venezuela, June-July 2014), the course on X-ray Powder Diffraction for the oil industry (Merida, Venezuela, October 2014), the short course on the PDF Technique (Mar del Plata, Argentina, November 2014), and the school on Synchrotron Radiation techniques (Mar del Plata, Argentina, November 2014).

Dissemination and popularization activities, such as the national crystal-growing contests and short courses for teachers in Argentina and Uruguay, were among other activities promoting crystallography all over Latin America: Lectures, Exhibitions, Science Fairs, Art and Photo contests and Educational Material.

Special mention must be given to the LNLS/CNPEM Brazilian Summit Meeting 22-24 September 2014, with the participation of 101 scientists from nine Latin-American countries (Brasil, Argentina, Uruguay, Chile, Paraguay, Venezuela, Colombia, Mexico and Peru). The event in Campinas gathered experienced researchers from LatinAmerican countries, younger scientists (Early Career Research Scientists - ECRS) and renowned world scientists as invited lecturers. The main objective was to evaluate the 
advances in recent decades in the field of structural crystallography applied to biological phenomena. One of the main points was the identification of barriers to integration, and the difficulties that hinder the development of competitive scientific research in the Latin-American region.

One of the activities planned for the first day of the event was a press conference with the presence of journalists and other media professionals in which prominent personalities were interviewed. Among them were Ada Yonath (2009 Nobel Prize in Chemistry), Marvin Hackert (President of the International Union of Crystallography), Glaucius Oliva (President of the Brazilian National Research Council CNPq), Carlos Henrique de Brito Cruz (Scientific Director of the Research Foundation of the State of Sao Paulo FAPESP), Kleber Gomes Franchini (Provisional Director of the National Center for Research in Energy and Materials CNPEM and Director of the National Laboratory for Biosciences - LNBio), Antonio José Roque da Silva (Director of National Synchrotron Light Laboratory - LNLS) and Samar Hasnain (Editor-in-Chief of the IUCr journals).

Some discussion sessions and round tables were organized with the participation of scientists of Latin-American origin that are at present established and working abroad (France, Spain and USA). During the morning of 23 September, Dr Lidia Brito, Regional Director for UNESCO in Latin America, talked about cooperation between UNESCO and the IUCr for the International Year of Crystallography.

A letter of intention was written by the participants and read at the closing ceremony of the event. One of the proposals in this letter was the creation of a UNESCO/IUCr Cooperation Fund for the promotion of crystallography in the region. The intention is to request governments, funding agencies, research institutes and enterprises for contributions towards a USD 100000 fund that could be destined to support student exchange activities and scientific events, and also finance the common use of large experimental facilities.

The organization of this Summit Meeting was sponsored by the Brazilian funding agencies FAPESP, CNPq and CAPES. The IUCr's contribution to financing Early Career Research Scientists is acknowledged.

\section{S. Garcia-Granda, IUCr Representative}

\subsection{International Organization for Crystal Growth (IOCG)}

No formal meeting of the IOCG (http://www.iocg.org/) was planned or organized in 2014.

The IOCG President for 2013-2016 is R. Fornari (Italy). Co-Vice-Presidents are T. F. Kuech (USA) and K. Kakimoto (Japan), the Secretary is H. A. Dabkowska (Canada), and the Treasurer is V. Fratello (USA). The members of the Executive Committee are J. M. Garcia-Ruiz (Spain), Y. Mori (Japan), K. Roberts (UK), M. Heuken (Germany), F. Puel (France), E. Vlieg (The Netherlands), Mu Wang (China), and J. De Yoreo (USA).

The connection with the Commission on Crystal Growth and Characterization of Materials (CCGCM) is evident, as
T. F. Kuech, K. Kakimoto, E. Vlieg and J. M. Garcia-Ruiz are also members/consultants of CCGCM.

The 18th International Conference on Crystal Growth and Epitaxy (ICCGE-18) will be held in Nagoya, Japan, 7-12 August 2016. Commission member Koichi Kakimoto will coChair ICCGE-18 with Yasuhiko Arakawa. Members and consultants of CCGCM are strongly involved in the work of the Programme and Advisory Committees of this meeting. Moreover, we are also discussing the possibility (as was done in the case of ICCGE-17) that some sessions could be officially co-organized by the IUCr.

Also encouraged by the occurrence of IYCr, some National Associations started campaigns to promote crystal growth among young students and scholars. They offer visits to crystal-growth laboratories and organize crystal-growth contests. Initiatives were organized in Spain (http:// www.rtve.es/alacarta/videos/la-aventura-del-saber/aventuracsic/ 3175138/), Italy (https://www.facebook.com/pages/ConcorsoNazionale-Crescita-Cristalli/1589346004681687) and Germany (http://www.dgkk.de/schulen/).

The Japanese Association for Crystal Growth (JACG) celebrated its 40th anniversary with many interesting initiatives.

A large part of the crystal-growth community was involved in the organization of or participated in the Montreal Congress. Other important events for the crystal-growth community have been:

6th International Workshop on Crystal Growth Technology, Berlin, Germany, 15-19 June 2014.

4th Granada International School of Crystallization, Granada, Spain, 25-30 May 2014.

Moreover, at the end of 2010 the European Network of Crystal Growth (ENCG) was constituted. One of the roles of ENCG was the organization of a European Conference on Crystal Growth every three years, to recover a tradition that was lost for about 20 years. ECCG4 was held in Glasgow, UK, 17-20 June 2012. ECCG5 will be organized in September 2015 in Bologna, Italy (http://www.imem.cnr.it/eccg5/index.php) together with the First European School on Crystal Growth (http://escg2015.eccg5.eu/). It really seems that the European community of crystal growers has been able to recover an opportunity for discussion and dissemination of crystal-growth science and technology - especially for the new generation of scientists. Many members/consultants of the Commission are directly involved in the organization of these events.

\section{A. Zappettini, IUCr Representative}

\subsection{International Centre for Diffraction Data}

The Commission on Powder Diffraction maintains close links with the ICCD and also with the International X-ray Absorption Society (IXAS) (http://www.ixasportal.net/ixas/).

P. Whitfield, IUCr Representative 


\section{Representatives on Other Bodies}

12.1. IUPAC Interdivisional Committee on Terminology, Nomenclature and Symbols (ICTNS)

There were no activities during 2014 that related to crystallography.

\section{P. Brock, IUCr Representative}

\subsection{International Council for Scientific and Technical Information (ICSTI)}

ICSTI offers a unique forum for interaction among organizations that create, disseminate, and use scientific and technical information. ICSTI is a Scientific Associate of ICSU, the International Council for Science. ICSTI's mission cuts across scientific and technical disciplines as well as international borders, to give member organizations the benefit of a truly global community.

The ICSTI 2014 Annual Members' Meeting was held in Philadelphia, USA, 22 February 2014 and included two Miniworkshops on: (i) New Trends in Publication and Data Metrics, which covered the use of traditional and alternative metrics to evaluate and measure the results, productivity and outcomes of basic and applied research programmes, as well as developments in the reporting and tracking of funding sources; and (ii) Science and Social Media: the Importance of an Online Presence, which provided an overview of the interactive media and their use by the science community to gather, disseminate and disambiguate information. These activities were in combination with the National Federation of Advanced Information Services Annual Conference, which addressed topics such as 'linking data and literature', 'trust in scholarly content' and 'the future involving big data'.

The ICSTI 2014 General Assembly and Annual Conference was held at the National Museum of Emerging Science and Innovation (Miraikan) in Tokyo, Japan, 18-21 October. The host was the Japan Science and Technology Agency - JST (http://www.jst.go.jp/EN/), who developed the conference theme in cooperation with the Japanese National Diet Library (http://en.wikipedia.org/wiki/National_Diet_Library), the National Institute of Informatics (http://www.nii.ac.jp/en/), and the National Association of Information Professionals. The conference was overall entitled Information and Infrastructure for Innovation - New Approaches for Knowledge Platforms. The details, including the conference presentations, can be found at http://www.prime-pco.com/icsti/icsti_2/ con_program.html. The IUCr could not be represented on this occasion.

J. R. Helliwell acknowledges with gratitude during these last three triennia, nine years in all, representing IUCr at ICSTI, the close collaboration with Brian McMahon, R\&D Officer of the IUCr, and with the IUCr Journals Executive Managing Editor, Peter Strickland.

\section{J. R. Helliwell, IUCr Representative}

\subsection{International Council for Science (ICSU)}

The International Council of Science (ICSU) now has a membership comprising 31 Scientific Unions, 121 National members and 22 scientific members (various Committees, Academies etc.). General Assemblies take place every three years, the most recent being in Auckland, New Zealand, 30 August - 3 September, 2014. Traditionally the IUCr is represented by its Immediate Past President, but with Professor Gautam Desiraju unable to attend, I was invited to attend this 31st ICSU General Assembly in his place.

Several events took place prior to the opening of the General Assembly. On 30 August separate Open Forum meetings were held for the representatives of the Scientific Unions and of the National Committees. This provided a useful opportunity to meet representatives of the other Scientific Unions, some of which (such as IUPAB) have significantly overlapping interests with IUCr. There is some disquiet among Unions at a perceived lack of transparency and at the way the ICSU budget is spent, and one major Union (IUBMB) announced that it planned to leave ICSU. There was also a feeling that ICSU is not well known among Unions; this could be addressed in our case through the IUCr Newsletter. Finally, it has been suggested that the Unions could develop clusters (e.g. Physics/Chemistry/Mathematics, Biology etc.) - though it is not obvious which cluster would be appropriate for the IUCr if this were done.

An interesting new development that took place in parallel, 28-29 August, was a two-day summit on science advice to governments, led by Sir Peter Gluckman FRS, Chief Science Advisor to the New Zealand government, who later reported to the General Assembly. Governments around the world are increasingly appointing national scientific advisors to provide informed scientific comment on matters of importance to society. These can be controversial and the means by which scientific advice should be assembled and provided is becoming recognized as a discipline in its own right. A second Global Conference on Scientific Advice to Governments is to be held in 2016 .

After an opening session on the evening of 31 August, the General Assembly took place 1-3 September. Current ISCU activities follow a strategic plan that was approved at the 30th General Assembly in Rome, in 2011 and runs from 2012-2017. The major focus is on environmental and sustainability issues, and in particular on climate change. This programme appears to be directed largely to national members, and it is not clear how most of the Scientific Unions can engage with it. The central part of the programme, instigated by ICSU and cosponsored by other international NGOs, is called Future Earth. Much of the discussion over the first two days of the General Assembly concerned various aspects of this initiative: environmental change, urban health and well-being, sustainable development goals, biodiversity, disaster risk reduction and assessment etc.

The Assembly agenda was punctuated with a number of excellent guest lectures, notably an inspiring address by Professor Bruce Alberts, former Editor-in-Chief of Science 
magazine, on the development of problem-solving skills in science that are appropriate to any nation, rich or poor. Posters from delegates were displayed throughout the meeting, and were summarized orally (in two-minute presentations), in Poster Expresso sessions at intervals through the programme.

One discussion that will be of interest to IUCr members concerned Open Access publishing, led by Professor John Ball, a mathematician from the University of Oxford, and a member of the ICSU Executive Committee. This endorsed the principle of open access to the scientific record, setting out five aspirational goals for achieving this end:

No financial barriers for researchers to contribute;

Freedom of access for any user;

No restrictions on re-use, subject to appropriate attribution; Quality assurance and timely publication;

Archiving to ensure availability in perpetuity.

Recommendations were made for achieving these goals. Cautions were also expressed against the misuse of metrics, along the lines of the San Francisco declaration, and the meeting reinforced that publishers should ensure that research datasets should be deposited in trusted and sustainable repositories - an area in which the IUCr has led the way.

Finally, the General Assembly concluded with the election of the new members of the Executive Committee. The President of ICSU for 2014-2017 is Gordon McBean, a climatechange expert from Canada (previously President-Elect) and he will be followed in 2017 by Professor Dayan Reddy, an internationally recognized mathematician from South Africa, who was elected as President-Elect at this Assembly.

\section{E. N. Baker, alternate IUCr Representative}

\subsection{ICSU Committee on Data for Science and Technology} (CODATA)

The major event for CODATA during 2014 was the biennial conference and General Assembly held in Delhi, India, 2-7 November. Due to time constraints on obtaining a visa, the IUCr was represented at this event by B. McMahon.

SciDataCon2014. The 24th International CODATA Conference was organized in partnership with its sister organization the ICSU World Data System (WDS) under the title SciDataCon2014 - International Conference on Data Sharing and Integration for Global Sustainability.

The CODATA Prize 2014, for Outstanding Achievement in the World of Scientific and Technical Data, was awarded to Professor Sydney R. Hall, University of Western Australia, for his leadership in the development of data-exchange standards including the Crystallographic Information Framework (CIF). The CODATA web site acknowledged that Professor Hall's work 'certainly met [the] criteria ... It is particularly fitting that a crystallographer should be so recognized during the International Year of Crystallography'. Professor Hall gave a presentation at the conference on The Implementation of STAR/CIF Ontologies.
B. McMahon presented a contribution by J. R. Helliwell on Sustainability of Life and Molecular Crystallography 3D data in the session Open Data Infrastructure and Best Practices. B. McMahon also took part in the satellite workshop Data Papers and Their Applications.

As always, this conference provides a useful opportunity to survey data-management practices across many different disciplines, and to showcase the leadership in data management, evaluation and availability of crystallography and structural science.

General Assembly. The Netherlands and Kenya were welcomed as new National Members of CODATA. The Research Data Alliance (RDA) was welcomed as a new CoOpted Organization. (Memoranda of Understanding were signed in March 2015 between CODATA, WDS and RDA to establish formal collaborations between these bodies.)

A resolution was passed urging visa-granting authorities to ensure that travel to scientific meetings was not harder or more onerous than travel to a country for recreational purposes.

The General Assembly appoints or re-confirms Task Groups and Working Groups to further the objectives of CODATA. The Task Groups approved by the 29th General Assembly for 2014-2016 are as follows (those marked with an asterisk are continuations of existing Task Groups):

Advancing Informatics for Microbiology*

Anthropometric Data for Special Populations*

Data at Risk*

Data Citation Standards and Practices*

Earth and Space Science Data Interoperability*

Interoperable Data Publications

Linked Open Data for Global Disaster Risk Research*

Global Roads Data Development*

Preservation of and Access to Scientific and Technical Data in Developing Countries (PASTD)*

Science and the Management of Physical Objects in the Digital Era

The Officers of CODATA (terms of office in parentheses) are: President, Geoffrey Boulton (UK; 2014-2018); Past President, Guo Huadong (People's Republic of China; 20142016); Vice-Presidents, Niv Ahituv (Israel; 2014-2018), Takashi Gojobori (Russia; 2014-2018); Secretary General, Sara Graves (USA; 2012-2016); Treasurer, John Broome (Canada; 2012-2016). Ordinary Members of the Executive Board are listed on the CODATA web site at http://www. codata.org.

Other activities. The CODATA/VAMAS Joint Working Group on the Description of Nanomaterials continued its work following the Workshops of 2012 (at which the IUCr was represented by Reinhard Neder) and 2013 (IUCr Representative Daniel Chateigner), eventually resulting in the publication of a Uniform Description System for Materials on the Nanoscale, available for download from the CODATA web site. J. R. Helliwell continues to represent the IUCr on this Working Group.

J. R. Helliwell was a formal contributor, in his role as IUCr Representative to CODATA, to an ICSU draft report on 
Table 1

Income and Expenditure Account (in Swiss Francs) for the year ended 31 December 2014.

\begin{tabular}{|c|c|c|c|c|}
\hline & 2014 & & 2013 & \\
\hline Membership subscriptions & & 163689 & & 162741 \\
\hline Journals, back numbers and single issues & 3141732 & & 3270884 & \\
\hline Books & 106883 & & 154174 & \\
\hline & & 3248615 & & 3425058 \\
\hline Income from investments & 31810 & & 3803 & \\
\hline Bank interest & 1145 & & 1191 & \\
\hline Profit on disposal & 64190 & 97145 & 69575 & 74569 \\
\hline \multicolumn{5}{|l|}{ Other income } \\
\hline Royalties and copyright fees & 7213 & & 7712 & \\
\hline Total income & & 3693940 & & 3787446 \\
\hline \multicolumn{5}{|l|}{ Expenditure } \\
\hline \multicolumn{5}{|l|}{ Journals } \\
\hline Publication costs & 418442 & & 577492 & \\
\hline Editorial expenses & 201127 & & 263581 & \\
\hline Technical editing & 1382539 & & 1242371 & \\
\hline Subscription administration & 118161 & 2120269 & 109704 & 2193148 \\
\hline \multicolumn{5}{|l|}{ Books } \\
\hline Publication costs & 6123 & & 42331 & \\
\hline Editorial expenses & 27282 & & 46507 & \\
\hline Technical editing & 67605 & 101010 & 62757 & 151595 \\
\hline General Assembly and Congress costs & & 74970 & & 18572 \\
\hline Ewald Prize & & 38894 & & - \\
\hline Committee meetings and expenses & & 147834 & & 116985 \\
\hline \multicolumn{5}{|l|}{ Publications and journals development } \\
\hline General & 422124 & & 434207 & \\
\hline Editors' meetings & 14593 & & 7809 & \\
\hline Promotion & 184223 & & 119420 & \\
\hline IUCrJ development & 165619 & & 122486 & \\
\hline STAR/CIF & 7695 & & 24198 & \\
\hline Business development & 112001 & 906255 & - & 708120 \\
\hline Subscriptions paid & & 4219 & & 6271 \\
\hline Visiting Professorship Programme & & 10893 & & 17302 \\
\hline \multicolumn{5}{|l|}{ Administration expenses: } \\
\hline Honorarium to General Secretary and Treasurer & 4907 & & 6820 & \\
\hline Audit and accountancy charges & 45487 & & 59739 & \\
\hline Legal and professional fees & 4765 & & 2512 & \\
\hline Travelling expenses & 16500 & & 16674 & \\
\hline Bank charges & 8725 & 80384 & 8327 & 94072 \\
\hline
\end{tabular}


Table 1 (continued)

2014

Executive Secretary's office:
$\quad$ Salaries and expenses
Travel expenses of IUCr Representatives on other bodies
Sponsorship of meetings
President's secretary
IUCr/FIZ agreement
Bad debts
Depreciation

Total expenditure

Deficit of income over expenditure (before realized exchange fluctuations)

Realized fluctuations in rates of exchange

Exchange movement on trading activities

(Deficit) of income over expenditure (after realized exchange losses)

Movement in market value of investments in year

Unrealized fluctuation in rates of exchange Exchange movement on trading activities Investment activities

Total recognized gains/(losses) relating to the year

Opening fund accounts at 1 January

Closing fund accounts at 31 December

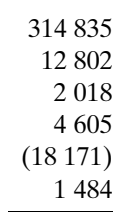

1484

2013

39946

(723 030)

95044

(627 985)

330985

(297000)

4596542

4299542
301510

33234

4204692

(417 246)

(422 889)

40727

(382 162)

(83 574)

(465 736)

5062278

4596542

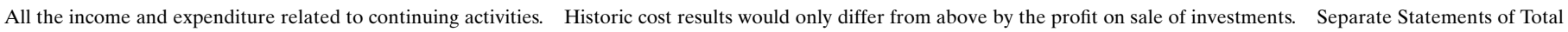
Recognized Gains and Losses and Reconciliation of Movements in the Fund Account are not given, as the information is incorporated in the above.

Open Access to Scientific Data and Literature and the Assessment of Research by Metrics that was presented to and approved at the 31st ICSU General Assembly in Auckland, New Zealand, in September 2014. The report is available at http://www.icsu.org/general-assembly/news/ICSU\%20Report\% 20on \%20Open \%20Access.pdf.

J. R. Helliwell, IUCr Representative, and B. McMahon, alternate IUCr Representative

\subsection{ICSU Committee on Space Research (COSPAR)}

COSPAR's (http://cosparhq.cnes.fr/) main objective is to promote international collaboration in scientific research in space, with an emphasis on the exchange of results, information and opinions. Developing world standards for the space environment and its protection requires the creation of national and international organizations and specialist working groups.
COSPAR's highest body is the Council. The Council comprises the Committee's President, Representatives of Member National Scientific Institutions and International Scientific Unions, the Chairs of COSPAR Scientific Commissions, and the Chair of the Finance Committee. The Council meets at the Committee's biennial Scientific Assembly. Between Assemblies it is the Bureau that runs COSPAR on a day-to-day basis.

COSPAR acts mainly as a body responsible for organizing biennial Scientific Assemblies and the 40th COSPAR Assembly was held in in Moscow, Russia, 2-10 August 2014. The previous (39th) took place in Mysore, India, 14-22 July 2012, the 41st will be in Istanbul, Turkey, 30 July - 7 August 2016.

The International Year of Crystallography (IYCr) provided an opportunity for some interactions between the IUCr and COSPAR officials. COSPAR Bureau representative, $\mathrm{Mr}$ Aaron Janofsky, and the Chair of the Panel on Capacity Building, Professor Mariano Mendez, both attended the IYCr Opening Ceremony in Paris. For the Moscow Assembly I 
Table 2

Balance sheet (in Swiss Francs) as at 31 December 2014.

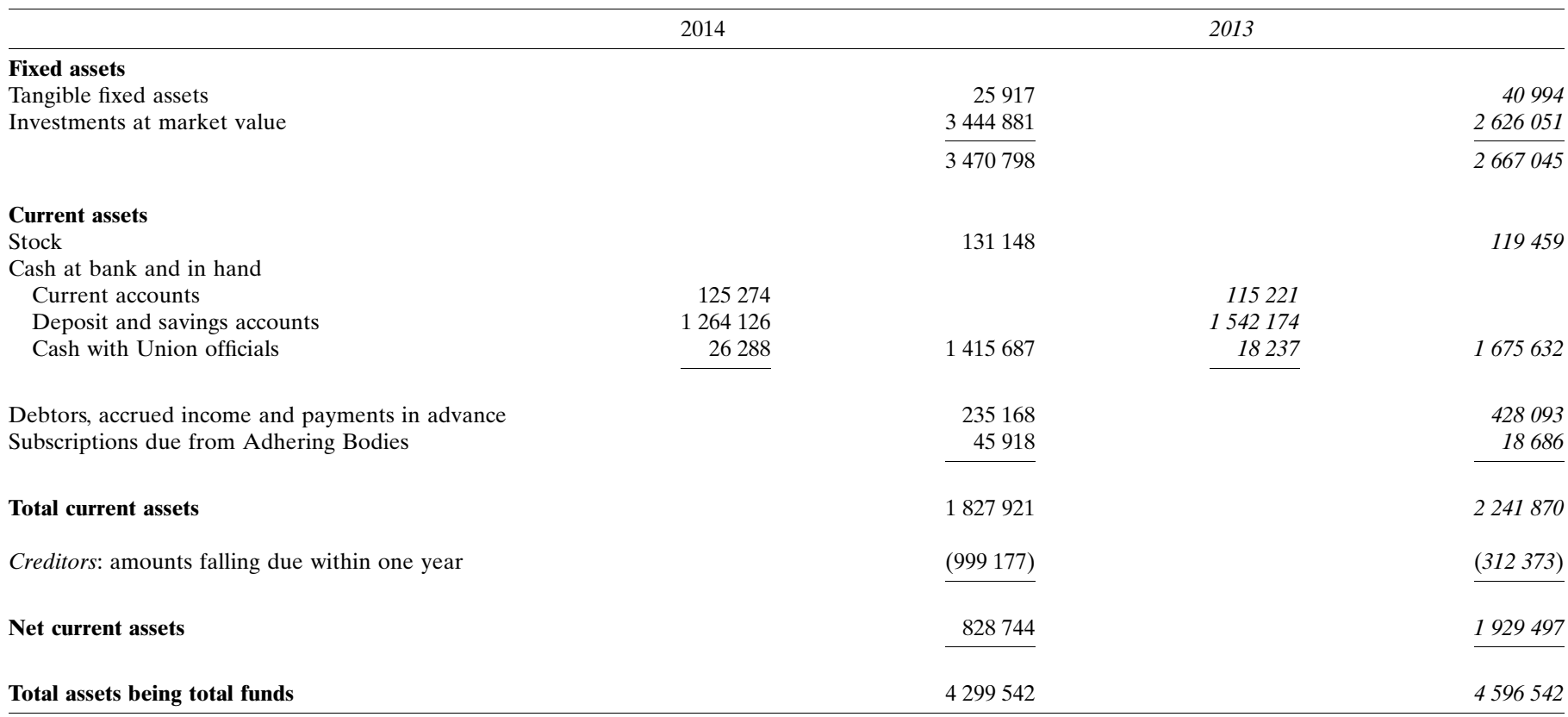

submitted to the COSPAR Council information about IYCr development and activities. As the 2014 COSPAR General Assembly in Moscow was exactly at the same time as the Montreal Congress, Professor Mariano Mendez acted as my proxy.

Most COSPAR activities are related to space topics (astronomy, astrobiology, geophysics, atmosphere studies, investigation of natural and artificial ecosystems, as well as space travel). The most interesting - for the IUCr - division of COSPAR is the Scientific Commission on Materials Science in Space (MSS Commission G), chaired by V. Shevtsova (Belgium) and co-Chaired by S. Amiroudine (France), T. Koenemann, (Germany) and S. Yoda (Japan). This Commission coordinates fundamental experiments in materials and fluid sciences performed in space, utilizing reduced gravity for their objectives. The Commission reviews fundamental, theoretical and experimental investigations, highlights new, significant achievements in the field, recommends promising avenues for future research, and facilitates exchange of information on scientific subjects. This approach helps the understanding of emerging fields by recommending promising avenues for future research.

Advances in Space Research (ASR, http://ees.elsevier.com/ asr/, 5-year impact factor 1.173) is the official journal of COSPAR. It covers all areas of space research, including - but not limited to - space studies of earth surface, climate, meteorology, fundamental physics in space, materials physics in space, space debris, weather and earth observation of space phenomena. ASR also includes COSPAR's information bulletin, Space Research Today. As of 14 April 2014 a new journal entitled Life Sciences in Space Research will be another COSPAR publication.
COSPAR President for the period 2014-2018 is Lennard A. Fisk (USA) and the Vice-Presidents are J. Wu (People's Republic of China) and A. Jayaraman (India). Members of the Bureau are: I. S. Batista (Brazil), K.-H. Glassmeier (Germany), S. Sasaki (Japan), J.-P. St-Maurice (Canada) and M. I. Panasyuk (Russia).

Some discussions are in progress about the mutual IUCr/ COSPAR public outreach/capacity building Symposium on the Importance of Crystallography in Past and Future Space Research. The subjects would cover the search for materials applied in building spacecraft, reports on crystallographic and crystal-growth experiments performed in space, and actual and future investigation of space debris by crystallographic methods. The timing and location of this potential meeting are being discussed by Professor Mariano Mendez (COSPAR side) and Professor Juan-Ma Garcia Ruiz (IUCr side), the potential site being South or Central America.

COSPAR co-sponsored the following meetings in 2014:

Panel on Capacity Building Fellowship Program (PCB FP), The Netherlands, 2014.

Advanced School on X-ray Astrophysics - Data Analysis of the XMM-Newton, Chandra, and Suzaku Missions, 17-28 November 2014, Ensenada, Mexico.

Satellite Remote Sensing, Water Cycle and Climate Change, 20-31 July 2014, Tver, Russia.

Matching Oceanographic Problems of the Indonesian Seas (ITF) to the Right Data Sets and Models, 13-22 January 2014, Bandung, Indonesia.

To learn about other COSPAR activities please go to http:// cosparhq.cnes.fr/events.

H. A. Dabkowska, IUCr Representative 
Table 3

Summary of Fund Accounts (in Swiss Francs) as at 31 December 2014.

\begin{tabular}{|c|c|c|c|c|c|c|c|}
\hline & \multirow[t]{2}{*}{$\begin{array}{l}\text { As at } \\
1 \text { January } 2014\end{array}$} & \multirow[t]{2}{*}{$\begin{array}{l}\text { Transfers } \\
\text { between } \\
\text { funds }\end{array}$} & \multirow[t]{2}{*}{$\begin{array}{l}\text { (Deficit)/ } \\
\text { surplus of } \\
\text { income over } \\
\text { expenditure } \\
\text { for the } \\
\text { year }\end{array}$} & \multirow[t]{2}{*}{$\begin{array}{l}\text { Increase in } \\
\text { market } \\
\text { value of } \\
\text { investments }\end{array}$} & Fluctuations & n exchange rates & \multirow[t]{2}{*}{$\begin{array}{l}\text { Balance } \\
\text { at } 31 \text { December } \\
2014\end{array}$} \\
\hline & & & & & Trading & Investments & \\
\hline \multicolumn{8}{|l|}{ Fund accounts } \\
\hline Journals Fund & 5251599 & $(540000)$ & 551212 & - & 155924 & - & 5418735 \\
\hline International Tables & $(548618)$ & - & (53 497) & - & $(17839)$ & - & (619 954) \\
\hline Publications and Journals Development Fund & 877647 & 50000 & (201471) & - & 21515 & - & 747691 \\
\hline Research and Education Fund & 822231 & 400000 & $(515006)$ & - & 20953 & - & 728178 \\
\hline Ewald Fund & 522023 & 50000 & $(38894)$ & - & 15795 & - & 548924 \\
\hline Newsletter Fund & 37479 & - & (32 551) & - & 146 & - & 5074 \\
\hline General Assembly and Congress & 288459 & - & $(26060)$ & - & 7774 & - & 270173 \\
\hline
\end{tabular}

\section{Finances}

Extracts from the full financial statements, namely the Income and Expenditure account, Balance Sheet and Summary of Fund Accounts, are given in Tables 1, 2 and 3, respectively. For comparison, the figures for 2013 are provided in italics. The accounts are presented in CHF.

The ICSU exchange rates, based on the official UN rates, have been used in the preparation of these accounts. As a consequence of the many fluctuations in exchange rates during the year, the following procedure has been adopted for the accounts. Assets and liabilities in currencies other than CHF at 31 December 2014 have been translated into CHF in the balance sheet at the rate operative at that date. For the income and expenditure accounts, transactions have been translated into CHF by applying the rates appropriate to the individual dates of these transactions. As a consequence of the fluctuation in exchange rates, overall an apparent gain has arisen on the assets of the Union, in terms of CHF, amounting to CHF 370 931. In the accounts this gain has been assigned as a 'Realized gain' (CHF 39 946) and 'Unrealized gain' (CHF 330 985). The gain attributable to investment activities has been assigned to the General Fund and the overall gain attributable to trading activities has been divided amongst the fund accounts in direct proportion to the balances on these accounts at 31 December 2014. It should be noted that this overall gain in CHF is not a real gain of money, but rather a gain on paper resulting from the accounts being expressed in CHF.

Investments are noted in the balance sheet at their market value at 31 December 2014.

The balance sheet shows that the assets of the Union, including the gain resulting from fluctuations in rates of exchange, have decreased during the year, from $\mathrm{CHF}$ 4596542 to CHF 4299542 . The movement in market value of the investments was CHF 95044 in 2014 (CHF 40727 in 2013).

The following transfers were made from the Journals Fund: CHF 50000 to the Publications and Journals Development
Fund; CHF 400000 to the Research and Education Fund; CHF 40000 to the President's Fund; and CHF 50000 to the Ewald Fund.

The following comments refer to figures in the full accounts.

The General Fund account shows a deficit of CHF 364 388, as compared with a deficit in 2013 of CHF 314822 . The administrative expenses were CHF 411174 in 2014 as compared with CHF 390282 in 2013. Of this amount, CHF 181931 was charged to the publications of the Union.

The expenses of the Union Representatives on other bodies were CHF 12 802. The cost of the Finance Committee meetings held in 2014 was CHF 27 639, while the Executive Committee meetings cost CHF 120 200. The income from the $\mathrm{IUCr} /$ Fachinformationszentrum agreement (to provide lowcost copies of the Inorganic Crystal Structure Database) was CHF 18 171. The subscriptions from Adhering Bodies were CHF 161014 . Interest on bank accounts and investments credited to the General Fund was CHF 32956.

Grants totalling CHF 42369 were paid from the President's Fund in 2014.

The Journals Fund account for 2014 shows a surplus of CHF 551212 before the transfer of CHF 540000 to the other fund accounts, as compared with a surplus of CHF 659194 in 2013 before the transfer of CHF 385000 to the other fund accounts.

The cost of the technical-editing office has been divided between the Journals Fund and the International Tables Fund in percentages based on the staff time spent on each publication. The technical-editing costs for the Journals Fund were CHF 1345603 as compared with CHF 1226333 in 2013. The Journals Fund has also been charged with administration expenses as in previous years as shown in the General Fund.

The International Tables account shows a deficit of CHF 53 497, as compared with a deficit of CHF 38057 in 2013. The net sales income was CHF 79100 in 2014 as compared with CHF 115295 in 2013.

The cost for the Union in producing the Newsletter in 2014 was CHF 32551. 


\section{international union of crystallography}

In the Publications and Journals Development Fund account, the computing and promotion expenses are divided between the General Fund, the Journals Fund and the International Tables Fund. STAR/CIF costs, IUCrJ development costs, Special Issue costs, journal grants and web input costs are also charged to the Publication and Journals Development account.

CHF 174268 for financial support to young scientists, to enable them to attend scientific meetings sponsored by the
Union, was charged to the Research and Education Fund. Visiting Professorships (CHF 22 115), Crystallography in Africa initiatives (CHF 33 500) and IYCr costs (CHF 279 400) were also charged to the Research and Education Fund. There were no inter-regional bursaries in 2014 (a Congress year).

In 2007 a General Assembly and Congress Fund was established so that the costs associated with the General Assembly and Congress could be spread over the triennium. In 2014 the expenses charged to this Fund were CHF 74970. 